\title{
Tabularia
}

Sources écrites des mondes normands médiévaux

Les bibliothèques médiévales de Normandie et des

mondes normands : échanges et circulation | 2014

\section{D'un lecteur à l'autre : emprunts et circulation de manuscrits à Rouen à la fin du Moyen Âge}

From one reader to another, borrowing and circulation of manuscripts in Rouen at the end of the middle ages

\section{Monique Peyrafort-Huin}

\section{(2) OpenEdition}

Journals

Édition électronique

URL : http://journals.openedition.org/tabularia/2257

DOI : 10.4000/tabularia.2257

ISSN : $1630-7364$

Éditeur :

CRAHAM - Centre Michel de Boüard, Presses universitaires de Caen

Référence électronique

Monique Peyrafort-Huin, « D'un lecteur à l'autre : emprunts et circulation de manuscrits à Rouen à la fin du Moyen Âge », Tabularia [En ligne], Les bibliothèques médiévales de Normandie et des mondes normands : échanges et circulation, mis en ligne le 25 avril 2014, consulté le 21 avril 2019. URL http://journals.openedition.org/tabularia/2257 ; DOI : 10.4000/tabularia.2257 


\title{
D'un lecteur à l'autre: emprunts et circulation de manuscrits à Rouen à la fin du Moyen Âge ${ }^{1}$ \\ From one reader to another, borrowing and circulation of manuscripts in Rouen at the end of the middle ages
}

\author{
Monique PEYRAFORT-HUIN \\ CNRS-IRHT, UPR 841 \\ monique.peyrafort@irht.cnrs.fr
}

Résumé:

Les sources concernant la circulation des livres à Rouen aux $\mathrm{XIV}^{\mathrm{e}}$ et $\mathrm{XV}^{\mathrm{e}}$ siècles sont particulièrement riches et, pour certaines d'entre elles, attendent encore d'être exploitées, notamment du point de vue de la transmission des textes.

$\mathrm{Au}$ travers du fragment de «registre de prêt» de Saint-Ouen (1372-1378) et des registres de délibérations conservés pour le chapitre de Notre-Dame de Rouen (1367-1493), il est proposé, pour ces deux bibliothèques, de se pencher principalement sur le prêt, mais aussi sur d'autres formes de circulation des livres (ventes, échanges..., à l'exclusion des legs et des dons) : quelles étaient les modalités du prêt des manuscrits? qui bénéficiait de cette circulation des livres? quels textes circulaient à Rouen à la fin du Moyen Âge? Un des derniers points, qui est seulement esquissé, concerne le vocabulaire utilisé dans les opérations de prêt.

Mots-clés: livre médiéval, bibliothèque médiévale, Rouen, Saint-Ouen, Ordre de saint Benoit, Notre-Dame, chapitre, prêt des livres, vente de livres, $\mathrm{XIV}^{\mathrm{e}}$ siècle, $\mathrm{XV}^{\mathrm{e}}$ siècle

Abstract:

The sources for the circulation of books in Rouen during the fourteenth and fifteenth centuries are particularly rich, and for some of them are still waiting to be exploited, especially in terms of the transmission of texts.

From a fragment of a "loan register" from Saint-Ouen (1372-1378) and the records of deliberations conserved for the chapter of Notre-Dame of Rouen (1367-1493), it is proposed here, for these two libraries, to analyse principally loans, but also other forms of book circulation (sales, exchanges..., excluding bequests and donations): what were the terms of manuscript loan? who benefited from the circulation of books? which texts circulated in Rouen at the end of the Middle Ages? One of the last points, which is only hardly evoked here, concerns the vocabulary used during the lending process.

Keywords: medieval books, medieval library, Rouen, Saint-Ouen, Order of Saint Benedict, Notre-Dame, chapter, book lending, book sales, $14^{\text {th }}$ century, $15^{\text {th }}$ century

1. Je souhaite dédier cet article à la mémoire d'une amie très chère, Annie Genevois, récemment disparue; responsable de la section de Codicologie de l'IRHT, c'est elle qui, la première, m'a encouragée à travailler sur les bibliothèques anciennes.

Tabularia «Études», n 14, 2014, p. 1-88, 25 avril 2014 http://www.unicaen.fr/mrsh/craham/revue/tabularia/print.php?dossier=dossier12\&file=01 peyrafort.xml 
Suetonium, quem in Anglia invenire non possum, facite transcribi et transscriptum mittite mihi per Dancardum presbyterum, vel per alium quem volueritis servientem ${ }^{2}$. Ainsi s'adresse entre 1107 et 1119 Herbert de Losinga $^{3}$ à son ami Roger de Bayeux ${ }^{4}$, qui est susceptible de lui fournir une copie de Suétone, qu'il ne parvient pas à trouver en Angleterre. Cette demande illustre très clairement le rôle primordial joué dans la constitution des bibliothèques médiévales par les échanges et prêts d'exemplaires entre institutions et/ou individus. Les exemples d'une telle circulation, supposée ou effective, des livres ne manquent pas comme en témoigne la correspondance d'un Anselme de Canterbury, à l'époque où, abbé du Bec-Hellouin, il écrivait fréquemment à l'archevêque de Canterbury, Lanfranc, ou à des moines originaires du continent placés à la tête des établissements stratégiques de l'Église d'Angleterre pour leur demander de lui trouver des modèles corrigés de tel ou tel texte ${ }^{5} \mathrm{ou}$, au contraire, pour leur envoyer des textes demandés ${ }^{6}$. On n'ignore plus l'importance, pour l'enrichissement des bibliothèques anglaises après 1066, des correspondances entre les responsables de l'Église d'Angleterre et les établissements monastiques normands dont la plupart étaient issus ${ }^{7}$. Et la fréquence des relations entre établissements monastiques ou, au moins, entre membres de ces établissements, a été remarquablement rappelée il y a maintenant quelques années ${ }^{8}$; je ne citerai, parmi bien d'autres, qu'un exemple, ayant trait à un établissement normand: en 1470, Guillaume, abbé cistercien de Beaubec, donne à l'abbé de Châalis, Pierre, un exemplaire des Sermons de Nicolas de Hacqueville et en reçoit en échange une pièce de serge noire ${ }^{9}$. Dans ce dernier cas, la mention est insuffisante pour déterminer si l'échange a lieu entre les personnages au titre de leur fonction à la tête de deux établissements d'un même ordre ou à titre privé.

À côté de ces mentions éparses portées sur les manuscrits et dont l'interprétation n'est pas toujours certaine ${ }^{10}$, d'autres documents témoignent de la

2. Cette lettre a été transmise par une copie du XVII ${ }^{\mathrm{e}}$ siècle (Bruxelles, Bibliothèque royale, mss 79657973) exécutée par les Bollandistes d'Anvers, sans doute sur un codex de Saint-Alban aujourd'hui disparu; Anstruther, 1846 : éd. p. 6, Epistola v.

3. Herbert (1054-22 juillet 1119) avait été moine à Fécamp, puis prieur de cette abbaye, avant de devenir (vers 1088) abbé de Ramsey, puis (vers 1094) évêque de Thetford-Norwich; Suétone n'était pas le seul texte recherché par cet évêque (voir WALLER, 1984, p. 246 et n. 53, p. 250).

4. Abbé de Fécamp du 21 décembre 1107 au 22 mars 1139; d'après GAZEAU, 2007, 2, p. 115 et p. 121-124, il ne s'agit pas de Raoul d'Argences [1189/1190-1219], comme indiqué par ReYnOLDS, 1982, p. 402.

5. Voir, notamment, la lettre 42 d'Anselme adressée à Maurice (SchmitT, 1946, p. 154).

6. Par exemple, dans sa lettre 66 adressée à l'archevêque Lanfranc (SchmitT, 1946, p. 186-187).

7. Waller, 1984, en part. n. 52-53 (cité par Dolbeau, 1991).

8. Dolbeau, 1991, n. 43, p. 502.

9. «Hunc librum [Summa sermonum dominicalium de Nicolas de Aquaevilla] dedit mihi fratri Petro abbati Karoliloci dominus Guillelmus abbas de Bellobecco, sacre theologiae professor, anno Domini 1470 . Et ego in recompensam eidem donavi unam peciam de optima sargia nigra ad faciendam unam cucullam mihi datam a domino de Longovillari» (Troyes, Bibl. mun., ms 1549, fol. 113); Bouveret, 1979, $\mathrm{n}^{\circ}$ 15585; l'intitulé Summa Nicolay de Aquavilla (fol. 4) ne permet pas de déterminer s'il s'agit des Sermones de tempore ou des Sermones de tempore et de sanctis de cet auteur (SCHNEYER, 4, 1972, p. 189-195 ou p. 195-205); pour d'autres exemples, voir DolbeaU, 1991.

10. Telle la mention "Lanfrancus hucusque correxi» portée sur plusieurs manuscrits et dont l'interprétation a prêté à controverse; GIBSON, 1978, p. 40 (cité par DolbEAU, 1991). 
circulation des livres entre individus: une typologie en a été dressée à partir des documents connus pour l'Europe de la fin du Moyen Âge ${ }^{11}$; quant aux testaments étudiés encore tout récemment ${ }^{12}$, ils fournissent plusieurs exemples de transferts de livres dans le milieu canonial de Rouen, notamment d'une génération à l'autre.

Il semble toutefois que ce début d'enquête sur la circulation des livres entre établissements religieux ou entre individus souvent issus de ces mêmes communautés demande à être poursuivi. Il subsiste en effet des gisements de sources susceptibles d'éclairer la circulation des livres à Rouen durant les deux derniers siècles du Moyen Âge et qui restent à exploiter plus systématiquement ou plus en profondeur que ce qui a été fait dans le passé.

En ce qui concerne la grande métropole religieuse de la Normandie, les deux feuillets enregistrant les prêts de livres à l'abbaye de Saint-Ouen de Rouen pour les années 1372, 1373 et 1378 ont été depuis longtemps signalés ${ }^{13}$. On peut toutefois s'interroger sur l'exploitation qui a été faite de ces informations noyées dans un document économique - un censier -, et pourtant si précieuses pour l'histoire intellectuelle de cette cité ${ }^{14}$.

D'autre part, le chercheur travaillant sur Rouen aux $\mathrm{XIV}^{e}$ et $\mathrm{XV}^{e}$ siècles a la chance de disposer d'une source capitale pour la connaissance du milieu canonial normand: les registres de délibération capitulaires, à ma connaissance sans équivalent dans les autres cités épiscopales normandes; à Bayeux, en effet, il ne subsiste que des copies modernes des délibérations et conclusions capitulaires ${ }^{15}$; à Coutances, les délibérations capitulaires ne sont conservées qu'à partir de 1464 et se trouvent, non aux Archives départementales, mais aux archives de l'évêché, dans la première série ${ }^{16}$; à Avranches, avant même les destructions de 1944, il ne subsistait que des fragments des registres de délibérations capitulaires pour la période $1541-1687^{17}$; à Évreux, les procès-verbaux des délibérations capitulaires conservés sont surtout riches pour le XVIII ${ }^{e}$ siècle ${ }^{18}$ et ne paraissent pas remonter au-delà de la période moderne, de même qu'à Sées où ces documents ne semblent conservés que pour l'époque moderne ${ }^{19}$; quant au chapitre de Lisieux, il ne semble pas que l'on ait conservé de registres de délibérations ${ }^{20}$. La richesse des

11. Pommerol, 1998

12. TABBAGH, 2008.

13. Delisle, 1849 (édition p. 227-230 et analyse); Dubois, 2001 : édition de référence désormais de ce document, p. 12-14.

14. On ne trouve en effet dans la dernière édition aucune identification des titres, ni des personnages mentionnés dans le document.

15. Caen, Arch. dép. Calvados, série G, Bibliothèque du Chapitre de Bayeux, mss 224 et 332.

16. Lechat, 1956, en particulier, p. 19 et 33; voir aussi, dans les mêmes archives diocésaines, (M 41), Fleury (E.), Extraits des délibérations du chapitre de la cathédrale de Coutances; et, plus récemment, DAIREAUX, 1997, notamment p. 92-93.

17. Avranches, Arch. dép. Manche, G 17; il semble qu'il n'y ait rien de plus aux archives diocésaines, dans la deuxième série, d'après LeCHAT, 1956, notamment p. 19 et p. 36-37.

18. Évreux, Arch. dép. Eure, G 54 et 2 DD 1-4.

19. Il n'en est en tout cas pas fait mention dans les Fasti, 9, 2005.

20. Du moins d'après les sources étudiées par Neveux, 1996, notamment p. 12. 
registres de délibérations capitulaires de Rouen a été mise en évidence de longue date, avant même ${ }^{21}$ et, surtout, depuis la publication de l'inventaire sommaire des Archives départementales de la Seine-Maritime ${ }^{22}$ qui détaille et met tout particulièrement l'accent sur les délibérations concernant les livres, ainsi que depuis la thèse consacrée par Vincent Tabbagh aux chanoines de Rouen ${ }^{23}$; cette source, essentielle pour l'histoire de ce groupe social, a déjà été en partie exploitée ${ }^{24}$. Il vaut cependant la peine de reprendre ces documents pour étudier le prêt et la circulation des livres à Rouen, aux $\mathrm{XIV}^{\mathrm{e}}$ et $\mathrm{XV}^{\mathrm{e}}$ siècles: qui avait accès aux bibliothèques de la métropole rouennaise et quels ouvrages étaient empruntés? En outre, que nous révèlent ces documents du fonctionnement et de la richesse de ces bibliothèques? Telles sont les questions auxquelles il est proposé d'apporter une amorce de réponse ${ }^{25}$.

Si l'on se propose de partir de la notion de prêt et de circulation des textes et des livres (quasiment tous manuscrits), on sera amené à élargir l'enquête à l'aliénation des livres, qui constitue un type particulier de circulation. Outre cette série de registres, on aura également à prendre en compte deux bibliothèques de particuliers, tous deux archevêques de Rouen, Guillaume de Lestrange et Philippe d'Alençon, uniquement du point de vue de la circulation des livres. En revanche, les legs et les dons de livres faits par les chanoines au chapitre ont été exclus de cette enquête, de même que les testaments, même si certains sont évoqués au cours de l'étude. De même, la richesse des documents pris en compte nous a empêchée d'utiliser les manuscrits subsistants, volet pourtant indispensable à la connaissance des fonds, mais qui ne pourra être repris que dans un second temps. Le terminus a quo de la présente enquête est fixé tant par le Livre des jurés de Saint-Ouen, qui n'enregistre les prêts qu'à partir de 1372, que par les registres capitulaires de la cathédrale dont le plus ancien couvre les années $1365-1373^{26}$. Le terminus ad quem retenu est le décès en 1493 de l'archevêque Robert de Croismare: avec le successeur de ce dernier, Georges d'Amboise (1494-1510), on entre en effet dans un tout autre monde, celui de la Renaissance et du livre imprimé ${ }^{27}$.

Cette étude s'articule en quatre parties, d'importance inégale. Le «registre de prêt» de Saint-Ouen, plus limité dans le temps, est examiné en premier. La deuxième partie est consacrée aux prêts et aliénations de livres au sein de la bibliothèque capitulaire ou chez les archevêques retenus. La troisième partie traite des textes mentionnés dans les documents analysés. Un quatrième point,

21. LANGLOIS, 1853.

22. Beaurepaire, 1-5, 1868-1892; Laborde, 1919.

23. TaвbAGH, 1988; Fasti, 2, 1998.

24. TABBAGH, 2008.

25. Cette étude en effet ne prétend pas à l'exhaustivité, tant se révèlent riches les sources pour Rouen. La liste des documents examinés (édités ou non) est donnée dans l'annexe 1.

26. Rouen, Arch. dép. Seine-Maritime, G 2115, premier de la très riche série de registres enregistrant les délibérations du chapitre de Rouen.

27. Sur cette période, rappelons notamment l'étude de VEnARD, 1997, ainsi que les travaux de Marie-Pierre Laffitte (LAFfitTe, 1999, LAfFitTe, 2012 et LAFFitTe, 2013) et de Gennaro Toscano (Toscano, 1999, Toscano, 2009). 
plus bref, rassemble quelques observations sur la terminologie relevée dans les documents ayant trait aux emprunts de livres. Deux listes sont données en annexe: une liste des documents pris en compte; une table des auteurs et œuvres cités dans ces documents.

\section{Un document fragmentaire, mais précieux, témoin du prêt des livres à Saint-Ouen}

Le premier document examiné, bien que limité en taille, est particulièrement précieux: il atteste en effet la pratique du prêt dans une abbaye bénédictine, Saint-Ouen de Rouen, l'une des plus anciennes de la région et que l'on pouvait imaginer comme un milieu fermé. La liste de prêts insérée dans un document à caractère économique, un censier connu sous le nom de Livre des Jurés ${ }^{28}$, se situe vraisemblablement à la fin de la période effective de l'abbatiat d'Arnaud $\mathrm{du}$ Breuil $^{29}$, à une période de troubles et de difficultés financières, nées des dépenses engagées, notamment pour son élection, par l'abbé Robert Duquesnay (1339-1362), alors qu'en 1338, au moment de l'enquête sur le temporel des abbayes de l'ordre bénédictin ordonnée par le pape Benoît XII, l'abbaye de Saint-Ouen était l'une des plus riches de Normandie ${ }^{30}$. On ne peut que supposer (mais sans certitude aucune) que la richesse de la bibliothèque était à la mesure de celle de l'abbaye. Hormis une allusion au rachat, en 1141/1142-1157, d'un «optimus textus acclesioe» parmi d'autres biens ${ }^{31}$, on ne connaît pas en effet, sur l'histoire et la composition de cette bibliothèque, d'autre document médiéval que ces mentions très lacunaires de prêt.

Cette liste d'emprunts a été portée sur un verso et un recto restés vierges après la rédaction du censier; les mentions de prêt qui sont notées à quatre dates différentes, dans un intervalle de moins de 6 ans $^{32}$, sont regroupées par nom d'emprunteur, selon un système qui prévaudra peu de temps après au Collège de Sorbonne ${ }^{33}$. Une question demeure cependant sans réponse. Le deuxième emprunt noté dans cette liste porte explicitement la date du 5 août 1372, mais ni le précédent, ni les suivants ne sont datés. On a donc considéré, peut-être à tort, que les prêts suivants avaient tous été consentis à cette même date ${ }^{34}$. Mais

28. Rouen, Arch. dép. Seine-Maritime, $14 \mathrm{H}$ 17, fol. 7v-8; Delisle, 1849 (édition p. 227-230 et analyse); Dubois, 2001 (édition, p. 12-14).

29. Celui-ci fut en effet frappé de paralysie en 1378, l'année même des dernières mentions de prêt consignées dans ce document. L'abbé Arnaud du Breuil semble avoir été bien en cour auprès des papes Innocent VI et Urbain V, ainsi que du roi Charles V, et signa un accord avec l'archevêque Philippe d'Alençon en 1371 (Gallia Christiana, 11, 1759, col. 150).

30. Voir, notamment, Mouradian, Roquelet, 1980, Introduction, p. 8-9.

31. Delisle, 1849 (éd. p. 219-220 et analyse).

32. 1372,5 août, 1373, 27 mars, et 1379 (n. st.), 25 janvier et 5 mars.

33. Vielliard, Pommerol, 200o; Pommerol, 1998, p. 363-367; Rouse, 1989, notamment p. 120-123; voir, plus récemment, Fournier, 2011 (en part. 3.6.2.).

34. Dans la suite de l'article, on a conservé, peut-être à tort, cette date de 1372, mais en la faisant suivre d'un «(?)». 
il semble étrange que près de 50 articles aient été prêtés le même jour à des personnages venus, comme on le verra, d'horizons divers. Peut-être peut-on penser plus simplement que l'on a oublié de préciser la date des autres emprunts qui s'échelonneraient donc entre le 5 août 1372 et le 27 mars 1373 ? Le fait même que l'on n'ait relevé aucun emprunt entre le 27 mars 1373 et le 5 février $1379^{35}$ (n. st. $)^{36}$ laisserait penser que ce registre n'était pas tenu de façon très régulière.

On notera avec intérêt qu'à Saint-Ouen, c'est le trésorier qui supervise les emprunts ${ }^{37}$. Chaque titre emprunté est assorti de diverses précisions: la plupart du temps des cotes topographiques, rarement des incipit et explicit repères, parfois des mentions de «littera...».

\section{La gestion des emprunts}

Comme l'a déjà souligné Marie-Henriette de Pommerol ${ }^{38}$, il semble que la pratique de demander un reçu (une «littera», c'est-à-dire un document, une charte) soit assez rare à Saint-Ouen: sur 19 emprunteurs, une lettre de reçu est mentionnée seulement à quatre reprises, toujours dans le cas d'emprunts de plusieurs livres ${ }^{39}$ : il s'agit des emprunts effectués par le «magister Petrus de Sirvilla» (art. 17, mais qui recouvre le prêt de trois volumes), par le «magister Radulphus Boutin» (art. 20-22), par le «magister Egidius de Campis» (art. 24-31) et par le «magister Ricardus Pieli» (art. 32-37); en général la mention de la lettre est portée au dernier article du groupe d'emprunts, avec une formule du type «de quibus habemus litteram», complétée parfois de "sub sigillo suo» (Petrus de Sirvilla), qui laisse penser que le document concerne tous les volumes empruntés. Cette pratique consistant à demander un reçu aux emprunteurs est certainement à rapprocher de la pratique en cours à la bibliothèque royale, dans les années qui suivirent ${ }^{40}$. À Saint-Ouen, tous les emprunteurs de lots de plusieurs volumes ne sont pas contraints de fournir un reçu, tels «Magister Egidius Abbatis» (art. 6-13) ou le "Prior conventus»" (art. 42-44). En un seul cas, la restitution d'un prêt est notée: il s'agit de l'emprunt effectué en janvier 1378 par «dant Simon» (art. 18bis); au demeurant, l'absence d'indication ne signifie pas que les restitutions n'aient pas eu lieu, puisque ce même ouvrage, emprunté en 1378

35. Ces emprunts éloignés dans le temps sont pourtant inscrits sur le même feuillet.

36. Il semble que Saint-Ouen, comme le chapitre et la Normandie, ait adopté le début de l'année à Pâques.

37. «Veci les livres qui sont prestés du thesorier de Saint-Ouan de Rouan...» (fol. 7v).

38. Pommerol, 1998, p. 358.

39. L'édition Dubois, 2001, n'affectant aucun numéro aux articles de cette liste, force a été d'en ajouter qui n'apparaissent dans aucune édition publiée.

40. Dans les inventaires de la bibliothèque du Louvre dressés en 1411, après la mort de Gilles Malet, et dans lesquels sont notées les pertes recensées par comparaison avec l'inventaire de 1373/138o, on retrouve le même type de mention d'un document annexe; voir, par exemple, «et si en appert par lettre du roy signee au doz B» (Paris, BnF, ms fr. 2700, fol. XLI, art. C 4 : inventaire C dressant les déficits dans la bibliothèque royale).

41. Demeuré non identifié; il n'est guère étonnant que le nom d'un prieur claustral, bien connu de la communauté, ne soit pas spécifié. 
par maître Simon (art. 18bis), l'avait déjà été en 1372 par le «magister Philippus $J a c o b »($ art. 18), sans que la restitution ait été notée. Ce contrôle qui paraissait assez minutieux ne suffisait toutefois pas à prémunir la bibliothèque contre les disparitions, comme en témoigne la liste de cinq livres manquants, dressée à la suite des emprunts de $1372^{42}$.

\section{La gestion de la bibliothèque}

Cette liste de prêts fournit également des informations sur la vie de la bibliothèque. Certains titres sont en effet suivis de noms de personnes au génitif. Si dans la grande majorité des cas, il s'agit de noms d'auteurs précisant tout naturellement le titre, dans deux cas on peut se demander s'il ne s'agit pas du nom de possesseurs antérieurs qui ont dû donner des livres à la bibliothèque, tel ce $\mathbf{P}$. du Coudray, peut-être l'ancien propriétaire des Sentences empruntées par Egidius Abbatis (art. 6), ou ce Johannes Blanc ${ }^{43}$ qui a dû donner des livres dont des Quaestiones en papier empruntées par un chanoine augustin de Beaulieu ${ }^{44}$ (art. 23); ce Jean Blanc était peut-être le prieur de Segy, du même nom, mentionné comme chargé d'une procuration en 1355 dans l'affaire de la Forêt Verte portée devant le nouveau duc de Normandie, Charles (futur Charles V) ${ }^{45}$. Dans un cas au moins, la formulation semble ne laisser aucune place au doute: il s'agit de l'Hugutius «quod fuit Nicolaus Mulot» emprunté par le prieur du couvent (art. 44); ce Nicholaus Mulot est probablement le moine de Saint-Ouen, dépêché en Avignon, après l'élection du nouvel abbé Renaut du Quesnay, pour s'assurer de la position du pontife ${ }^{46}$.

En outre, comme il a déjà été souligné ${ }^{47}$, ce document atteste très clairement l'existence de deux catalogues de la bibliothèque de Saint-Ouen, tous deux aujourd'hui perdus: dans la notice consacrée à l'emprunt par l'archevêque de Rouen d'un Cassien (art. 41), deux cotes topographiques sont indiquées pour cet ouvrage, l'une, «secundum anticum registrum», l'autre "secundum novum». On ne sait auquel des deux se référait Pommeraye quand il écrivait avoir «lû dans les Archives un vieux catalogue des manuscrits qui étoient autrefois dans l'abbaye, lesquels étoient en assez grand nombre pour ce temps-là... ${ }^{48}$.

42. "Isti qui secuntur non habemus» (fol. $7 \mathrm{v}$ ).

43. Les documents examinés étant rédigés indifféremment en latin ou en français (parfois simultanément dans les deux langues), il a paru plus commode de classer à la forme latine du prénom et donc d'indiquer au moins une fois cette forme (généralement en gras). La traduction du latin en français des patronymes a été proscrite et la forme d’origine le plus souvent conservée. Dans quelques cas de personnages particulièrement connus, les deux formes, en latin et en français, ont été conservées. Pour les chanoines de la cathédrale, nous avons le plus souvent adopté la forme retenue dans les Fasti, 2, 1998.

44. Notre-Dame de Beaulieu, abbaye, puis prieuré de chanoines réguliers augustins, fondé en 1189 par Jean de Préaux (d'après BoudeT, 1964, p. 7 et n. 7, p. 23; la date de 1200 [Du Monstier, 1663, 916] serait la date d'une charte de confirmation); dép. Seine-Maritime, cant. Darnétal, c. de Préaux.

45. MiCHEL, 1840 , p. 91.

46. Ibid., p. 31.

47. Delisle, 1849, p. 226; Pommerol, 1998, p. 358 et n. 129; Nortier, 1966, p. [187].

48. Pommeraye, 1662, p. 215. 


\section{La disposition des livres et leur nombre}

Le rédacteur de cette liste d'emprunts a relevé la cote topographique pour chacun des livres empruntés, y compris pour ceux qui n'ont pas été retrouvés, à l'exception toutefois des livres prêtés le 27 mars à «mestre Robert Jacob »; pour ce dernier lot, l'incipit du deuxième et du dernier feuillets ont en revanche été notés. D'après le libellé des cotes, les livres sont répartis à droite ou à gauche (17 seulement) d'une séparation centrale ${ }^{49}$, seule la localisation à gauche étant spécifiée («a parte sinistra»). Pour chaque volume est précisé d'abord un numéro de linea ${ }^{50}$ indiqué en chiffres romains, puis une littera, généralement en minuscules, enfin un autre chiffre romain. Que signifie donc ce terme de linea qui n'est pas courant dans le vocabulaire bibliothéconomique? Une seule occurrence est relevée chez John Clark, dans le catalogue de la bibliothèque de Cîteaux dressé au temps de l'abbé Jean de Cirey (1476-1501) ${ }^{51}$. Et s'il ne retient pas ce terme dans la liste des termes désignant les meubles de bibliothèques médiévaux, Clark qui voit dans la linea de Cîteaux une étagère, de même qu'André Masson ${ }^{52}$, estime qu'à Saint-Ouen de Rouen le même mot désigne plutôt une rangée de meubles (probablement des lutrins) ${ }^{53}$. De fait, si linea avait pour seul sens celui d'étagère, pourrait-on imaginer trois étagères (linea I-III) courant le long des murs et divisées en casiers thématiques (les lettres) ${ }^{54}$ ? Ne pourrait-on se représenter plutôt des meubles «alignés» (mis en linea) sur trois rangées, sur trois travées, de part et d'autre d'une séparation centrale? La lettre serait toujours supposée désigner des divisions thématiques, peut-être matérialisées par des cloisons verticales, délimitant des sortes de casiers; le second chiffre romain marquerait, lui, le numéro d'ordre de chaque volume à l'intérieur de ces casiers.

Cette hypothèse de meubles alignés sur trois travées ne règle toutefois pas toutes les questions. Il reste en effet difficile de calculer le nombre de meubles disposés sur une seule rangée; s'il y en avait en effet un seul, de part et d'autre de la séparation centrale, il en résulterait un nombre assez faible (six au total) de meubles qui auraient alors été de grande contenance. On peut aussi imaginer qu'il y avait plusieurs meubles alignés de part et d'autre de l'allée; dans ce cas de figure les casiers auraient été marqués par des lettres en continu d'un meuble

49. S'agissait-il d'une allée prolongeant une fenêtre, une porte, une cheminée... ou bien les meubles de rangement étaient-ils installés sur deux murs opposés de la pièce et donc à droite et à gauche d'un point central?

50. Il est difficile de voir dans la linea autre chose qu'une ligne horizontale; s'agissant d'emplacement des livres dans une bibliothèque, rien ne permet de traduire ce mot par un terme bibliothéconomique se référant à une «étagère»; peut-être le mot «rangée» conviendrait-il mieux?

51. Dans la bibliothèque du dortoir décrite en tête de ce catalogue, certains livres étaient rangés sur des pupitres (des «bancae»), le plus souvent bi-faces: d'après le titre de la première subdivision de ce catalogue, seul le premier pupitre semble avoir été pourvu d'une «2a linea» (ClarK, 1902, p. 98-99).

52. Masson, 1964 : «chacun [de ces meubles en épi] comportant deux rayons (lineae)» (p. 6o).

53. Clark, 1902, p. 239-241; Clark avoue d'ailleurs son impuissance à déterminer la forme des meubles contenant les livres d'après la seule terminologie: «increased study has convinced me $[\ldots]$ that the words were used quite loosely» (p. 239).

54. C'est plus ou moins la solution imaginée par Delisle, 1849 et reprise par Pommerol, 1998. 
à l'autre sur une même demi-travée; les meubles utilisés pouvaient aussi être bifaces (comme l'étaient nombre de pupitres). Ces diverses hypothèses permettraient ainsi de rendre compte du nombre assez élevé de subdivisions connues pour un même meuble (lettres «a» à «V» pour le pupitre I).

Une autre question concerne la façon dont les livres eux-mêmes étaient disposés. L'étaient-ils à plat, selon l'usage du temps? En ce cas, ils auraient occupé une place importante. Est-il alors pensable que le système de rangement adopté à Saint-Ouen de Rouen ait été proche, pour prendre un exemple quasicontemporain, de celui en vigueur à Hereford vers 1394 (soit 20 ans après la date de ces emprunts) et dont il subsiste de beaux spécimens ${ }^{55}$, et en ce cas, les livres pourraient-ils avoir déjà été rangés à la verticale? On le voit, à la différence de Léopold Delisle qui, d'une plume alerte et quasi lyrique, dépeint très précisément la bibliothèque de Saint-Ouen dans les années $1370^{56}$, nous avons quelque difficulté à nous représenter concrètement le mode de rangement des livres d'après un schéma aussi lacunaire.

De même, il ne nous paraît pas réaliste de nous risquer à une évaluation globale du nombre de livres conservés à Saint-Ouen, à partir de la cinquantaine de cotes connues par ce document. Certes, on peut noter que le nombre de livres à l'intérieur de chaque subdivision ne dépassait pas «X», mais calculer le nombre de subdivisions existant pour chaque demi-travée à partir des seules données connues pour la linea I (moins fragmentaires que celles des autres lineae) pour en déduire un nombre total de volumes paraît assez hasardeux ${ }^{57}$, et ce d'autant plus que l'on ignore totalement s'il existait d'autres dépôts dans l'abbaye, et combien. En l'état, on ne peut que remarquer que l'«anticum registrum» présentait lui aussi un système de cotes topographiques, sans doute différent de celui exposé dans le nouveau catalogue: on relève en effet que le Cassien classé dans le nouveau catalogue au niveau I, à gauche, était rangé, dans l'ancien, au niveau IV et qu'au lieu d'occuper, comme dans l'ancien, le quatrième rang dans la subdivision, il occupait la sixième position dans le nouveau classement; en revanche, dans l'ancien, comme dans le nouveau catalogue, il ressortissait à la série «l»; cette seule mention d'une cote de l'ancien catalogue ne permet pas de déterminer si dans l'ancien catalogue on avait déjà une séparation entre un côté gauche et un côté droit (peut-être non précisé, comme dans le nouveau

55. Clark, 1902, fig. 73 et p. 168-169.

56. «Nous nous la figurons dans une pièce voûtée, assez petite, plus longue que large. La porte s'ouvre dans un des petits côtés. En face le jour pénètre par une croisée grillée. Des armoires sont adossées aux murs des grands côtés...» (DELISLE, 1849, p. 226-227). On remarquera simplement que ce tableau reflète peut-être plus la pratique bibliothéconomique de l'époque du grand érudit que celle contemporaine du document.

57. Le nombre de 750 volumes avancé par NORTIER, 1966, p. [187] nous paraît en effet beaucoup trop sujet à caution, car il ne nous paraît pas possible de déduire un nombre de volumes suffisamment fiable à partir de chiffres fondés sur une cinquantaine de cotes (2o casiers par linea, avec une moyenne de 6 livres par casiers). Rien ne prouve en particulier que le nombre de casiers soit constant d'une linea à l'autre. Geneviève Nortier a cependant raison de souligner que la succession même des cotes dans une même série, parfois discontinue, prouve, s'il en était besoin, le caractère fragmentaire de cette source. 
catalogue), auquel cas, le Cassien, pour lequel le côté est passé sous silence, aurait été classé à droite, alors qu'il était rangé à gauche dans le nouveau catalogue.

\section{Le classement des livres}

Il reste toutefois possible de raisonner d'après les données fiables que représentent la cinquantaine de cotes fournies par ce document ${ }^{58}$ pour esquisser une hypothèse sur le classement des livres dans le nouveau catalogue (voir le tableau ci-après). En effet, si on reprend les indications topographiques fournies pour une cinquantaine d'articles et si l'on essaye de répartir les livres par linea puis, à l'intérieur de chaque linea, par lettre, on constate que les livres de droit sont rangés à droite, sur la linea I, dans les subdivisions «a » à «e» au moins; les bibles sont également à droite, sur la linea I, dans les subdivisions «h» et «k»; toujours à droite, mais sur la linea II, les commentaires exégétiques semblent occuper les subdivisions « $\mathrm{a}$ » $\mathrm{a}$ " $\mathrm{f}$ » au moins avec, néanmoins, la présence quelque peu incongrue d'une Somme d'Azon dans la subdivision "e $»^{59}$; l'exégèse biblique semble se poursuivre sur la linea III, dans les subdivisions "a " à «f» peut-être; sur la même linea, la théologie scolastique semble se déployer dans les subdivisions «g» à «l». Pour la partie gauche, les hypothèses échafaudées sont plus incertaines encore, du fait du faible nombre de volumes mentionnés: il est possible que la patristique soit rangée sur la linea I, dans les subdivisions « $\mathrm{a}$ » $\mathrm{a}$ «e $\mathrm{e}$ au moins; les homéliaires pourraient être rangés toujours sur la linea I, dans la subdivision «h» et peut-être dans les suivantes, alors que les volumes relatifs à la vie monastique occuperaient les subdivisions «l» et « $\mathrm{m}$ » au moins de cette première linea I, les chroniques et peut-être l'histoire étant rangées dans la subdivision « $\mathrm{O}$ » et peut-être dans d'autres. Avec la linea II, on semble aborder les classiques, au moins dans les subdivisions «b $»^{60}$ et «d», les subdivisions «f» à «k» étant peut-être occupées par les recueils de sermons, tandis que la subdivision «p» au moins semble être consacrée à l'hagiographie. Il n'est quasiment pas possible de déterminer le contenu de la linea III, les données étant par trop clairsemées.

\section{Les emprunteurs}

Au-delà de ces hypothèses sur le classement et la disposition des livres, on peut s'intéresser à l'identité des emprunteurs. Comme bien souvent, ceux-ci sont parfois désignés, non par leur nom, mais par leur fonction «Episcopus Belvacensis» ou "Decanus Rothomagensis» ou encore "Archiepiscopus Rothomagensis»; et quand bien même le nom des emprunteurs est donné, il vaut la peine d'examiner à quel milieu ils sont liés, ou quelles sont leurs charges.

58. Les articles de l'emprunt de 1373 (art. 51-55) en sont dépourvus.

59. Il pourrait s'agir d'une simple erreur, la linea II ayant été indiquée pour la I (je remercie Anne-Marie Turcan de cette suggestion).

60. À moins que cette subdivision $I I, \mathrm{~b}$, ne relève encore de l'histoire, puisqu'il s'agit d'un historien classique, Lucius Annaeus Florus. 


\begin{tabular}{|c|c|c|c|c|c|c|c|}
\hline \multicolumn{4}{|c|}{ A parte sinistra } & \multicolumn{4}{|c|}{ A parte dextra } \\
\hline linea & littera & nombre & Contenu & linea & littera & nombre & Contenu \\
\hline$I$ & $a-e$ & 2 & Patristique & $I$ & a-e & $\begin{array}{l}12 \\
\text { articles }\end{array}$ & Droit \\
\hline$I$ & $\mathrm{~h}$ & 1 & Homéliaires & $I$ & h-k & 4 & Bibles \\
\hline$I$ & $1-m$ & 2 & $\begin{array}{l}\text { Vie et règles } \\
\text { monastiques }\end{array}$ & & & & \\
\hline$I$ & o & 1 & Histoire & $I$ & $\mathrm{v}$ & 1 & Droit \\
\hline II & $b, d$ & 2 & Classiques & II & $a-b, f$ & 6 & $\begin{array}{l}\text { Exégèse } \\
\text { biblique }\end{array}$ \\
\hline II & $\mathrm{k}$ & 1 & Sermons & $I I$ & $\mathrm{e}$ & 1 & $\begin{array}{l}\text { Droit } \\
\text { civil }\end{array}$ \\
\hline II & $\mathrm{p}$ & 2 & Hagiographie & & & & \\
\hline III & c & 1 & $\begin{array}{l}\text { Philososphie } \\
\text { en français }\end{array}$ & III & $a-f$ & 3 & $\begin{array}{l}\text { Exégèse } \\
\text { biblique }\end{array}$ \\
\hline III & $\mathrm{e} / \mathrm{c}$ & 1 & $\begin{array}{l}\text { Poème } \\
\text { moralisant }\end{array}$ & III & $\begin{array}{l}\text { g-k } \\
\text { ou } 1\end{array}$ & 7 & Théologie \\
\hline III & $\mathrm{i} / \mathrm{l}$ & 1 & $\begin{array}{l}\text { Spiritualité } \\
\text { monastique }\end{array}$ & & & & \\
\hline
\end{tabular}

Tableau (simplifié) de la répartition ${ }^{61}$

Certes, plusieurs personnages cités n'ont pu être identifiés, tels Ricardus de Barbero ${ }^{62}$ qui emprunte, le 5 août 1372, quatre livres de droit (art. 2-5), Guillelmus de Bellomonte à qui est prêté en 1372 (?) la Somme d'Azon (art. 15), Guillelmus Trubet ${ }^{63}$, moine de Notre-Dame de Beaulieu ${ }^{64}$ qui emprunte en 1372 (?) des Questiones (art. 23), Johannes Bosquet à qui est prêté en 1372 (?) un recueil hagiographique (art. 40) ou encore ce Philippus Jacob qui emprunte en 1372 (?) deux volumes de droit (art. 18-19), puis le 27 mars 1374 (n. st.), par l'entremise de son frère Robert (inconnu, lui aussi), cinq autres volumes de droit (art. 51-55). D’autres emprunteurs, désignés uniquement par leur office, tel le prieur de «Condeto ${ }^{65}$ (art. 45), ou le prieur de Saint-Ouen (art. 42-44)

61. Cette tentative de reconstitution ne s'appuie que sur les quelque 50 articles portant une cote, laissant évidemment dans l'ombre tous les livres non mentionnés par les emprunts.

62. Il nous a en effet paru difficile de rapprocher ce Richard de Barbero du chanoine de Rouen, Richardus Barbe (Fasti, 2, 1998, nº 24; voir TABBAGH, 1988, 3, n 24).

63. Ce chanoine n'apparaît pas parmi les personnages cités dans BOUDET, 1964, p. 7-25.

64. Sur ce prieuré de chanoines réguliers augustins, voir supra, n. 44.

65. Il s'agit certainement de Condé-sur-Aisne ou Condeto prope Valliacum, prieuré de Saint-Ouen de Rouen (dép. Aisne, cant. Vailly-sur-Aisne). 
demeurent inconnus. Un certain nombre d'emprunteurs ont pu en revanche être identifiés; un grand nombre sont des gradés de l'université: on pense, par exemple, au prêtre de Rouen, Egidius Abbatis, maître, puis docteur en théologie en même temps que Gilles Deschamps, maître régent de la Faculté de théologie en $1387^{66}$ qui, en 1372 (?), n'emprunte pas moins de 9 volumes; il s'agit d'une bible, qualifiée de «bonne» (art. 8) et d'un commentaire d'Origène sur les Épîtres de Paul (art. 7), mais surtout d'ouvrages théologiques de Pierre Lombard (art. 6), de Guillaume d'Auxerre (art. 9), de Thomas d'Aquin (art. 10), de Bonaventure (art. 11 et 13), ainsi que de recueils de sermons (art. 12 et 14). Ludovicus Clerici, lui, est licencié en lois et bachelier en décret en 1378-1379 ${ }^{67}$, peu de temps après le moment (en 1372 [?]) où il emprunte, sans doute au moment de ses études, un Décret complet (art. 16); Radulphus Boutin, maître ès arts et bachelier en lois ${ }^{68}$, emprunte, toujours en 1372 (?), deux livres de droit (art. 20 et 22), mais aussi une petite bible (art. 21). De ces premiers cas, on peut conclure, sans surprise, que les emprunts de livres sont en rapport étroit avec la spécialité embrassée par les gradés: les canonistes empruntent plutôt des livres de droit, les théologiens, de la théologie ou de l'exégèse.

À côté des gradés de l'université, les personnages admis à emprunter dans la bibliothèque de Saint-Ouen sont parfois des personnalités d'une certaine importance. Ainsi, le «magister Petrus de Sirvilla » qui emprunte à Saint-Ouen, en 1372 (?), les Enarrationes in Psalmos d'Augustin en 3 volumes (art. 17) doit être identifié à Petrus de Siherville ${ }^{69}$, prêtre de Rouen issu de la bonne bourgeoisie de cette cité, l'un des premiers sociétaires de la Sorbonne $(1354)^{70}$, chanoine (13631366), puis chantre de l'église de Rouen (1366-1394 ${ }^{71}$. C'est dans cette fonction qu'il multiplie les emprunts de livres; plus qu'à la bibliothèque de Saint-Ouen, c'est en effet à la bibliothèque capitulaire de Rouen ${ }^{72}$ que, naturellement, il s'adresse à plusieurs reprises: le 3 juin $137 \mathrm{O}^{73}$, il restitue au chapitre trois livres empruntés parmi un lot qui venait d'être rapporté au mois de mars précédent: une bible, les Histoires naturelles de Pline l'Ancien et un liber consiliorum ${ }^{74}$;

66. Denifle, Chatelain, 1894, n ${ }^{\circ} 1518$, p. 396, et n. 9 p. $398, \mathrm{n}^{\circ} 1538$ p. 447 (Rotulus magistrorum regentium facultatis theologiae).

67. Ibid., $\mathrm{n}^{\circ} 1434$, p. 270-274, Rotulus plurium magistrorum, doctorum, licentiatorum, baccalareorum et scolarium de Universitate Parisiensi, de 1378-1379, en part. p. 270.

68. Ibid., p. 267.

69. Fasti, 2, 1998, $\mathrm{n}^{\circ} 471$

70. Maître (1362), puis docteur en théologie; voir, notamment, GlorieuX, 1966, p. 324, 333.

71. Il était également chanoine de Tournai.

72. Dans la suite de l'article, les références aux documents sont constituées par une sorte de «clef» d'identification : pour les documents relevant de la bibliothèque capitulaire, la "clef» comprend le nom du personnage et la date; pour Saint-Ouen, la "clef» se compose du nom de Saint-Ouen, suivi du numéro d'article attribué par nos soins, puis du nom de l'emprunteur; pour ne pas trop alourdir une référence déjà longue, la date n'est indiquée que dans les annexes. Cette «clef» est en effet reprise dans l'annexe 1 et suivie de la cote du document, avec, éventuellement, la mention d'une édition; la table des auteurs et des œuvres donnée dans l'annexe 2 se réfère à la même «clef».

73. Petrus de Sihervilla, 1370 (n. st.), 4 mars, puis 1370, 3 juin.

74. Aussi orthographié dans le même document: «liber conciliorum». 
le 16 juillet de l'année suivante il emprunte une petite bible ${ }^{75}$; le 29 mai $1372^{76}$, le chapitre lui prête encore deux livres, de nouveau les Histoires naturelles de Pline ${ }^{77}$ et une Cité de Dieu d'Augustin; ces trois volumes (la bible, Pline et la Cité de Dieu), ainsi que des Lettres échangées entre Augustin et Jérôme, sont restitués au chapitre le 16 août $1382^{78}$ et aussitôt empruntés, la bible, par Guillaume Carrel, chanoine de 1379 à 1415, les deux autres livres par Gilles Deschamps, personnage sur lequel nous aurons bientôt à revenir. Guillelmus Carrel $^{79}$, d'origine paysanne, exerçait la fonction de scribe apostolique en 1372 et accumula les prébendes dans divers chapitres collégiaux ou cathédraux ${ }^{80}$; enfin, le $1^{\text {er }}$ mai $1389^{81}$, Pierre de Siherville emprunte un liber de claustro anime d'Hugues de Fouilloy contre la promesse d'en prendre soin, de ne pas l'aliéner et de le restituer si on lui en fait la demande.

Un autre chanoine de Rouen, Ricardus Piel († 1387, juillet) ${ }^{82}$ emprunte, à Saint-Ouen et toujours en 1372 (?), six livres (art. 32-37), dont quatre d'exégèse biblique: il s'agit du commentaire d'Angelome de Luxeuil sur les Rois et de trois volumes de Postilles, sur le Pentateuque, Josué et les Rois d'une part, sur les Épîtres de Paul et l'Apocalypse, d'autre part, ainsi que sur les Évangiles; les deux autres sont un Augustin (art. 36, De confessionibus) et un recueil de sermons de Jean Halgrin d'Abbeville (art. 37). Quelques mois avant (le 29 mai 1372) ${ }^{83}$, Richard Piel avait emprunté au chapitre de la cathédrale de Rouen une concordance des évangiles ("unum Esquatuor», c'est-à-dire Unum ex quattuor ${ }^{84}$ ) et 4 ouvrages en 5 volumes, à savoir : la Cité de Dieu, la concordance des évangiles de Jérôme, des sermons, des Lettres d'un certain Hugues, ainsi qu'une bible. Docteur en théologie et maître régent de la Faculté (1364), Richard Piel qui était issu d'une famille de solides propriétaires terriens, bénéficia de plusieurs prébendes ${ }^{85}$. Peu de temps après ces divers emprunts, Richard Piel devint pénitencier de l'archevêque (1377-1378).

Le «dant Simon» qui emprunte à Saint-Ouen le 25 janvier 1379 (n. st.) le Sexte avec la Lecture sur le même texte de Jean André (art. 18bis) ${ }^{86}$ est à coup sûr le Simo du Bosc qui emprunte à nouveau deux volumes le 5 février 1379 (n. st.), deux autres livres de droit, civil, cette fois, les Institutes et le Digeste nouveau (art. 56-57); ce personnage devait par la suite jouer un rôle éminent dans les affaires du royaume,

75. Petrus de Sihervilla, 1371.

76. Petrus de Sihervilla, 1372

77. D’après les incipit repères, sans doute l'exemplaire déjà emprunté deux ans auparavant.

78. Petrus de Sihervilla, $\mathbf{1 3 8 2}$.

79. Fasti, 2, 1998, n ${ }^{\circ} 84$.

80. Il fut en effet chanoine de Saint-Martin de Tours (1363), puis chanoine de Sainte-Croix de Cambrai (1377), chanoine de Bayeux.

81. Petrus de Sihervilla, 1389.

82. Fasti, 2, 1998, no 405; Denifle, Chatelain, 2, 1891, p. 641 et n. 25; Millet, 1982, p. 518

83. Ricardus Piel, 1372.

84. Je remercie Anne-Marie Turcan de m'avoir suggéré cette interprétation.

85. À Évreux où il tenait l'office de chantre en 1364, à Lisieux jusqu'en 1371, à Rouen de 1371 à 1387, ainsi qu'à Laon de 1372 à 1374

86. Il s'agit du volume qui avait déjà été prêté à Philippus Jacob en 1372 (et donc rendu par ce dernier). 
notamment au cours du Grand Schisme ${ }^{87}$. D'abord étudiant à la Faculté de décret de Paris, Simon du Bosc devint docteur en droit (1386), tout en recevant la charge de plusieurs établissements et devint en 1391 abbé de Jumièges, abbaye qu'il sut gérer avec efficacité, même s'il la délaissa au profit de séjours parisiens; il lui offrit notamment d'assez nombreux codices ${ }^{88}$. Né à Rouen vers 1350 , Simon du Bosc, qui fit ses premières études à Saint-Ouen de Rouen, devait donc avoir moins de 30 ans au moment de ces emprunts qui se situent certainement pendant ses études; or, à chaque fois, ces livres lui sont portés (à Rouen? à Paris?), d'abord par frère Guiot (art. 18bis), puis par «Franquet le messagier» (art. 56-57). On peut supposer que la protection dont il devait bénéficier de la part de son oncle l'évêque de Bayeux, Nicolas du Bosc, membre du Conseil royal entre 1380 et 1388 , ne fut pas étrangère à ce qui semble un régime de faveur pour un étudiant.

De même, le «decanus Rothomagensis» cité en 1372 (?) pour l'emprunt d'un «liber qui dicitur Julius Folius» (art. 39) n'est autre que Nicholaus Oresme ${ }^{89}$, chanoine (1365-1371) et doyen (1365-1376) de Rouen, évêque de Lisieux (1377-1382); il n'est pas besoin de rappeler ici le rôle éminent joué par Nicole Oresme dans le mouvement de traductions initié par le roi Charles $\mathrm{V}^{90}$, ni la protection accordée par ce dernier à son traducteur: en témoignent la délibération capitulaire prise en chapitre général, le 18 août $1372^{91}$, et qui accorde au doyen, à sa propre requête et à celle du roi, le droit de percevoir ses revenus et les distributions, malgré son absence du chapitre et de l'église "usque ad perfectionem libri Polleticorum quem scribit pro dicto domino rege ${ }^{92}$, ou encore, la délibération du 21 décembre 1375 renouvelant cette faveur, au moment où le doyen du chapitre traduisait le De caelo et $m u n d o^{93}$, sans même mentionner les importantes sommes d'argent allouées par le roi à son traducteur en 1372, puis en $1374^{94}$; après son élévation à l'évêché de Lisieux en 1377, une autre délibération capitulaire lui accorda, toujours à la demande du roi, la jouissance de l'hôtel canonial que le traducteur occupait à Rouen comme doyen ${ }^{95}$. Les années 1370-1372 correspondent à une période d'intense activité de traductions au service du roi ${ }^{96}$ et l'on relève d'autres emprunts effectués par le doyen, cette fois auprès de la librairie capitulaire de Rouen: ainsi

87. Sur sa carrière ultérieure et aussi sur ses premières années, voir BoüARD, 1955.

88. NORTIER, 1966, p. [156].

89. Fasti, 2, 1998, $\mathrm{n}^{\circ} 388$; sur le rôle dévolu par le roi au doyen du chapitre de Rouen, souvent opposé à l'archevêque Philippe d'Alençon, voir surtout Neveux, 1990.

90. Sur le rôle de Nicole Oresme comme traducteur au service du roi, voir, notamment, VAN MoÉ, 1929, p. 3-15; et, surtout, Menut, 1957 et Menut, 1970.

91. Et non le 28 août (Neveux, 1990, n. 63, p. 35).

92. Rouen, Arch. dép. Seine-Maritime, G 2115, fol. 93v; Langlois, 1853, p. 18 : éd. partielle, n. 2 ; cette même délibération du chapitre a été reprise, mais en anglais par MENUT, 1970, p. 19.

93. Rouen, Arch. dép. Seine-Maritime, G 2116, fol. 67v; VAN MoÉ, 1929, p. 3-15, en particulier n. 1, p. 7; sur cette traduction, voir, notamment, Costé, 1997.

94. Delisle, $1874, \mathrm{n}^{\circ} 889$, p. $458-459$ et $\mathrm{n}^{\circ} 1061$, p. 552.

95. Rouen, Arch. dép. Seine-Maritime, G 2118, fol. 11v; Chéruel, 2, 1844, n. 1, p. 426-427, reprise par Menut, 1970, p. 20, n. 41.

96. Sur la chronologie des œuvres et des travaux de traduction de Nicole Oresme, voir, notamment, Menut, 1970, p. 18-20. 
le 4 mars 1370 (n. st.), il restitue au chapitre cinq livres ${ }^{97}$ : une bible, les Histoires naturelles de Pline l'Ancien, un «liber conciliorum», une "porcio evangeliorum» et un Sexte commenté; les trois premiers volumes firent immédiatement l'objet d'un nouvel emprunt, cette fois par Pierre de Siherville (voir supra) qui les restitua en juin de la même année, ainsi que par l'archidiacre du moment (voir infra). Les emprunts par Nicole Oresme à Saint-Ouen, comme à la bibliothèque capitulaire, se situent donc dans le contexte des travaux de traduction qu'il avait entrepris, à la demande et avec le soutien du roi de France, et à une période où les absences de Rouen du doyen du chapitre étaient fréquentes ${ }^{98}$.

Quant à l' "Episcopus Belvacensis» qui emprunte une bonne bible (art. 38), il s'agit de Johannes d'Angerant (1312-1375, 24 janvier), doyen de Chartres, puis, à la suite de son oncle, Louis de Vaucemain, évêque de cette même cité (1360-1368); après de difficiles tractations, il finit par accepter l'évêché de Beauvais (1368-1375) qui lui donnait le titre de comte et pair de France; conseiller au Parlement de Paris, puis président en la chambre des comptes, Jean d'Angerant fut membre du conseil des rois Jean II le Bon, puis Charles V. Par sa sœur Isabelle qui avait épousé Jean II de La Rivière, il était apparenté à une famille de fidèles serviteurs du roi. Il fut en outre le protecteur de Raoul de Presles ${ }^{99}$. Il s'agit donc encore d'un homme proche du roi (Charles $\mathrm{V}$, au moment de ce prêt) et bien implanté dans les organes de gouvernement développés par les Valois.

Au nombre de ceux qui empruntent en 1372 (?) un lot important de livres à Saint-Ouen, figure un autre personnage éminent: Egidius de Campis (ou Gilles Deschamps), à qui sont prêtés rien moins que huit ouvrages (art. 24-31). Pour des raisons chronologiques, il s'agit de Gilles I Deschamps ${ }^{100}$ ( $† 1414,15$ mars), bachelier en théologie avant 1375, licencié en 1383, professeur enfin en théologie, mais aussi licencié en droit civil (qu'il partit étudier à Orléans entre 1375 et 1378); recteur de l'université dès 1371, puis du collège de Navarre (1389), successivement chanoine de plusieurs chapitres ${ }^{101}$ dont celui de Rouen (1381-1408), aumônier (1406-1408) du roi Charles VI, Gilles Deschamps joua un rôle de premier plan durant le Schisme, assurant de nombreuses missions diplomatiques, notamment auprès de Benoît XIII, avant de prononcer officiellement la soustraction du royaume à l'obédience de ce pape; l'évêché de Coutances (1408-1411), puis la pourpre cardinalice (1411) vinrent récompenser cette carrière au service de l'union de l'Église et aussi du roi de France dont il fut conseiller dès 1388 et jusqu'en $1403^{102}$. Les emprunts effectués par Gilles Deschamps auprès de SaintOuen se situent donc pendant ses années de formation et sont assez variés:

97. Et non quatre comme annoncé dans le texte de la délibération (Nicholaus Oresme, 137o [n. st.]).

98. Elles sont notamment soulignées par MENUT, 1970, p. 18-21; voir aussi le tableau des présences de Nicole Oresme au chapitre de Rouen entre 1366 et 1377, dans Neveux, 1990, p. 22, ainsi que l'analyse de ses absences de plus en plus fréquentes et des tensions ainsi provoquées avec les membres du chapitre.

99. CAZElles, 1982, notamment p. 474-475.

100. Fasti, 2, 1998, n ${ }^{\circ} 139$

101. Paris, Bayeux, Coutances, Langres / Bar-sur-Aube.

102. Millet, 1994, p. 231-241; voir aussi Gorochov, 1997, p. 606-607. 
il s'agit d'œuvres exégétiques (art. 24-25), de théologie (art. 26 et, peut-être, art. 27), d'œuvres de morale (art. 28), et de textes relatifs à la vie monastique (art. 29), mais on relève aussi un De officiis de Cicéron (art. 30) et, peut-être, un poème allégorique et satirique (art. 31). Membre du chapitre de Rouen, Gilles Deschamps avait aussi accès à la bibliothèque capitulaire: outre le prêt de deux ouvrages accordé en 1382 (voir supra), il emprunte au chapitre, le 3 février 1400 (n. st. $)^{103}$, un «librum consiliorum», contre la promesse de le restituer à la demande du chapitre; en l'état de nos connaissances, il est bien difficile de savoir s'il s'agit du même ouvrage que celui, à l'intitulé variable, emprunté, puis restitué, par Nicole Oresme, puis à nouveau emprunté par Pierre de Sihervilla, 30 ans environ auparavant (voir supra). Il est en revanche établi que ce livre fut bien restitué au chapitre (voir infra). Comme chancelier, Gilles Deschamps fut chargé de dresser, avec Guillaume de Baudribosc, l'inventaire de 1425 des biens de la fabrique de la cathédrale de Rouen ${ }^{104}$.

Enfin l'«Archiepiscopus Rothomagensis» qui, en 1372 (?), emprunte un Cassien (art. 41) n'est autre que Philippus d'Alençon ${ }^{105}$ (né vers 1338-1339, $\dagger$ à Rome le 16 août 1397) ${ }^{106}$, fils cadet de Charles d'Alençon († 1346) et donc cousin du roi Jean le Bon, chanoine de Chartres en 1351, évêque de Beauvais en 1356, transféré sur le siège de Rouen en 1359 où, dans un premier temps il appuya le dauphin, puis roi de France, Charles V, avant d'entrer en conflit avec lui et avec le chapitre ${ }^{107}$. D'après la mention de 1372 (?), le prélat n'avait emprunté à Saint-Ouen que ce seul ouvrage de Cassien ${ }^{108}$. Cet emprunt se situe au plus fort de la crise qui opposa l'archevêque et son petit-neveu, Charles, devenu roi de France, et qui devait s'achever par la défaite de l'archevêque ${ }^{109}$.

$\mathrm{Au}$ demeurant, Philippe d'Alençon était un fin connaisseur de livres: le 20 février 1363 (n. st.), il reconnaissait que le chapitre de Rouen lui avait remis, en compensation d'une somme qui lui était due, plusieurs objets, au nombre desquels on relève trois livres ${ }^{110}$, parmi d'autres objets liturgiques. De fait, outre

103. Egidius de Campis, 1400 (n. st.).

104. Daté du 28 septembre (Rouen, Arch. dép. Seine-Maritime, G 2094, seconde partie, p. 29-37 [p. 32-35 pour les seuls livres]).

105. Et non pas, pour des raisons chronologiques, Guillaume de Lestrange (Fasti, 2, 1998, p. 113): en 1372, ce prélat, qui n'était encore qu'évêque de Carpentras, négociait au nom du pape une trêve entre les rois de France et d'Angleterre, finalement conclue en 1374, succès diplomatique qui lui valut en 1375 l'archevêché de Rouen (Lestrange, 1888, p. II-III).

106. Fasti, 2, 1998, no 4347 , p. 107-109.

107. Voir, notamment, Neveux, 1990, notamment p. 16-18.

108. L'exemplaire du XII siècle de Saint-Ouen, suivi par des textes patristiques (Isidore, Augustin) et les Dialogues de saint Grégoire (Rouen, Bibl. mun., ms 508 [A 333], fol. 1-154) aurait pu s'identifier à ce volume, mais le codex de Rouen ne présente aucune trace de cote qui puisse correspondre aux cotes citées dans ce fragment de registre de prêt.

109. Sur arrêt du Parlement, le roi fit saisir les domaines de l'archevêque et l'expulsa de Normandie en 1373; sur ce conflit né au sujet de l'étendue de la juridiction ecclésiastique, voir notamment, CHÉRUel, 2, 1844 .

110. Paiement à Philippus d'Alençon, 1362 (n. st.): «[...] una cum quodam parvo libro pro baptismo et sepultura, .xx. scut. [...] Item unum pulcrum librum episcopale nuncupatum in III voluminibus .L. scut. Item unum magnum Missale euvangelistarum et epistolarum .L. scut». 
les livres de sa chapelle ${ }^{111}$, le prélat possédait en propre une riche bibliothèque de près de 130 volumes, dont un inventaire avait été dressé à Saint-Jean des Vignes de Soissons, le 17 janvier $1367^{112}$; à côté des livres possédés par ce prélat cultivé et dont certains avaient d'illustres provenances ${ }^{113}$, on relève plusieurs volumes dont il avait obtenu le prêt: des petites concordances empruntées aux Frères mineurs de Rouen et qui leur furent rendues (art. 12), un «Libellus de Summa Biblie, et aliis» appartenant à un curé de Sainte-Agathe ${ }^{114}$ (art. 13), un De animalibus d'Albert le Grand propriété d'un certain maitre G. Comte ${ }^{115}$ (art. 49). Mais si Philippe d'Alençon empruntait des volumes, il savait aussi prêter ses livres, comme en témoignent plusieurs notes portant sur certains articles: ainsi, au moment où l'inventaire est dressé, le petit Missel à l'usage de Rouen, muni d'une reliure de couleur verte (art. 35), est entre les mains d'un «dominus Stephanus» ${ }^{116}$. C'est à un certain J. de Foris que revient le plus grand nombre de volumes empruntés à l'archevêque ${ }^{117}$ : il s'agit des Questiones d'Oldradus de Ponte, à la reliure de couleur rouge (art. 80), d'une Summa Biterrensis seu Berengarii de Bérenger de Frédol, à la reliure de couleur noire (art. 83) et de plusieurs Lectures par G. de Tyonvilla (art. 118-124), dont la restitution est notée. Ce Johannes de Foris n'est pas tout à fait inconnu: il est tout d'abord le rédacteur de l'inventaire de 1368 des livres de l'archevêque ${ }^{118}$ et donc, sans doute, un de ses proches serviteurs ou familiers. Il est très vraisemblable que c'est ce même fidèle compagnon de Philippe d'Alençon qui fut institué en l'église de Tourny «par main commune» de l'archevêque et de Jean de Tourny, en vertu

111. Inventoriés en septembre 1366 à Pontoise, sans doute au cours d'un déplacement du prélat (document 368.2 A, Pommerol, Monfrin, 2001, p. 383-384).

112. Vaticano (Città del), Archivio Segreto Vaticano, Registra Avenionensia, 161, fol. 310-314 (368.2 B), Pommerol, Monfrin, 2001, p. 384-388 (désormais désigné comme «Philippus d'Alençon, 1367»).

113. Tels ces livres donnés par la reine Jeanne de Boulogne (Philippus d'Alençon, 1367, art. 2), le Pape Clément VI, ancien archevêque de Rouen de 1330 à 1338 (art. 30-34), ou hérités de la reine Clémence de Hongrie (art. 40) ou ceux ayant appartenu à Jean de Marigny, sans doute son prédécesseur, de 1347 à 1351 (art. 56) ou encore à Foulque Bardoul (art. 127), chanoine et doyen d'Angers, puis évêque d'Avranches (1358-1359), chancelier du duc Philippe d'Orléans (1336-1375) et conseiller de Charles V. Dans ces mentions de provenance la formule utilisée est généralement au passé: «dedit» (art. 2), «dati» (art. 30-34), «quod fuit», «que fuerunt» (art. 56), "que fuerunt» (art. 127), et généralement suivie d'un datif (art. 40). C'est la raison pour laquelle l'art. 127 désigne, non pas un emprunt à Foulque Bardoul (comme indiqué dans l'édition Pommerol, Monfrin, 2001, p. 383), mais un livre ayant appartenu à ce personnage.

114. Sans doute Sainte-Agathe d'Aliermont, dép. Seine-Maritime, cant. Londinières.

115. Demeuré non identifié; l'emploi du présent «qui est magistri G. Comitis» laisserait penser qu'il s'agit d'un emprunt à un détenteur encore vivant, plutôt que le rappel d'un possesseur précédent. Pourrait-on identifier ce personnage au libraire Guillaume Le Conte, cité comme libraire de l'Université de Paris, dans des lettres patentes de Charles V du 5 novembre 1368 visant à exempter du guet un certain nombre d'artisans travaillant au service de l'université (DELALAIN, 1891, p. 44)? Ce rapprochement est sans doute insuffisamment étayé pour être adopté, sans autre argument.

116. Demeuré non identifié; la formule «Dominus Stephanus habet» désigne sans ambigüité un emprunt.

117. Les emprunts sont généralement désignés par la formule "commodata/commodate J de Foris", l'adjectif «commodatus» s'accordant avec le titre du livre immédiatement précédent.

118. "Inventarium per magistrum Johannem de Foris, die XVII ${ }^{a}$ januarii anno LXVII ${ }^{\circ}$, de libris factum apud Sanctum Johannem in Vineis, traditum J Pierin» (Philippus d'Alençon, 1367). 
d'un accord entre ledit de Tourny et Thomas Haudri, official et vicaire, et Jean de La Moricière, sénéchal et garde du temporel de l'archevêché ${ }^{119}$. Toutefois, la traduction du nom de Jean de Foris en Jean «des Fours » ${ }^{120}$ nous parait erronée; s'il fallait traduire ce patronyme de Foris, nous proposerions «de hors». Du même coup, on peut rapprocher ce personnage de plusieurs mentions connues par ailleurs: ainsi, il est probable que ce Jean de Foris/Dehors soit lié à Jean et Robert Dehors qui, le 5 mai 1357, reçurent en fief des religieux et abbé de Saint-Ouen une maison, avec le fond de terre, sis à Saint-Paul lez Rouen, pour 18 sous de rente.

De surcroît, ce rapprochement de patronymes, sans doute plus correct, permet d'identifier le premier des emprunteurs noté en tête de la liste de prêt de Saint-Ouen, avant, sans doute, le 5 août 1372: le «mestre Johan Dehors» qui emprunte à Saint-Ouen (sans mention de date) des Clémentines (art. 1) n'est certainement autre que Johannes Dehors, le familier de l'archevêque de Rouen, Philippe d'Alençon, évoqué ci-dessus. S'il s'agit bien du même personnage, et si donc ce Jean de Foris est licencié dans les deux droits ${ }^{121}$, son emprunt de Clémentines est tout à fait en rapport avec sa formation et la protection de l'archevêque explique qu'il ait eu accès à une bibliothèque bénédictine à laquelle lui-même ou des membres de sa famille devaient être liés.

La cinquantaine d'emprunts connue par ce fragment de liste de prêts est riche d'enseignements. Bien que fragmentaire, cette liste ouvre une fenêtre sur la composition d'un fonds assez mal documenté et qui dut subir de sévères destructions durant les Guerres de Religion ${ }^{122}$. Elle atteste d'autre part l'ouverture de ce fonds monastique à d'autres que les seuls membres de la communauté. Et même si cette liste d'emprunteurs, dont plusieurs attendent encore d'être identifiés, est très partielle, on sent que ces personnages sont souvent gens d'importance, ce qui tendrait à démontrer la richesse et l'intérêt que pouvait présenter le fonds de Saint-Ouen pour des personnages qui avaient certainement accès à d'autres bibliothèques, quand ils n'en avaient pas une en propre; plusieurs d'entre eux apparaissent en effet proches des cercles de pouvoir (ecclésiastique ou laïc) ou du monde du savoir.

119. Rouen, Arch. dép. Seine-Maritime, G 1739; Beaurepaire, 2, 1874, p. 78 ; la date de l'acte n'est pas indiquée dans l'inventaire d'archives.

120. Adoptée dans l'éd. Pommerol, Monfrin, 2001, p. 383.

121. "Jean Des Fours, licencié in utroque» (ibid., p. 621).

122. Du moins à en croire le Gallia Christiana, 11, 1759, col. 137: "Anno igitur 1562 Sancti Audoëni basilicam hostiliter ingressi Calvinisto furentes, chori subsellia, altare majus, aliasque subvertunt aras [...] aut deturpant tum invadentes sacrarium, pretiosas quasque vestes \& ornamenta, receptaculum sanctissimi Sacramenti, cruces octo, textus evangelicos septem, calices duodecim...». Pour être précise, cette description doit être considérée avec circonspection: d'une part, le verbe «deturpare» paraît impliquer des dommages moins irrémédiables que la pure destruction; d'autre part, si sept des onze livres liturgiques décrits dans l'inventaire du trésor de 1537 (Rouen, Arch. dép. Seine-Maritime, 14 H 485), ont subi des dommages lors de cette incursion, la bibliothèque est absente de la liste des biens perdus ou endommagés au cours de ces troubles. 


\section{Les livres de la bibliothèque capitulaire de Rouen: emprunts et aliénations}

Les registres de délibérations capitulaires de Rouen attestent, eux aussi, une pratique assez courante du prêt des livres. Il s'agit d'un ensemble documentaire exceptionnel, dont on ne peut prétendre épuiser la richesse. Comme à SaintOuen, la responsabilité des livres revenait au trésorier ${ }^{123}$, mais les décisions concernant la bibliothèque étaient prises collégialement par les chanoines réunis en chapitre et étaient scrupuleusement consignées dans les registres de délibérations ${ }^{124}$. Leur nombre était donc particulièrement élevé, qu'il s'agisse de prendre la décision de faire bâtir une nouvelle bibliothèque ${ }^{125}$, d'y faire édifier un nouvel escalier ${ }^{126}$, de faire rédiger un nouveau catalogue ${ }^{127}$ ou d'accepter des legs de chanoines ${ }^{128}$.

\section{Les emprunts sans limite}

Tout au long de la période envisagée ${ }^{129}$, le prêt de livres aux chanoines était particulièrement réglementé et, comme toute autre mesure concernant la bibliothèque, décidé en chapitre, notamment en ce qui concerne sa durée. Ainsi, dans les années qui suivent la rédaction du registre de prêt de Saint-Ouen, le chapitre se contente d'enregistrer les prêts à des chanoines, comme on l'a vu pour un Petrus de Sihervilla ou pour un Ricardus Piel (voir supra).

En 1492, le 4 juin ${ }^{130}$, le chapitre enregistre simplement le prêt au chantre, Michael Petit ${ }^{131}$, d'un livre de la bibliothèque (au titre non spécifié, «assertum librum») qu'il prétendait vouloir faire imprimer. Et le 24 février $1494^{132}$ le même chantre reçut la permission d'emporter chez lui un bréviaire en papier «ad habendam pleniorem cognitionem servicii et ceremonialis ecclesiastici». Ce docteur en théologie ( $†$ 1500, 22 juillet) avait été chanoine à Lisieux (1472), puis chanoine et chantre de Rouen (1483-1500), avant de devenir doyen de ce même chapitre (1500). À l'orée de cette carrière qui s'avéra brillante, avant même de devenir chanoine, Michel Petit, sans doute jeune encore, car alors bachelier

123. LABORDE, 1919, n. 2, \$1-2, p. 32-33.

124. Elles ont tout aussi scrupuleusement été détaillées dans les inventaires d'archives de la série $\mathrm{G}$ (particulièrement BeAurePaIRE, 2, 1874), qui complètent ainsi, parfois fort utilement, l'étude pionnière de Laborde.

125. LABORDE, 1919 , n. 1 , p. 24 , n. 1 , p. 25 , n. 1 , p. 49

126. Ibid., p. 51, n. 1-3, p. 52, n. 1, p. 53.

127. Rouen, Arch. dép. Seine-Maritime, G 2131, fol. 92 ; 1447 (n. st.), 22 ou 24 février, LABORdE, 1919, n. 1, p. 33; Rouen, Arch. dép. Seine-Maritime, G 2142, fol. 98, 1484 (n. st.), 3 février, mentionné par LANGLOIS, 1853, p. 24.

128. LABORDE, 1919, p. 36-37, n. 1

129. Comme il a déjà été précisé, les premiers registres capitulaires conservés remontent au milieu des années 1360 et l'enquête s'arrête, au décès en 1393 de l'archevêque Robert de Croismare.

130. Michael Petit, 1492.

131. Fasti, 2, 1998, n ${ }^{\circ} 402$; ce chanoine copia les Sermons de Carême de Jacques de Voragine, ainsi qu'une partie des Commentaires bibliques de Nicolas de Lyre (TABBAGH, 2008, p. 42 et n. 88).

132. Michael Petit, 1494 (n. st.). 
en théologie, reçut avec un docteur en théologie, Rogerus de Tournebu (qui n'avait apparemment pas de prébende à Rouen), le droit d'accorder la clef de la bibliothèque à tout chanoine qui désirerait y étudier, mais avec interdiction expresse d'en faire fabriquer une nouvelle (1467 [n. st.], 20 février) ${ }^{133}$.

Parfois, l'autorisation de prêt était assortie de la promesse faite par l'emprunteur de restituer le livre. Ainsi le 4 décembre $1389^{134}$, le doyen Hugo Lenvoisie (1346-1414, avril $)^{135}$ fut autorisé par le chapitre à emprunter un répertoire de droit canon, le «Martinian », précisément décrit (avec relevé d'incipit et explicit repères), avec la seule précision que le doyen devait rendre le livre. Cet emprunt, le seul à avoir été retrouvé, ne fut certainement pas unique, puisqu'à sa mort, ses exécuteurs testamentaires semblent ${ }^{136}$ avoir restitué en mai $1414^{137}$ au chapitre sept ouvrages qu'il détenait chez lui; il s'agissait de livres variés: un Catholicon, une Cité de Dieu d'Augustin, des Sermons d'un frère Guillaume, une Lettre de l'archevêque Hugues; certains de ces emprunts sont cités de façon un peu énigmatique ${ }^{138}$. Chanoine (en 1376) et doyen (en 1379) de Rouen, Hugues Lenvoisie était un personnage important: fils d'un fruitier du roi Jean le Bon, licencié en théologie (1374) et sociétaire du Collège de Navarre (1368) ${ }^{139}$, il avait accumulé de nombreuses prébendes ${ }^{140}$ et devint curé de Caudebec en Caux (1401). Chapelain de Clément VII (ca. 1378-1382), il fut particulièrement actif durant le Grand Schisme: théologien parisien éminent, il fut en effet l'un des deux procureurs dépêchés par l'évêque d'Évreux, Guillaume de Valan, pour le représenter à l'Assemblée du clergé qui devait s'exprimer sur la soustraction d'obédience (1398) et il vota également comme représentant de Saint-Ouen de Rouen et du chapitre de la cathédrale ${ }^{141}$.

De même, le jeudi 13 novembre $1466^{142}$, le chanoine Guillelmus du Désert (ca. 1400-1471, février ${ }^{143}$ obtient du chapitre l'autorisation d'emprunter un livre de Sermons, très certainement de Guillaume Peyraut, qu'il s'engage à restituer à la demande des membres du chapitre. Licencié en droit canon, Guillaume du Désert semble avoir bénéficié à deux reprises d'une grosse prébende de la cathédrale (1427-1432, puis, de nouveau, à partir de 1445); après avoir été officier (1444-1448) de l'archevêque Raoul Roussel, il jouit des revenus de plusieurs cures

133. Rouen, Arch. dép. Seine-Maritime, G 2137, fol. 102v; LABOrde, 1919, n. 3, p. 41, $\mathrm{n}^{\circ} 14$.

134. Hugo Lenvoisie, 1389.

135. Fasti, 2, 1998, no 305 ; voir Valois, 3, 1901, p. 105; Millet, 1982, p. 345-346.

136. L'interprétation de ce texte n'indique pas en effet clairement s'il s'agit d'une restitution à la suite d'emprunts ou s'il s'agit d'un legs au chapitre; nous avons choisi de l'interpréter comme une restitution.

137. Hugo Lenvoisie, 1414.

138. Liber qui incipit Prefacio. Virorum... [art. 2], Epistola quam auctor libri diligit (sic) [art. 5], de Evangeliis et differentia [art. 7]; nous reviendrons par la suite sur quelques-uns de ces titres.

139. Gorochov, 1997, p. 659-66o.

140. Chanoine de Chartres (1378-1397), de Laon (1382-1409) et sous-trésorier de Laon (1386), chanoine de Soissons (1386).

141. Millet, 1997, p. 233 et n. 6-7; Millet, Poulle, 1988, cédules nº 40, p. $85-86$ et nº 120, p. 157-158.

142. Guillelmus de Deserto, 1466, 13 novembre.

143. Fasti, 2, 1998, $\mathrm{n}^{\circ} 142$ 
dans le diocèse. Chargé de plusieurs missions à l'étranger, il fit notamment un voyage en Angleterre (1449) pour réclamer les biens encore dus au chapitre sur la succession du duc de Bedford, et le 14 février $1466^{144}$, il fit déposer au chapitre 5 livres qu'il entendait lui léguer, mais qui semblent avoir eu pour origine la succession du régent anglais, comme le prouve la réclamation de ces mêmes volumes par un commissaire parisien chargé de cette succession ${ }^{145}$. Il s'agissait d'un «beau» Psautier, de concordances des Évangiles, d'un commentaire augustinien sur les Épittres de Paul, d'un De regimine principum de Gilles de Rome et d'un Martyrologe; le chapitre semble avoir conservé les concordances et le commentaire augustinien.

Les emprunts qui viennent d'être évoqués semblent être des emprunts de longue durée, que l'on prend soin de noter, mais sans en fixer le terme. C'est sans doute le sens des formules "promisit [...], ymmo restituere ad voluntatem dominorum ${ }^{146}$, «debet eundem librum restituere capitulo ${ }^{147}$, «unum librum [...] quem promisit reddere, restituere ad beneplacitum dominorum ${ }^{148}$.

\section{Les restitutions}

Lorsque l'on a la chance de disposer à la fois des mentions d'emprunt et de restitution, on constate effectivement que le laps de temps séparant la restitution de l'emprunt est le plus souvent assez important, comme en témoigne le prêt au chanoine Thomas Durand $(\dagger 1394)^{149}$. Celui-ci, en effet, emprunte le 12 novembre $1375^{150}$ un graduel et un antiphonaire, ce dernier en deux volumes. Lors de la restitution, le 16 septembre 1379, une note est ajoutée d'une autre main et d'une autre encre, au-dessous de la notice d'emprunt, dans l'espace laissé vierge de la marge inférieure du feuillet ${ }^{151}$ : cette note précise seulement la date de restitution, sans énumérer à nouveau les livres indiqués juste au-dessus. En outre, la restitution est notée dans un registre suivant ${ }^{152}$, à la date idoine, avec, cette fois, le détail des ouvrages restitués et le relevé notamment les incipit et explicit repères. Thomas Durand était chanoine de Rouen depuis 1370; il avait auparavant été maître ès arts, maître régent ès arts à Paris dans les années 1360; il devint curé de Thiouville ${ }^{153}$ (1380), mais son soutien à Urbain VI lui valut d'être déposé le $1^{\text {er }}$ avril $1384^{154}$.

\footnotetext{
144. Guillelmus de Deserto, 1466 (n. st.), 14 février.

145. Guillelmus de Deserto, 1470.

146. Petrus de Sihervilla, 1389.

147. Hugo Lenvoisie, 1389.

148. Guillelmus de Deserto, 1466, 13 novembre.

149. Fasti, 2, 1998, $\mathrm{n}^{\circ} 159$.

150. Thomas Durand, 1375.

151. La notice d'emprunt se trouvait être la dernière délibération notée sur la page.

152. Thomas Durand, 1379.

153. Cant. et c. d'Ourville-en-Caux (Dictionnaire topographique, 2, 1984, p. 973).

154. VAlois, 2, 1896, p. 366.
} 
Parfois, au contraire, l'emprunt est de très courte durée, comme dans le cas de cette Cité de Dieu d'Augustin empruntée, le 6 mars $1447^{155}$, par Laurencius Surreau ${ }^{156}$ et restituée presque immédiatement, le 24 mars; la brièveté de l'emprunt explique sans doute la notation, assez lapidaire, de la restitution: la délibération accordant le prêt fut cancellée et une brève mention de la date de restitution ajoutée. Fils d'un trésorier de France, Pierre Surreau ${ }^{157}$, Laurent Surreau (1408-1479) était chanoine de Coutances, dès 1431, et chanoine de Rouen en 1439, ainsi que sacriste de la collégiale de Gournay-en-Bray; licencié dans les deux droits, il avait été avocat à la cour de l'archevêque (1438) et venait d'être official (1444-1446). Contrairement à son père qui ne semble pas avoir disposé d'une importante bibliothèque, du moins d'après son inventaire après décès, Laurent Surreau paraît avoir manifesté un goût assez vif pour les livres. Le chapitre venait tout juste de lui confier, avec Pierre de La Hazardière, la rédaction d'un inventaire de la bibliothèque capitulaire ${ }^{158}$. Il semble dès lors avoir été associé à la gestion de la bibliothèque, puisque dans la même séance Pierre de La Hazardière et Laurent Surreau furent chargés avec d'autres chanoines de réclamer au roi le bois nécessaire à la réalisation de la bibliothèque et des sièges ${ }^{159}$. Le même chanoine prit soin de léguer et de donner au chapitre, avant même son décès le 6 novembre $1479^{160}$, un ensemble de 18 ouvrages de grande qualité, imprégné de théologie scolastique mais aussi d'œuvres d'humanistes comme Pétrarque et Boccace. À ce don, s'ajoute un lot de quatre ouvrages de droit civil apportés au chapitre, le 20 mars 1480 (n. st. $)^{161}$, par les exécuteurs testamentaires du chanoine. On verra comment Laurent Surreau sut mettre à profit le courant de circulation des livres qui se formait autour de la bibliothèque capitulaire pour enrichir sa propre collection.

Assez souvent, cependant, les emprunts à la bibliothèque capitulaire ne sont connus que par les mentions de restitution, comme on l'a vu pour Nicole Oresme en mars 1370 (voir supra) et pour l'emprunt de Pierre de Siherville de juin 1370, qui n'est connu que par la mention de restitution apposée en marge des ouvrages rapportés en mars de la même année par Nicole Oresme (voir supra).

Ainsi, après le décès du chanoine (en 1358) et chancelier (en 1365-1379) Jean de Pontoise ( $† 1379,26$ juillet) ${ }^{162}$, le livre des Sermons de Maurice de Sully qu'il avait emprunté ${ }^{163}$ et qui avait été retrouvé dans son hôtel est rapporté au chapitre

\footnotetext{
155. Laurencius Surreau, 1447 (n. st.).

156. Fasti, 2, 1998, no 476.

157. Voir, notamment, FÉLIX, 1892.

158. Rouen, Arch. dép. Seine-Maritime, G 2131, fol. 92 ; Laborde, 1919, p. 33, n. 1.

159. Ibid., p. 33, n. 1, \$2.

160. Par un appendice à son testament daté du 9 septembre 1479 (Rouen, Arch. dép. Seine-Maritime, G 2140, fol. 23Ov; FÉLIX, 1892, p. 203-211, avec identifications des œuvres; en ligne sur Pecia, billet du 17 mai 2011).

161. Rouen, Arch. dép. Seine-Maritime, G 2141, fol. 30v; mention Laborde, 1919, n. 2, p. 28.

162. Fasti, 2, 1998, $\mathrm{n}^{\mathrm{o}} 417$.

163. La mention de cet emprunt n'a pas été retrouvée dans Rouen, Arch. dép. Seine-Maritime, G 2115 (comme indiqué par Beaurepaire, 2, 1874, p. 207) et n'est donc connue que par la note de restitution de 1381.
} 
le 18 juillet 1381 et sa restitution est soigneusement notée ${ }^{164}$. Cet avocat à la cour de l'archevêque (1350) et ancien chevecier de Lisieux, particulièrement actif, était aussi conseiller au Parlement de Paris (1364-1371); il échoua cependant à se faire élire doyen de la cathédrale.

De même, on ne sait pas exactement quand le chanoine Johannes Deudemare ${ }^{165}$ obtint le prêt, mais, le 11 février 1447 (n. st.) ${ }^{166}$, il rapporta au chapitre un livre d'homélies qui fut immédiatement enchaîné dans la librairie, par une décision du chapitre aussitôt notifiée. Le chanoine Jean Deudemare ( $\dagger$ en février 1466) était le frère de Robert Deudemare, avocat à la cour de l'archevêque; enfant de chœur à la cathédrale de Rouen et maître ès arts, il exerça lui-même les fonctions de maître des enfants de chœur (1433), avant de devenir chanoine (1439-1466).

La restitution des livres n'était cependant pas toujours aussi aisée que les cas précédents pourraient le laisser penser. Des difficultés pouvaient surgir, notamment quand l'emprunteur partait poursuivre ailleurs sa carrière. Un cas en est fourni par le Liber consiliorum (ou conciliorum) emprunté (voir supra) en 1400 (n. st.) ${ }^{167}$ par Egidius de Campis (Gilles Deschamps) ${ }^{168}$, alors chanoine de Rouen; contrairement à l'engagement pris par le chanoine au moment du prêt de rendre le livre dès que le chapitre lui en ferait la demande, l'ouvrage ne fut rendu au chapitre que le 18 décembre $1406^{169}$ par l'entremise du chanoine Guillelmus Gorren ${ }^{170}$; cette restitution tardive ne dut pas se faire sans mal, car il est probable que Gilles Deschamps avait emporté le livre à Paris durant les années où il était membre du conseil et aumônier du roi, charge qui est opportunément rappelée; Guillaume Gorren emprunta dans la foulée ce même livre, promettant de le restituer au chapitre et établissant une cédule. C'est le même Guillaume Gorren qui se chargea le 26 octobre $1413^{171}$ de recouvrer un recueil de lettres adressées par et à Jérôme, emprunté par le nouvel évêque de Coutances (14081414), Gilles Deschamps, à l'époque où ce dernier était chanoine de Rouen; les chanoines tenaient d'autant plus à ce livre qu'il faisait partie du lot de livres offert à la bibliothèque par l'archevêque Rotrou (1165-1183) ${ }^{172}$. Toutefois, ils consentirent à prêter à nouveau ce précieux livre au chanoine Guillaume Gorren qui était donc particulièrement intéressé à son retour dans la bibliothèque capitulaire. C'est seulement à la mort du chanoine Guillaume Gorren (1353-1416) que ces deux livres, le Liber consiliorum / conciliorum et le recueil épistolaire de Jérôme

\footnotetext{
164. Johannes de Pontissera, 1381.

165. Fasti, 2, 1998, $\mathrm{n}^{\circ} 147$.

166. Johannes Deudemare, 1447 (n. st.).

167. Egidius de Campis, 1400 (n. st.).

168. Fasti, 2, 1998, no 139; Millet, 1994, p. 231-241.

169. Egidius de Campis, puis Guillelmus Gorren, 1406.

170. Fasti, 2, 1998, n 208.

171. Egidius de Campis, puis Guillelmus Gorren, 1413.

172. Rouen, Bibl. mun., ms 1193 (Y 44), fol. 54, deuxième article de la section "Libri venerabilis patris nostri Rotrodi Rothomagensis archiepiscopi ${ }^{\prime}$, DELISLE, 1849, p. 218; BECKER, 1885, n 82 ; éd. H. Omont, in CGM in- $8^{\circ}, 1,1886$, p. XI-XII.
} 
retrouvèrent le chemin de la bibliothèque capitulaire: ces deux titres figuraient en effet dans un lot de livres (avec une bible et un Catholicon) restitués par le chanoine Henri Gorren, le frère du défunt, le 29 juin $1416^{173}$. Guillaume Gorren, qui avait aussi été chanoine de Bayeux (jusqu'en 1391), était bachelier en théologie et avait été pénitencier de l'archevêque de Rouen (1400-1408).

\section{Les emprunts en cascade}

Les livres empruntés étaient en effet souvent immédiatement réempruntés, comme on l'a vu dans le cas des livres restitués par un Nicole Oresme, par un Pierre de Sihervilla ou par un Gilles Deschamps, et immédiatement prêtés à d'autres chanoines (voir supra); quelques autres cas illustrent cette pratique.

Ainsi, le dernier des livres restitués le 4 mars 1370 (n. st.) ${ }^{174}$ par Nicole Oresme, un Sexte muni d'un triple apparat, fut immédiatement prêté à l'archidiacre du moment; il s'agissait sans doute de Petrus Roger de Beaufort, chanoine et archidiacre de Rouen (1350-1371) ${ }^{175}$, mais surtout neveu du pape Clément VI, qui l'éleva en 1348 au cardinalat, d'où il accéda au pontificat sous le nom de Grégoire XI (1371-1378).

Le plus souvent, comme dans le cas des emprunts de Guillaume Gorren examinés supra, c'est le décès de l'emprunteur qui permettait un nouvel emprunt.

À la suite du décès en avril 1392 du chancelier Thomas Le Grand (ou Magni) ${ }^{176}$, un recueil de droit canon réunissant le Sexte et les Clémentines fut prêté le 20 novembre $1395^{177}$ au chanoine Dionisius Le Villain (ou Villani, $\dagger$ mai 1410) $)^{178}$, à la condition qu'il le rapporte aussitôt qu'il plairait aux chanoines. Le laps de temps écoulé entre la mort du chancelier et le nouvel emprunt (plus de trois ans), ainsi que la condition mise à ce prêt, pourraient laisser penser que le règlement de la succession du défunt chancelier se heurta à des difficultés qui ralentirent la restitution de ce livre. Issu de la bourgeoisie de Rouen et parent $\mathrm{du}$ receveur des aides pour la guerre Jean Le Villain, Denis Le Villain qui avait étudié à Paris en 1363 était licencié in utroque jure. Chanoine de Thérouanne, Denis Le Villain était chanoine de Rouen depuis 1373.

Le 17 février 1438 (n. st.) ${ }^{179}$, c'est le prêtre Guillaume Lefournier, exécuteur testamentaire du chanoine Henricus Gorren (1364-1438, février) ${ }^{180}$, qui restitua un bréviaire noté à l'usage de Rouen emprunté par le défunt chanoine. Issu de la bourgeoisie de Harfleur et bachelier in utroque jure d'Orléans et de Paris, Henri Gorren, frère du chanoine Guillaume Gorren (voir supra), avait été notaire à

173. Guillelmus Gorren, 1416.

174. Nicholaus Oresme, 1370 (n. st.), art. 6.

175. Fasti, 2, 1998, $\mathrm{n}^{\circ} 448$.

176. Ibid., $\mathrm{n}^{\circ} 288$; peut-être parent d'un maire de Rouen, ce chanoine, bachelier en droit canon à Paris, résida en Avignon, avant de revenir à Rouen, lors de son entrée au chapitre.

177. Thomas Legrand / Magni, puis Dionisius Villani, 1395.

178. Fasti, 2, 1998, $\mathrm{n}^{\circ} 322$.

179. Henricus Gorren, 1438 (n. st.).

180. Fasti, 2, 1998, $\mathrm{n}^{\circ} 209$. 
Paris (1410). Chanoine de Rouen (1414-1438), il avait accumulé les prébendes ${ }^{181}$ et était en outre curé du Mesnil-Raoul.

\section{Un lent mouvement vers la limitation des prêts}

Les exemples qui précèdent dénotent l'attention manifestée par le chapitre de Rouen à la restitution des ouvrages et ce, d'autant plus que les emprunts n'étaient guère limités dans le temps. Dans les rares cas où l'on connaît à la fois la date d'emprunt et celle de la restitution, on constate que les prêts pouvaient parfois s'étirer dans le temps; si un Laurent Surreau rapporte en moins d'un mois la Cité de Dieu empruntée en mars 1447, la durée de certains prêts se comptait en années: quatre années pour le prêt accordé à Thomas Durand (1375, novembre-1379, septembre), six années pour Gilles Deschamps (1400, février-1406, décembre), trois et dix années pour Guillaume Gorren (1406, décembre et 1413, octobre - 1416, juin). Et encore, dans bien des cas, c'est le décès de l'emprunteur qui amenait la restitution.

Le chapitre était sans doute bien conscient que la restitution devenait d'autant plus difficile que le prêt s'allongeait dans le temps. Parfois, donc, les chanoines s'efforcèrent de réduire la durée du prêt et l'engagement de restituer le livre était alors assorti de l'indication d'une date de retour. Ainsi un livre de médecine qui contenait également un herbier figuré fut-il prêté le 7 octobre $1399^{182}$ à Henricus de Fécamp ${ }^{183}$ avec la condition expresse de le restituer avant la Toussaint de la même année. Ce délai très bref ne fut pas respecté, puisque ce n'est que le 25 juin $1401^{184}$, plus de dix-huit mois après le terme fixé, que l'emprunteur restitua enfin le précieux manuscrit ${ }^{185} \ldots$ qui fut aussitôt prêté à un certain chanoine Nicholaus Couette [sic pro Le Couete] (1364-1417) ${ }^{186}$, pour une durée de seulement huit jours. Petit-neveu de l'archevêque de Rouen Jean de Marigny (1347-1351) et descendant d'Enguerrand de Marigny, Henri de Fécamp (1350-1411) devint chanoine en 1367 et était qualifié de clerc du roi en 1388. Fils d'un maire de Rouen dont il portait le prénom, le chanoine Nicolas Le Couete (1390-1417) bénéficia de plusieurs prébendes ${ }^{187}$ et de la cure d'Ourville-en-Caux; il est connu pour avoir dilapidé son patrimoine.

De même, le 4 août $1430^{188}$, le chapitre prêta un ouvrage de controverses, «Hyreneus ${ }^{189}$ Lugdunensis Contra hereses... », dont les incipit et explicit repères

181. Chanoine de Pontoise (depuis 1402), de Notre-Dame La Ronde de Rouen (1404), de Tournai (1409) et de Bayeux.

182. Henricus de Fiscano, 1399.

183. Fasti, 2, 1998, $\mathrm{n}^{\circ} 179$.

184. Henricus de Fiscano, puis Nicholaus Le Couete/ Couette, 1401

185. Contrairement à ce qui a été écrit, «On ignore si le chanoine Henri a rendu le manuscrit au chapitre» (VAGENHEIM, 2011, p. 9).

186. Fasti, 2, 1998, $\mathrm{n}^{\circ} 272$.

187. Il était en effet chanoine de Saint-Merri à Paris (1378-1390) et chanoine de Coutances depuis 1403 .

188. Nicholaus Couppequesne, 1430.

189. Cette lecture, donnée déjà par LABORDE, 1919, diffère du «Lyrenensis» avancé, à tort, par Beaurepaire, 2, 1874. 
sont relevés, au chanoine Nicholaus Couppequesne (1423-1432, juillet) ${ }^{190}$, avec l'engagement pris sous seing manuel de le restituer quatre mois plus tard; le chanoine Couppequesne, bachelier en théologie et ancien recteur des écoles de grammaire de Rouen (1410-1419), alors curé de Gonneville, respecta cette promesse, puisqu'il restitua cet ouvrage le 7 novembre suivant; peu de temps après, le 11 septembre ${ }^{191}$, les chanoines accordèrent au chanoine Nicholaus Caval (1421-1457, août) ${ }^{192}$, quasiment dans les mêmes termes, mais pour un mois seulement, le prêt d'un Commentaire d'Isidore sur l'Ancien Testament, en en précisant l'incipit et l'explicit repères; on ignore toutefois si le livre fut rendu dans les délais. Neveu du chanoine Pierre Caval, pourvu de plusieurs prébendes canoniales, bachelier en droit canon et licencié en droit civil, Nicolas Caval fut assesseur au procès de Jeanne d'Arc (peu après cet emprunt): vicaire de l'évêque de Lisieux, le cardinal Branda Castiglione (1420-1423), il devint scelleur de l'archevêque de Rouen, Raoul Roussel, en 1445 et 1446, avant de témoigner en 1452, puis en 1456, au procès de réhabilitation de Jeanne d'Arc. Le 26 avril $1466^{193}$, le chanoine (1436-1483) et sous-chantre (1460-1483) Jean Quatreul ( $\dagger 1483$, 12 janvier) ${ }^{194}$ fut, lui aussi, autorisé à emprunter, contre la promesse de le rendre trois jours après ${ }^{195}$, un livre qui n'est pas défini autrement que par ses incipit et explicit énigmatiques. Quelques années après, le 27 décembre $1475^{196}$, le même Jean Quatreul fut autorisé à emprunter un De avibus qui figurait dans un lot de livres laissés en gage par les religieux de l'abbaye cistercienne de Beaubec ${ }^{197}$; cette fois, aucune durée de prêt n'était spécifiée, mais l'emprunteur devait laisser en gage une petite tasse et des ciseaux en argent. Ces emprunts se plaçaient à une période où le chanoine ne disposait sans doute plus des clefs de la librairie que lui avait transmises le chanoine Raoul de Hangest par décision capitulaire du 9 septembre $1447^{198}$. D'extraction très modeste, Jean Quatreul était musicien de Louis de Luxembourg et compositeur de musique religieuse; en $148 \mathrm{o}^{199}$, le chanoine Guillaume Roussel lui légua un "Cantuarium exemplorum».

Toutefois, l'engagement de restituer le livre dans un certain délai ne suffisait sans doute pas à garantir le retour des emprunts. Comme on l'a vu pratiquer à Saint-Ouen de Rouen, le chapitre en vint à exiger la rédaction d'une cédule, sorte de reconnaissance d'emprunt, qui était sans doute supprimée à la restitution du ou des ouvrages. Ainsi, le 27 août $1443^{200}$, c'est au trésorier, Radulphus Roussel, le futur archevêque (1444-1452), que le chapitre accorde en prêt un livre d'église

190. Fasti, 2, 1998, n ${ }^{\circ} 127$.

191. Nicholaus Caval, 1430.

192. Fasti, 2, 1998, no 96; Neveux, 1996, p. 321, 329, 442.

193. Johannes Quatreul, 1466.

194. Fasti, 2, 1998, n ${ }^{\circ} 427$.

195. «infra tres dies».

196. Johannes Quatreul, 1475.

197. Saint-Laurent et Notre-Dame de Beaubec (dép. Seine-Maritime, cant. Forges-les-Eaux, c. Beaubec-la-Rosière); voir BondÉELle, 1991, p. 17, H.

198. Rouen, Arch. dép. Seine-Maritime, G 2131, fol. 136v; Laborde, 1919, n. 3, \$ 7, p. 41.

199. Rouen, Arch. dép. Seine-Maritime, G 3440.

200. Radulphus Roussel, 1443. 
dit Valense; ainsi que l'avance Léon de Laborde ${ }^{201}$, on peut vraisemblablement identifier ce titre à la «Summa Galencii» léguée, le 20 février 1437 (n. st.) ${ }^{202}$, par le chanoine Petrus Maurice ${ }^{203}$, parmi une trentaine de volumes, mais l'absence d'incipit repères pour ces titres empêche d'acquérir toute certitude à cet égard. Ce prêt n'est toutefois accordé que moyennant la remise par l'emprunteur d'une cédule signée de son seing manuel par laquelle il s'engage à restituer le livre. De fait, il est noté à la suite de cette notice de prêt que l'ouvrage fut rendu le 10 juillet 1444 et la «cedula cassatur».

Le 24 janvier 1480 (n. st.) ${ }^{204}$, ce même titre (le même exemplaire?), la "Somme de Galense», fut de nouveau prêté, cette fois à Johannes Masselin $(1434-1500)^{205}$, contre une «cedulam de recepisse» et avec la promesse de rendre le livre. Fils d'un marchand, le chanoine (1468 à 1500) et doyen (1488-1500) Jean Masselin (†1500, $27 \mathrm{mai}$ ) réussit une belle carrière ecclésiastique, accumulant les prébendes ${ }^{206}$ ainsi que les dignités ${ }^{207}$; licencié en droit canon, il avait été avocat (1463), puis officier (1477) à la cour de l'archevêque, ainsi que vicaire général d'Évreux (1470), et vicaire de Jean Balue pour Fécamp (1469-1476); réputé pour être un homme disert et habile, il participa enfin comme député du bailliage de Rouen aux États généraux de Tours (1484) dont il a laissé un journal ${ }^{208}$. Il fut l'un des exécuteurs testamentaires de l'archevêque Robert de Croismare. On aura à revenir par la suite sur une certaine acquisition qu'il fit en 1489 (voir infra).

La même année, le 11 octobre $^{209}$, le chanoine Petrus Escoulant ${ }^{210}$ obtint du chapitre le prêt d'un De mulieribus illustribus; ce prêt lui fut accordé moyennant la rédaction d'une cédule par laquelle il s'engageait à rendre le livre dans un délai bref, avec la précision "quemadmodum est consuetum». Maître ès arts en 1453, Pierre Escoulant resta chanoine de Rouen de cette date à sa mort en juillet 1489; il fut en outre curé de Sainte-Marguerite-sur-Duclair (1463-1489). Il devait posséder en propre une bibliothèque dont il est difficile de mesurer l'importance puisque les articles n'en sont pas détaillés; il en disposa par testament en la léguant à ses neveux Jean, André et Guillaume dits Meslin ${ }^{211}$; toutefois il réservait à la bibliothèque capitulaire deux livres, le De casibus virorum illustrium de Boccace et les Lettres de Jérôme, précisément parce qu'elle ne disposait pas du premier de ces textes. D'après une mention marginale, cette disposition en faveur de ses trois neveux aurait été résiliée. Quant aux deux livres destinés à la bibliothèque capitulaire ${ }^{212}$, ils furent reçus par le chapitre le 7 septembre 1482 et munis d'un ex-dono.

201. LABORDE, 1919, n. 2, p. 45-46.

202. Rouen, Arch. dép. Seine-Maritime, G 2128, fol. 18; Langlois, 1853, p. 64-65 (annexe n ${ }^{\circ} 5$ ).

203. Fasti, 2, 1998, $\mathrm{n}^{\circ} 352$.

204. Johannes Masselin, 1480 (n. st.).

205. Fasti, 2, 1998, $\mathrm{n}^{\circ} 345$.

206. Il fut en effet chanoine de Lisieux, de Coutances et d'Évreux.

207. Il fut successivement official (1483-1493), puis vicaire général (1494-1500).

208. Bernier, 1835; voir aussi TABbagh, 2008, p. 42.

209. Petrus Escoulant (ou Escoullant), 1480.

210. Fasti, 2, 1998, $\mathrm{n}^{\circ} 162$

211. Sur ce testament, voir TABBAGH, 2008 , p. 41 et n. 83 .

212. Rouen, Arch. dép. Seine-Maritime, G 2144, fol. 111v-112. 
Comme on l'a vu dans le cas de Jean Quatreul (voir supra), la remise d'une cédule par l'emprunteur pouvait paraître insuffisante au chapitre désireux de recouvrer les livres prêtés et, parfois, les chanoines n'hésitèrent pas à réclamer le dépôt d'un gage. Bien souvent ce gage pouvait consister en un autre livre, comme dans le cas du doyen Nicholaus de Bosco (ou Dubois [1409-1486]) ${ }^{213}$ qui, le 13 février 1456 (n. st.) ${ }^{214}$, obtint le prêt d'un De ecclesiastica potestate, moyennant le dépôt au chapitre d'un autre livre, un recueil de Lettres de Jérôme. En 1448, c'est le même Nicolas de Bosco qui, avec un autre chanoine, Matheus Gaudin (chanoine de 1448 à 1489) ${ }^{215}$ et en qualité de doyen, reçut du chapitre les clefs de la librairie. Issu d'une famille noble du diocèse de Bayeux et bachelier en théologie de la toute nouvelle université de Caen, le chanoine (1446-1486) Nicholaus de Bosco exerça la dignité de doyen de 1445 à 1485 et fut exilé par ordre du roi de 1466 à 1470 .

De même, le 14 mars 1470 (n. st.) ${ }^{216}$, le chanoine Guillelmus Roussel († 1481, 27 mars) ${ }^{217}$ est autorisé à emprunter deux livres, l'un un commentaire sur les Évangiles d'un certain docteur Lucien, l'autre une Cité de Dieu d'Augustin, mais en donnant un gage qui n'est pas précisé. Le 9 avril suivant ${ }^{218}$, le même chanoine apporte en gage un commentaire d'Hervé du Bourgdieu sur Isaïe qu'il laisse au chapitre pour pouvoir emprunter deux livres: un Sedulius sur parchemin et une Table alphabétique de la Cité de Dieu. Ce système du gage se révéla efficace, au moins dans ce cas, puisqu'une note ajoutée le 10 août 1470 précise $^{219}$ que Guillaume Roussel restitua les deux livres empruntés et qu'il lui fut rendu celui qui avait été donné en gage. Ce même commentaire d'Isaïe par Hervé du Bourgdieu (du moins la première partie ${ }^{220}$ ) se retrouve parmi la vingtaine de livres que Guillaume Roussel légua à la bibliothèque capitulaire en $148 \mathrm{o}^{221}$ et qui témoignent d'un esprit ouvert et cultivé, sensible aussi aux innovations: dans cette intéressante collection de livres qui comptait plusieurs classiques, on relève en effet un imprimé à la reliure estampée et orné d'un bois. Licencié dans les deux droits, le chanoine Guillaume Roussel était un neveu de l'archevêque Raoul Roussel (1444-1452) et le frère et le cousin de deux autres chanoines, Johannes Roussel et Thomas Le Cervoisier; bénéficiant de deux cures, il disposait d'une certaine fortune. Le 17 novembre $145 \mathrm{O}^{222}$, il se vit confier les clefs de la bibliothèque pour un docteur, maître Johannes Blondel qui n'était pas encore chanoine de Rouen ${ }^{223}$.

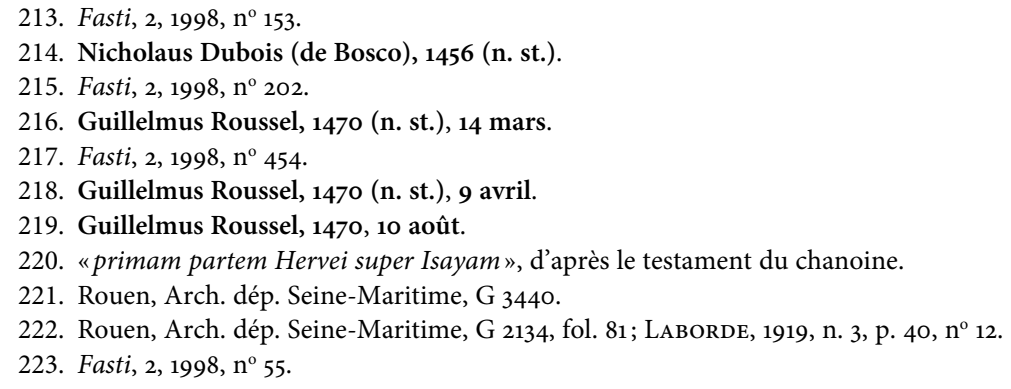


Désireux d'emprunter des Sermons de Jacques de Voragine, le chanoine (1465-1492) Johannes Gouel ( $† 1492,6$ mars) $)^{224}$ dut, le 12 novembre $1471^{225}$, laisser en gage un Inforciat. Licencié en droit canon de l'université de Caen, Jean Gouel était le fils d'un sénéchal de l'archevêque et le frère d'un procureur du roi à Rouen; il fut lui-même officier de l'archevêque (1483-1491) et bénéficia de la cure de Daubeuf (1468-1492). Son testament ${ }^{226}$ ne comportait pas de livres.

Quant au chanoine Robertus du Quesnay (1431-1499, 27 février ${ }^{227}$, lorsque le 14 mars 1471 (n. st.) ${ }^{228}$ il voulut emprunter un petit livre contenant une table sur la Cité de Dieu d'Augustin ${ }^{229}$, il dut laisser en gage une Glose ordinaire sur les Petits Prophètes. Le 19 décembre de la même année, le chanoine restitua la table empruntée et du même coup recouvra son propre livre ${ }^{230}$. Ce chanoine de Rouen (1468 à 1499) qui avait fait ses études au Collège d'Harcourt et était docteur en théologie de l'université de Paris, était aussi chanoine de Soissons et bénéficiait de plusieurs cures. Issu d'une famille noble, il exerça les fonctions de lecteur ${ }^{231}$ et théologal. Par ses fonctions, il s'intéressait visiblement aux livres et aux bibliothèques, puisqu'il avait pris part à la rédaction de l'ancien inventaire de la bibliothèque capitulaire ${ }^{232}$.

\section{Les emprunts par l'intermédiaire d'un chanoine}

Les exemples précédents montrent diverses procédures de prêt, mais toujours à destination de chanoines de la cathédrale. Est-ce à croire que les chanoines ouvraient moins libéralement leur bibliothèque que les bénédictins de SaintOuen? Certaines délibérations accordant le prêt de livres à des personnages extérieurs au chapitre tendraient à prouver le contraire, et notamment, celles, bien connues, accordant le prêt des clefs de la bibliothèque et fixant les obligations de ceux qui les détenaient et de ceux à qui elles pouvaient être prêtées ${ }^{233}$. Sans revenir sur ces délibérations, on retiendra simplement qu'après avoir été réservé aux seuls chanoines, le prêt des clefs fut concédé, le 20 août 1439, aux «notabilibus viris eas petentibus» ${ }^{234}$. Au nombre des personnes qui en avaient

224. Fasti, 2, 1998, $\mathrm{n}^{\circ} 210$.

225. Johannes Gouel, 1471.

226. Rouen, Arch. dép. Seine-Maritime, G 3431.

227. Fasti, 2, 1998, nº 430 .

228. Robertus du Quesnay, 1471 (n. st.).

229. Pourrait-il s'agir du même ouvrage que celui emprunté par Guillaume Roussel (voir supra)? Rien ne permet de l'affirmer.

230. Restitution par Robertus du Quesnay, 1471 (n. st.) mentionnée à la suite de la notice d'emprunt.

231. Succédant à maître Alain Olivier dans cette fonction, il réclama le 21 juin 1468 l'autorisation de fonder son enseignement sur une autre lecture que celle du Psautier commencée par son prédécesseur (Rouen, Arch. dép. Seine-Maritime, G 2137, fol. 209; je remercie mon collègue Martin Morard de ses éclaircissements sur ce texte).

232. Rouen, Arch. dép. Seine-Maritime, G 2140, fol. 177v; Rouen, Arch. dép. Seine-Maritime G 2142 fol. 98 (1484 [n. st.], 3 II).

233. LABORDE, 1919, notes, p. 39-43.

234. Rouen, Arch. dép. Seine-Maritime, G 2129, fol. 48v; Laborde, 1919, n. 2, \$ 1, p. 39. 
précisément fait la demande, on relève le nom de l'humaniste Simon de Plumetot († 1443), alors réfugié dans Rouen sous domination anglaise pour échapper aux troubles qui secouaient Paris.

Pour ceux qui ne pouvaient ou ne voulaient pas se rendre eux-mêmes à Rouen, il existait la possibilité d'emprunter les livres par l'entremise de chanoines. Ainsi le 21 février 1443 (n. st.) ${ }^{235}$, le chapitre accède à la demande de l'évêque d'Avranches Martinus Pinard, présentée au chapitre par le chanoine Guillelmus de Livet ${ }^{236}$, d'emprunter un pontifical, durant tout le temps qu'il conviendrait au chapitre et moyennant la promesse faite en son nom propre par le chanoine Guillelmus de Livet de rendre le livre. Chanoine d'Avranches, Martin Pinard avait été porté au siège épiscopal de cette cité, le 3 septembre 1442. Il prenait la succession d'un évêque, Johannes de Saint-Avit (1391 au 22 juillet 1442), qui, nommé juge au procès de Jeanne d'Arc, avait fini ses jours en prison pour avoir pris la défense de l'accusée; cet emprisonnement de l'évêque avait certainement perturbé la bonne marche de l'église d'Avranches où le nouvel évêque aurait dû, en d'autres circonstances, trouver un pontifical, livre par excellence de l'évêque.

Les emprunts par les évêques de Lisieux sont plus fréquents. Déjà le 21 septembre $1440^{237}$, l'évêque de Lisieux, Pierre Cauchon († décembre 1442), avait obtenu du chapitre, par l'entremise du chanoine Nicholaus Caval ${ }^{238}$, le prêt d'un volume d'Augustin au contenu imprécis ${ }^{239}$ que le chanoine Caval avait promis de rendre au chapitre. On serait curieux d'identifier précisément l'œuvre cachée sous ce titre augustinien assez vague; il semble que ce titre soit celui noté sur les ais du volume ${ }^{240}$, ce qui laisserait penser que les volumes présentaient des étiquettes. Il est inutile de rappeler ici le rôle attribué à Pierre Cauchon durant le procès de Jeanne d'Arc; on ne peut toutefois pas borner à ce seul épisode la vie de ce Rémois d'origine, licencié en droit canon, docteur en théologie. Outre une brillante carrière ecclésiastique ${ }^{241}$ qui lui permit de pratiquer sans retenue le népotisme, il semble qu'il ait mené une action très positive pour son diocèse; il a par ailleurs contribué à la fondation de l'université de Caen. Une note ajoutée au bas de l'autorisation d'emprunt de 1440 atteste en tout cas que le volume fut rendu par le chanoine Nicolas Caval, et replacé dans la bibliothèque le 2 juin 1442, en présence de plusieurs chanoines députés par le chapitre. Cette restitution intervenait peu avant le décès de l'évêque qui n'oublia pas la bibliothèque capitulaire dans ses dernières volontés, puisqu'il légua à la bibliothèque du chapitre ${ }^{242}$ quatre volumes ${ }^{243}$ : une Lecture d'Henri Bohic

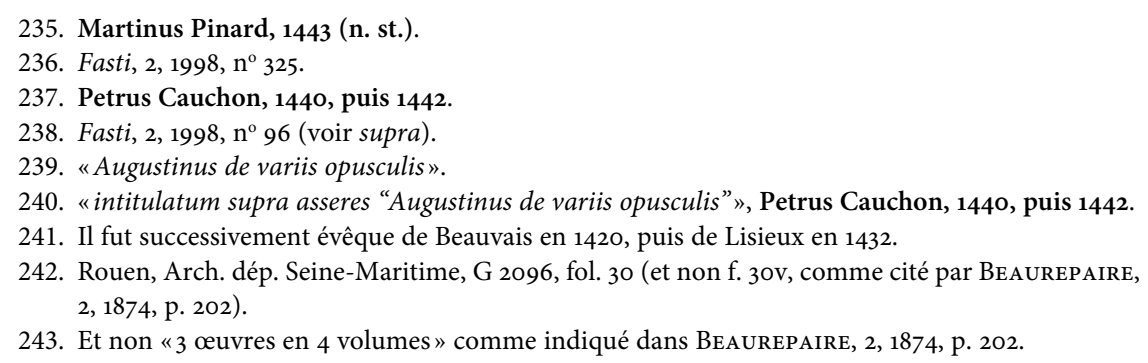


(deux tomes), un Caton glosé et un Rational des Divins Offices de Guillaume Durand et une Summa confessorum, pour une valeur totale de 100 écus; ces livres n'étaient sans doute pas en très bon état, puisque le 18 novembre $1444^{244}$, les chanoines décidèrent de faire réparer les livres légués par Pierre Cauchon, avant de les faire enchaîner dans la bibliothèque capitulaire.

Le 11 août $1444^{245}$, un autre évêque de Lisieux (1443-1447, 28 janvier), Pasquerius de Vaux ( $† 10$ juillet 1447), obtint le prêt, jusqu'au mois de septembre, d'un graduel, moyennant la caution des chanoines Robertus Suttor et Petrus de Laigny et leur engagement de rendre le volume emprunté. L'engagement fut apparemment tenu puisque le 14 décembre $1445^{246}$, un peu plus tard, donc, que prévu, les mêmes Robertus Suttor et Petrus de Laigny restituèrent le volume aux chanoines qui leur en donnèrent quittance. Docteur en droit canon en 1427, puis régent à Paris (1427-1430), Pasquier de Vaux qui était le frère d'un procureur du roi, accumula les prébendes ${ }^{247}$, dont celle de chanoine de Rouen ${ }^{248}$, ainsi que les évêchés ${ }^{249}$, mais, surtout, il joua un rôle politique comme chancelier du duc de Bedford et président de la Chambre des Comptes de Rouen.

On ignore si la caution apportée par les deux intermédiaires pour le prêt de Pasquier de Vaux était d'ordre moral ou financier ${ }^{250}$. Il est en revanche d'autres cas où des cédules de reconnaissance, voire des gages, furent réclamés aux emprunteurs. Ainsi, lorsque le 22 septembre $1459^{251}$, Ludovicus d'Harcourt († 15 décembre 1479) qui était encore archevêque de Narbonne (1451-1460) ${ }^{252}$, voulut emprunter 3 volumes de théologie successive vocitata Penthateucon, le chapitre demanda, outre une cédule de reconnaissance, un ou plusieurs livres (non spécifiés) en gage. Le 20 janvier 1479 (n. st.) ${ }^{253}$, pour l'emprunt de l'Hegesippe consenti, cette fois par l'intermédiaire du chanoine Robertus du Quesnay, à Louis d'Harcourt, seule une cédule de reconnaissance signée du seing manuel du prélat fut exigée et présentée au chapitre, puis enfermée par le chanoine Nicholaus Gaillart dans un coffret du bureau du chapitre. Fils légitimé du comte Jean VIII d'Harcourt, né en 1424 et licencié en droit canon, Louis d'Harcourt mena une carrière ecclésiastique dans le sillage de son oncle, Jean d'Harcourt, auquel il succéda sur le siège archiépiscopal de Narbonne en 1451. Évêque de Bayeux (1460-1479) et patriarche de Jérusalem, également abbé de Lyre (1463), il devint chancelier de l'université de Caen et joua un rôle éminent au plan politique et administratif: il présida à plusieurs reprises les États et l'Échiquier de Normandie

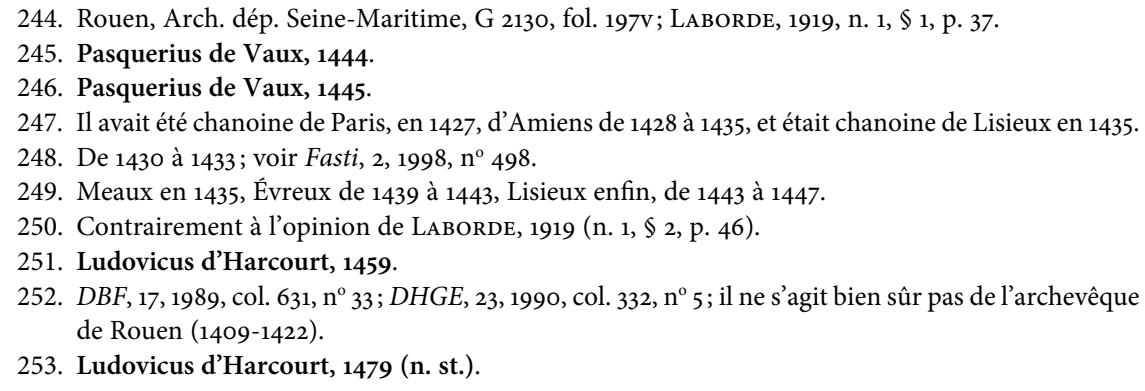


et célébra le 5 août 1461 les obsèques de Charles VII à Notre-Dame de Paris. Un temps en disgrâce pour ses prises de position lors de la Ligue du Bien Public, il fut chargé par le roi Louis XI de plusieurs missions diplomatiques et de la défense de la Normandie contre les Anglais.

Moins illustre que Louis d'Harcourt, un autre personnage, chanoine, lui, de Rouen, eut recours, le 3 mars 1488 (n. st.) ${ }^{254}$, aux bons offices d'un confrère, le chanoine Ludovicus de Groussy ${ }^{255}$ pour emprunter lui aussi un Hegesippe (le même que celui prêté à Louis d'Harcourt?). Il s'agit de Guillelmus Le Brument ${ }^{256}$, chanoine de 1489 à 1517, qui, après avoir été secrétaire (1473-1479) de l'évêque de Bayeux Louis d'Harcourt, dont il vient d'être question, reprit à partir de 1483 la même fonction auprès de l'archevêque Robert de Croismare (1483-1493). Le prêt fut consenti contre la promesse du chanoine Louis de Groussy de restituer le livre aux prochaines Pâques. Si le délai ne fut pas précisément respecté, le livre fut rendu en juin de la même année ${ }^{257}$. Le 20 août $1495^{258}$, le curé de Martonville, Stephanus d'Ourmesnil, légua à Guillelmus Le Brument, un de ses exécuteurs testamentaires, un de ses «grans livres qui se nomme De vita Christi».

Parmi ces emprunteurs plus ou moins extérieurs au chapitre, on relève tout particulièrement un trésorier de France qui emprunta des Chroniques le 20 mars 1451 (n. st. ${ }^{259}$. D'après la date, il s'agit de Johannes Bureau ${ }^{260}$, trésorier de France depuis $1443^{261}$.

Les prêts et dons de livres aux paroisses dépendant du chapitre représentaient un autre courant de circulation des livres; il est inutile de s'attarder sur ces prêts et ces dons de livres liturgiques ou de bréviaires qui ont été déjà amplement mis en lumière ${ }^{262}$. On notera simplement qu'il s'agissait de prêts généralement de très longue durée, comme le prouve le cas du bréviaire d'un certain Jacobus Saoul ${ }^{263}$ apporté le 9 octobre $1379^{264}$ au chapitre par le chanoine Jean Blanchecape ${ }^{265}$ pour être confié au prêtre Johannes Gilles (ou Egidius), apparemment jusqu'à la fin de ses jours, à charge pour lui de le garder soigneusement et de le léguer ensuite à un autre prêtre qui priera pour lui. Il ne s'agit là que d'un cas parmi bien d'autres.

254. Guillelmus Le Brument, 1488 (n. st.), 3 mars.

255. Fasti, 2, 1998, $\mathrm{n}^{\circ} 219$.

256. Ibid., $\mathrm{n}^{\circ} 261$.

257. Guillelmus Le Brument, 1488, juin.

258. Rouen, Arch. dép. Seine-Maritime, G 3445.

259. Johannes Bureau, 1451 (n. st.).

260. Sur ce personnage, voir notamment GAUSsin, 1982, en particulier l'Appendice, p. 104-130, «Brefs curriculum vitae des conseillers de Charles VII (1418-1461)", notice p. 111.

261. D’après BRÉQUignY, 1790, Jean Bureau est qualifié de trésorier de France, dans des Lettres de Charles VII du 20 juin 1451 (p. 137-139 et p. 140-141 et 144, n. [c]), du 7 avril 1453 (p. 280) et du 8 juin 1456 (p. 405).

262. LABORDE, 1919, p. 46 et n. 2, $\$ 1-13$, p. 46-49.

263. Jacques Saoul est sans doute, comme Jean Gilles (ou Egidius), un prêtre ou un chapelain et, à ce titre, ils ne figurent pas dans les Fasti, 2, 1998.

264. Johannes Gilles (ou Egidius), 1379.

265. Sur la dimension mémorielle de cette transmission, voir TABBAGH, 2008, p. 41 et n. 85. 
Dans un cas au moins, le chapitre semble avoir quelque peu forcé la restitution. Le 11 novembre $1439^{266}$, le chapitre décide de retirer à un certain Petrus Gerland ${ }^{267}$, qui l'avait alors en prêt ${ }^{268}$, un bon bréviaire noté, relié et muni de deux fermoirs, appartenant à la chapelle Saint-Mathurin de l'autel Saint-Pierre, pour le prêter à Pierre de Laigny; celui-ci promet de le rendre si les chanoines le réclament et quand ils le souhaiteront; chanoine de Rouen (1438-1447), puis de Meaux, Pierre de Laigny se trouvait être un familier de l'archevêque Louis de Luxembourg.

\section{La valeur marchande du livre}

Le prix des livres - et c'est un point bien connu ${ }^{269}$ - n'était certainement pas étranger à ce souci de recouvrer les livres prêtés. À plusieurs reprises, les décisions de prêt des livres spécifient le prix des livres, notamment lorsqu'ils sont confiés à des paroisses ${ }^{270}$. Parfois, l'estimation des livres était communiquée au chapitre, comme dans le cas de ces livres de droit estimés, le 21 novembre $137 \mathrm{O}^{271}$, à 20 florins d'or par des avocats à la cour de l'official de Rouen; les livres pouvaient aussi être prisés, comme le furent les ouvrages de la succession de Guillaume de Lestrange mis en vente à Paris ${ }^{272}$.

Par sa valeur marchande, le livre faisait l'objet de diverses tractations. Comme on l'a déjà vu dans le cas de Philippe d'Alençon (voir supra) qui en 1363 (n. st.) s'était fait remettre des livres en échange d'une somme qui lui était due par le chapitre, les chanoines décidèrent le 30 août $1456^{273}$ de céder un mi-temps commençant à l'Avent, et qualifié de livre de chant, au notaire Jean des Essarts "pro scripturis et litteris extraordinariis per me $e^{274}$ pro capitulo scriptis».

Dans d'autres cas, c'est le chapitre qui recevait des livres en paiement de droits non acquittés, tel cet antiphonaire noté proposé le 28 janvier 1422 (n. st.) ${ }^{275}$ par le sieur de Torchy, Guillaume d'Estouteville, ou comme ce "notabilem librum» offert le 4 juin $1431^{276}$ par l'évêque de Bayeux, Zanon de Castiglione, pour se faire dispenser du droit de past ${ }^{277}$. Le livre servait également de gage en cas de

266. Petrus de Laigny, 1439, puis 1442

267. Ce personnage non identifié n'était pas chanoine de Rouen. Était-il le chapelain ou le desservant de la chapelle Saint-Mathurin?

268. "de presenti obtinet [...] in custodia».

269. Un bon aperçu de cette question est donné par Bozzolo, Ornato, 1983, notamment «I. La production du livre manuscrit en France du Nord»; à compléter par OrNATO, 1997, «III. La production et le marché du livre médiéval».

270. Prêt à Magnavilla (Manneville)-la-Goupil, 1372 et 1391; prêt à Saint-Ouen de Prenembourse, 1393 ; prêt à Sassetot, 1409 (n. st.).

271. Rouen, Notre-Dame, chapitre (estimation), 1370.

272. Guillelmus de Lestrange, 1389.

273. Johannes des Essars / Essarts, 1456.

274. C'est le même notaire qui rédige les décisions capitulaires.

275. Guillelmus de Estoutevilla, 1422 (n. st.)

276. Zano de Castiglione, 1431.

277. Le "droit de past», aussi appelé «justus pastus», était une somme que les évêques pouvaient verser pour se dispenser de donner un somptueux banquet, lors de leur sacre (d'après Formeville, 1871). 
prêt consenti par le chapitre à des établissements religieux voisins, ainsi qu'en témoigne la liste de neuf ouvrages (surtout de patristique) laissés en gage en mars $1486^{278}$ par l'abbaye cistercienne de Beaubec, sans doute dans une période de difficulté; au moins un autre livre de l'abbaye avait déjà été laissé en gage dès 1475 , puisqu'il fut alors prêté au chanoine Jean Quatreul (voir supra, à ce nom).

Constituée depuis le $\mathrm{XII}^{\mathrm{e}}$ siècle au moins par des dons et des legs, la bibliothèque capitulaire devait posséder certains textes en double, voire en plusieurs exemplaires; par ailleurs certains livres devaient être mis de côté, soit parce qu'ils étaient périmés ou (on pense à des livres liturgiques) étaient à un autre usage que celui de Rouen, ou, tout simplement, par manque de place. Par ailleurs, les frais occasionnés par la guerre franco-anglaise, joints peut-être aux dépenses engagées pour les diverses constructions dans la cathédrale et à l'entour, mirent en difficulté la fabrique. Pour toutes ces raisons, le chapitre se résolut à recourir à la vente de livres. Dès l'extrême fin du XIV ${ }^{e}$ siècle, le chapitre prit ainsi la décision de se séparer de livres à l'usage d'autres diocèses: le 2 novembre $1399^{279}$, il décida de faire vendre des livres qui étaient à l'usage du diocèse d'Auch, au motif que les livres s'abîmaient et que les gens de l'archevêque d'Auch alors présents à Rouen cherchaient à les acheter ${ }^{280}$; le 3 décembre suivant ${ }^{281}$, une transaction fut conclue entre le chapitre et le chanoine Nicholaus Le Couete (ou Couette; voir supra) qui acheta cinq livres à l'usage d'Auch, pour la somme de 50 écus d'or, que le chanoine, connu pour avoir dilapidé sa fortune, s'engageait à acquitter avant la fête de la nativité de Jean-Baptiste (24 juin). Le reçu de cette somme est daté du 6 juillet $1400^{282}$.

Tout au long du $\mathrm{XV}^{\mathrm{e}}$ siècle, le chapitre eut ainsi recours aux ventes pour «désherber " la bibliothèque et financer certaines opérations. Le 12 décembre $1448^{283}$, le chapitre décida de vendre des livres anciens ( «libri antiqui») dont malheureusement la localisation n'est pas précisée ${ }^{284}$, ou bien de les prêter aux chanoines intéressés, contre une cédule de recepisse. L'année suivante, le 19 juillet ${ }^{285}$, ce sont encore des livres anciens du trésor que le chapitre fit vendre lors de la Sainte-Madeleine suivante (22 juillet) au plus offrant, pourvu que l'acheteur soit ecclésiastique, mais sans obligation d'être attaché à la cathédrale. De nouveau, le 25 février 1450 (n. st. ${ }^{286}$, les

278. "Copia inventarii librorum datorum in pignus capitulo per religiosos de Bello Becco» (mise en gage par Beaubec, 1486).

279. Rouen, Notre-Dame, chapitre (vente), 1399, 2 novembre.

280. Plus qu'une manœuvre de partisans de Jean d'Armagnac, archevêque d'Auch ( $\dagger 1408$, 20 septembre) qui devait être nommé, de façon éphémère, archevêque de Rouen par Benoît XIII, à la mort de l’archevêque Guillaume de Vienne (†1407, 18 février), il faut sans doute lier la présence de ces livres liturgiques étrangers au diocèse à l'administration de ce diocèse gascon que reçut l'archevêque Philippe d'Alençon lorsqu'il fut nommé patriarche d'Aquilée par le pape, ayant dû abandonner le siège métropolitain de Rouen, à la suite de son conflit avec le roi Charles V (voir supra).

281. Rouen, Notre-Dame, chapitre (vente), 1399, 3 décembre.

282. Ibid., d'une encre plus foncée.

283. Rouen, Notre-Dame, chapitre (vente), 1448, 12 décembre.

284. «libri $[\ldots]$ existentes in [suivi d'un blanc]».

285. Rouen, Notre-Dame, chapitre (vente), 1449.

286. Rouen, Notre-Dame, chapitre (vente), 1450 (n. st.), 25 février. 
chanoines prirent la décision de se défaire de livres abrités dans la chambre haute du trésor, mais aussi dans le chapitre, livres jugés «non [...] necessarii pro ecclesia». Le mois suivant, le 12 mars $^{287}$, l'opération confiée à Johannes Deudemare, Guillelmus du Désert et Laurentius Surreau fut renouvelée pour des livres anciens, qui devaient être vendus «ad commodum capituli ecclesie». Le 19 mars 1459 (n. st. ${ }^{288}$ ce sont encore des livres inutiles et anciens qui furent vendus par le chapitre. Le 22 août de la même année ${ }^{289}$, le chapitre reçut ainsi 79 l. de la vente de ces volumes jugés «inutiles».

Ces ventes constituaient ainsi une source appréciable de revenus qui permettaient de financer réparations d'immeubles ou fonctionnement de la bibliothèque. Ainsi le 14 juin $1448^{290}$, le chapitre décida de mettre en vente des livres, dont une bible en deux volumes et d'autres livres conservés dans la chambre haute du trésor, afin de procéder à des réparations dans la maison dite du Cornet d'argent. En mars 1452 (n. st. $)^{291}$, la décision fut prise de vendre au plus offrant une petite bible ${ }^{292}$, afin de financer la remise en ordre et l'enchaînement des livres de la librairie capitulaire. Un mois plus tard, le 21 avril ${ }^{293}$, le chapitre décidait de se séparer de la bible donnée par Pierre de La Hazardière ${ }^{294}$ († 1450, 28 juillet ${ }^{295}$ ou en $1462^{296}$ ), de nouveau pour financer l'enchaînement de livres. On rappellera ici que Pierre de La Hazardière est une figure marquante de la Normandie du $\mathrm{XV}^{e}$ siècle, même si ce n'est pas le lieu ici d'énumérer toutes les étapes de la carrière de cet humaniste ${ }^{297}$. Il suffira de mentionner que ce chanoine de Rouen (1444-1450 ${ }^{298}$, dont on a vu (voir supra) qu'en 1447 (n. st.), il avait été chargé avec Laurent Surreau de dresser le catalogue de la librairie capitulaire, donna $\operatorname{six}^{299} \mathrm{ou} \mathrm{sept}^{300}$ livres à cette même bibliothèque, à charge pour le chapitre d'inscrire son nom dans l'obituaire du chapitre; il est à regretter qu'aucune de

287. Rouen, Notre-Dame, chapitre (vente), 1450, 12 mars.

288. Rouen, Notre-Dame, chapitre (vente), 1459 (n. st.), 19 mars.

289. Rouen, Notre-Dame, chapitre (vente), 1459, 22 août.

290. Rouen, Notre-Dame, chapitre (vente), 1448, 14 juin.

291. Rouen, Notre-Dame, chapitre (vente), 1452 (n. st.), 13 mars.

292. "quedam biblia [...] in parvo volumine».

293. Rouen, Notre-Dame, chapitre (vente), Johannes Gauffridus (achat), 1452, 21 avril, puis, 26 avril.

294. Fasti, 2, 1998, no 232; Vielliard, Pommerol, 2000, notice p. 664; Beltran, 1991, particulièrement p. 128-130.

295. D’après les Fasti, 2, 1998.

296. Vielliard, Pommerol, 2000; Beltran, 1991; il est toutefois à noter que dans la délibération du 19 février 1451 (1452 n. st.), le chanoine est dit «Petrum de la Hazardiere, dum vivebat canonicum Rothom.».

297. Maître ès arts à l'université de Paris, en 1430, il poursuivit des études de théologie, et à ce titre fut admis comme «hôte», puis comme sociétaire du collège de Sorbonne, dont il devint prieur (1435), fonction dans laquelle il côtoya Jean Castiglioni, alors bibliothécaire du collège, cousin de Zanon de Castiglione; c'est alors qu'il emprunta au collège deux classiques, les Verrines de Cicéron et les Déclamations de Sénèque l'Ancien qu'il rendit le 4 juillet 1436. Lié à Charles d'Orléans rentré en France, il fut l'un des premiers et des plus éminents professeurs de théologie de la jeune université de Caen, avant d'en devenir régent (1444).

298. Il fut aussi chanoine de Champeaux, puis de Bayeux (1449).

299. Rouen, Notre-Dame, chapitre (vente), 1451 (n. st.) et 1452 (n. st.), 19 février.

300. Rouen, Notre-Dame, chapitre (vente), 1452 (n. st.), 13 mars. 
ces délibérations ne donne le détail de ces quelques livres; Laurent Surreau fut chargé de faire enchaîner les livres conservés de ce legs. La bible devait être une bible de prix car elle fut vendue, le 26 avril $1452^{301}$, au secrétaire de la duchesse de Bedford, le chanoine Johannes Gauffridi (ou Godefroy; ca. 1394-1464, 24 juillet) ${ }^{302}$, pour un prix de 14 écus d'or qui furent versés à Laurent Surreau. La multiplicité des décisions capitulaires consacrées au sort des livres de Pierre de La Hazardière montre assez l'importance qualitative de ce don.

Outre les opérations d'enchaînement de volumes, le produit de ces ventes permit de financer des acquisitions. Ainsi une délibération du 29 décembre $1466^{303}$ trahit la gêne financière de la fabrique qui peinait à acquérir les ouvrages de Nicolas de Lyre. Le jour même ${ }^{304}$, le chapitre chargea le chanoine Ricardus Perchart ${ }^{305}$, qui était aussi curé de Saint-Gervais de Paris, de prendre dans la librairie du chapitre deux volumes d'Henri Bohic, pour financer l'achat des commentaires de Nicolas de Lyre, en complétant le produit de la vente par une somme prise sur les finances de la fabrique.

Outre les bénéfices, parfois assez substantiels, qu'en retirait le chapitre, ces ventes de livres permettaient aux chanoines de la cathédrale de compléter leurs propres collections, même si, comme on l'a vu ${ }^{306}$, ces ventes n'étaient pas exclusivement réservées aux chanoines. Ainsi, le 10 mai $1452^{307}$, le chapitre décida de mettre en vente aux enchères ${ }^{308}$ plusieurs livres: le pénitencier de l'archevêque, Johannes Fabri ${ }^{309}$, put alors acquérir une bible du chapitre au prix de 30 écus d'or ${ }^{310}$, somme qu'il versa, lui aussi, à Laurent Surreau; le même personnage acquit un Décret payé dix écus d'or; au cours de la même vente, c'est Laurent Surreau qui emporta comme dernier enchérisseur une glose de Jean André, au prix de 7 l. 10 s. Quinze ans plus tard, le 20 février 1467 (n. st.) ${ }^{311}$, le chapitre se résolut à nouveau à faire vendre aux enchères quelques livres de droit au profit de la fabrique; on ignore tout du détail des livres vendus, comme de la somme rapportée par cette vente. Le 15 septembre suivant ${ }^{312}$, le receveur de la fabrique, Eude Le Senescal, put encaisser la somme de 181.8 s. produite par la vente de 9 livres de droit, achetés presque tous par des chanoines: le chanoine Guillelmus

301. Rouen, Notre-Dame, chapitre (vente), Johannes Gauffridus (achat), 1452, 26 avril.

302. Fasti, 2, 1998, $\mathrm{n}^{\circ} 206$.

303. Rouen, Notre-Dame, chapitre (vente), 1466.

304. Rouen, Notre-Dame, chapitre (vente), 1466.

305. Fasti, 2, 1998, $\mathrm{n}^{\circ} 400$.

306. Supra, Rouen, Notre-Dame, chapitre (vente), 1449.

307. Rouen, Notre-Dame, chapitre (vente), 1452, 10 mai.

308. Il semble que le chapitre ait eu assez souvent recours à ce type de vente, ce qui dément l'assertion «Les ventes aux enchères de livres apparues à la fin du XVI ${ }^{\mathrm{e}}$ siècle aux Pays-Bas...» (Esprit des livres, Introduction, $2^{\mathrm{e}}$ paragraphe); voir aussi (infra) la vente en 1389 des biens de Guillelmus de Lestrange.

309. Fasti, 2, 1998, n 277; bachelier en théologie, il était aussi chanoine de Lisieux et sous-chantre de Bayeux et curé de Saint-Pierre de Caen. Johannes Fabri est un des chanoines dont le nom apparaît le plus souvent dans les délibérations touchant à l'attribution des clefs de la bibliothèque.

310. LABORDE, 1919, n. $2, \$ 10$, p. 36.

311. Rouen, Notre-Dame, chapitre (vente), 1467 (n. st.), 20 février.

312. Rouen, Notre-Dame, fabrique (vente), 1467, 15 septembre. 
Galland (ou Gallandi, $\dagger 1500,4$ mai) ${ }^{313}$ acquit ainsi un Institute sans glose et un Digeste vieux ( "Geste vielle»), un certain "messire» Thomas Legrant ${ }^{314}$ acheta des Décrétales, peut-être un recueil de Constitutions et de Décrétales ${ }^{315}$, un Code et un Inforciat; un Digeste neuf ( Geste nove») fut dévolu au chanoine et avocat à la cour de l'archevêque, Pierre Courel ${ }^{316}$; un certain Jacquet Duval acquit, lui, un Institute, et un personnage demeuré non identifié acheta un exemplaire du Décret. Le 6 octobre $1468^{317}$, c'est encore le même receveur de la fabrique, Odon Le Senescal, qui reçut pour le chapitre la somme de 195 l. t. produite par la vente de livres de droit: Laurent Surreau acquit deux volumes du canoniste Henri Bohic pour 60 saluts ( «salucia») d'or ${ }^{318}$, Jean de Atrio (de Laitre) ${ }^{319}$, bachelier en droit civil, acquit un Décret et des Décrétales respectivement pour 55 l. t. et 24 l. t.; le trésorier (1454-1468) de l'archevêque, Guillelmus Auber ( $†$ 1482, 25 août) ${ }^{320}$, reçut des Clémentines et un Digeste neuf, pour 10 écus d'or et $101.10 \mathrm{~s}$. t.

Le chapitre n'était pas le seul à mettre en vente des livres, devenus pour lui inutiles; le règlement de certaines successions ou certaines décisions de justice contribuaient à remettre des livres en circulation. Dès $1389^{321}$, les biens du défunt archevêque Guillelmus de Lestrange furent mis en vente aux enchères; plusieurs livres figuraient dans cette vente: un énigmatique «livre pour prelat appelé Candilecta» resta à l'abbé de Valmont ${ }^{322}$ pour $4 \mathrm{~s}$. p.; le chanoine d'Évreux, Guido Rabaschier, auquel le Parlement de Rouen avait confié l'organisation de cette vente ${ }^{323}$, acquit un ordinaire de Rouen pour 24 s. p.; un

313. Fasti, 2, 1998, n ${ }^{\circ}$ 197; licencié en droit civil, il était depuis 1467 avocat à la cour de l'archevêque où il fut officier, avant de devenir conseiller à la cour du sénéchal de Normandie. En 1494, il avait légué aux Franciscains de Pontoise « une Raymondine que Mr de Mortemer a de luy» (Montignyle-Bretonneux, Arch. dép. Yvelines, G 3431); voir la notice BMF, en ligne sur le site Libraria, au nom de «Guillelmus Gallandi» (http://www.libraria.fr/fr/BMF/guillelmus-gallandi-1494).

314. À ne pas confondre avec le chanoine et futur chancelier, Thomas Legrand ( $\dagger$ 1392, avril; voir Fasti, 2, 1998, n 288).

315. L'acheteur en effet n'en est pas précisé, mais cet article se situe parmi ceux acquis par Thomas Legrand.

316. Fasti, 2, 1998, n ${ }^{\circ} 130$; ce chanoine, sous-chantre du chapitre (1500-1505) avait été étudiant à Pavie (1458-1464), avant de devenir avocat à la cour de l'archevêque, puis doyen de l'exemption de Montivilliers (1474). Sur le livre d'astrologie écrit en français que ce chanoine donna à la bibliothèque capitulaire, le 6 mars 1494 (n. st.), voir FÉLIX, 1892, p. 181 et TABBAGH, 2008, p. 40.

317. Rouen, Notre-Dame, chapitre (vente), 1468.

318. Somme estimée à environ 2001 . dans FÉLIX, 1892, p. 216, n. 1.

319. Fasti, 2, 1998, $\mathrm{n}^{\circ} 248$; ce chanoine, issu de la bourgeoisie rouennaise et officier de l'archevêque (1491-1495), copia les chroniques de Froissart. Sociétaire du collège de Sorbonne, qualifié de «scribe de l'Université», il se révéla un lecteur assidu des livres de la bibliothèque du collège, du moins au vu de ses assez nombreux emprunts effectués entre 1405 et 1418 (VIELliard, Pommerol, 2000, p. 611). À sa mort, il disposait de la somme conséquente de 1300 l. t.; sur le legs de son exemplaire des chroniques de Froissart à son petit-neveu, voir TABBAGH, 2008, p. 42 et n. 88 .

320. Fasti, 2, 1998, n ${ }^{\circ} 13$; sur les dispositions testamentaires de ce chanoine, voir TABBAGH, 2008, p. $40-41$ et n. 81 .

321. Guillelmus de Lestrange, 1389.

322. Notre-Dame de Valmont, abbaye O.S.B., fondée en 1169 par Nicolas d'Estouteville; dép. SeineMaritime, arr. Yvetot, chef-lieu de cant.

323. "Le compte de Guy Rabaschier, chanoine d'Évreux, ordené et commis par la court de parlement...» (Lestrange, 1888, p. 1); il s'agit donc d'un compte d'exécution testamentaire. 
pontifical à fermoirs d'argent, à l'usage de Paris, fut emporté après plusieurs enchères par un certain Johannes Ysebarre pour 31 fr.; ce même personnage semble avoir vu lui échapper un missel à l'usage de Rome, à deux fermoirs d'argent, emporté finalement pour 32 fr. par l'évêque de Saintes, qui n'était autre que le frère ou le neveu du défunt archevêque, Elias de Lestrange ${ }^{324}$, quand Jean Ysebarre en avait proposé 20 fr. Ce même prélat acquit aussi un diurnal à l'usage de Rome (un journal) pour $3 \mathrm{fr}$. Comme Jean Ysebarre, le chanoine Guy Rabaschier qui avait proposé $12 \mathrm{fr}$. pour un missel ancien à l'usage de Rome, se vit ravir la mise par un certain Huguelin de Morant qui emporta le missel au prix de 15 fr. Parmi les biens de Guillaume de Lestrange trouvés en l'hôtel parisien de l'évêque de Pampelune, Martin de Zalva, et prisés par le libraire parisien maitre Olivier de Lempie, on relève des bréviaires, portatifs ou non, ainsi que plusieurs articles acquis par l'évêque de Saintes: deux parties de pontifical, une règle dite des «Hermites Gruel» (?), ainsi qu' une chronique en papier. Le même document précise que plusieurs livres de droit du défunt furent donnés à ses neveux.

Le registre de comptes de l'archevêchés ${ }^{25}$ mentionne par ailleurs la vente, en 1474, des biens d'un certain Jehan Le Sesne, apparemment reconnu coupable de vol; au nombre de ces biens figuraient sept livres qui rapportèrent la somme de 9 l. 12 s.: un livre de Jacques de Voragine, deux volumes de Sermons, d'énigmatiques lettres d'Ezéchiel à Samuel, un De viciis et virtutibus, une Somme de Raymond, sans oublier un De senectute de Cicéron. On ignore cependant à qui furent vendus ces volumes.

En $1489^{326}$, c'est lors de la vente des biens du chanoine Ludovicus Blosset $(\dagger 1488)^{327}$ que furent dispersés les quelque 25 titres formant la bibliothèque du chancelier, mort couvert de dettes; pour chaque volume un prix est indiqué ${ }^{328}$, ainsi que, dans trois cas, le nom de l'acquéreur : il s'agit du doyen Jean Masselin (voir supra) qui se procura ainsi un commentaire imprimé de Virgile (art. 18), un répertoire de Nicolas de Lyre sur la Bible, lui aussi imprimé (art. 23) et un recueil commençant par des Casus breves, seu Notabilia Decretalium (art. 26) qui, lui, pourrait être manuscrit. Ernouf a proposé de voir en Jean Masselin le précédent propriétaire des livres de Louis Blosset, mais il faut remarquer que, Jean Masselin ayant survécu une douzaine d'années à Louis Blosset, il y a donc tout lieu de penser que les livres ont été acquis par le cadet, plutôt que par l'aîné329. Il est également intéressant de noter que, sur trois livres achetés, deux sont des imprimés.

\footnotetext{
324. (†) 1418, 17 juillet, évêque de Saintes de 1381 à 1396.

325. Johannes Le Sesne, 1474-1475.

326. Ludovicus Blosset, 1489.

327. Fasti, 2, 1998, n ${ }^{\circ} 56$; issu de la noblesse normande et parent du sénéchal de Normandie, pourvu de plusieurs prébendes (Chartres, Lisieux, Bayeux), il exerça la charge de maître des requêtes (1482), avant d'entrer en 1488 au service du duc de Lorraine.

328. Ce qui a permis d'évaluer à 21.12 s. t. le prix moyen de ses livres (TABBAGH, 2008, n. 73, p. 39).

329. On peut d'ailleurs remarquer que le nom de Jean Masselin, le seul cité pour cette vente est au datif, non au génitif.
} 
Certaines de ces transactions ont ainsi bénéficié en priorité à des chanoines de la cathédrale qui, par la suite, léguèrent ou donnèrent leur collection à la bibliothèque capitulaire, produisant ainsi un bel effet «boomerang».

Comme le remarquait déjà François Dolbeau ${ }^{330}$, les échanges de livres semblent avoir été plus rares. On en trouve cependant un exemple: le 27 août 1460 ${ }^{331}$, les chanoines décidèrent d'envoyer à Paris le chanoine Guillaume Roussel (voir supra) pour y procéder à l'échange de plusieurs livres d'Henri Bohic. Cet exemple illustre bien le rôle de Paris comme plaque tournante du commerce du livre à la fin du Moyen Âge; il est certain que la proximité de la capitale (déjà sensible au temps des relations entre Charles V et son traducteur, Nicole Oresme) et le fait que plusieurs chanoines y avaient des cures ou y exerçaient officiellement des fonctions, ont pu favoriser les échanges culturels ou commerciaux entre les deux métropoles.

\section{Une fenêtre ouverte sur les textes disponibles à Saint-Ouen, comme dans la bibliothèque capitulaire}

On peut s'interroger sur ce que ces divers documents nous permettent de saisir de la composition de ces deux fonds médiévaux. On a déjà souligné qu'en dehors de ces mentions de prêt et d'une mention de rachat d'un livre au XII siècle (voir supra), on n'a conservé aucun document médiéval pour la bibliothèque de Saint-Ouen. Pour la bibliothèque capitulaire, on pourrait imaginer que la situation documentaire est meilleure, mais un examen des sources démontre assez vite que, hormis les deux inventaires du XII siècle $^{332}$, on ne dispose guère d'autre liste qu'un inventaire incomplet dressé au XVIII ${ }^{e}$ siècle, qui regroupe sous l'intitulé «Mss» un certain nombre d'items ${ }^{333}$. Quant à l'inventaire rédigé en $1425^{334}$, il ne concerne que les biens (dont les livres) déposés en l'hôtel de la fabrique, à l'exclusion des volumes de la bibliothèque capitulaire.

\section{La part d'incertitude}

Tant pour Saint-Ouen que pour la bibliothèque capitulaire, on peut évaluer à 236 le nombre d'occurrences de textes relevées dans les divers documents recensés dans notre étude; et encore s'agit-il du nombre de mentions, non du nombre de textes, car on peut parfois se demander si ce ne sont pas les mêmes volumes qui sont empruntés à différentes reprises ${ }^{335}$. Il convient en outre de pondérer cette

330. Dolbeau, 1991, p. 500-501.

331. Rouen, Notre-Dame, chapitre (échange), 1460.

332. L'inventaire de la bibliothèque au temps de l'archevêque Gaufridus (Rouen, Bibl. mun., ms 1405 [Y 27], p. 128) et celui du trésor et de la bibliothèque dressé après 1183 (Rouen, Bibl. mun., ms 1193 [Y 44] fol. 50, 52v-54).

333. Rouen, Bibl. mun., ms 1456 (U 27) fol. 195.

334. Rouen, Arch. dép. Seine-Maritime, G 2094, p. 29-37 (p. 32-35, pour les livres).

335. C'est à l'évidence le cas lors d'emprunts effectués à la chaîne. 
relative importance numérique par la faible qualité de ces mentions. En effet, l'objectif des rédacteurs de ces documents n'est pas de donner une description exacte des volumes et des textes cités, mais de permettre d'identifier le volume pour en assurer le retour. On voit ainsi qu'à plusieurs reprises, seule la première œuvre d'un volume est spécifiée, et complétée par la formule "cum aliis»" Dans d'autres cas, les mentions de livres sont trop générales pour que l'on puisse envisager même une identification: c'est le cas des volumes vendus autour du milieu du XV $\mathrm{XV}^{\mathrm{e}}$ siècle, désignés comme «libri ${ }^{337}$, «certi libri ${ }^{338}$, «assertum librum consistentem in libraria $»^{339}$, «libri antiqui ${ }^{340}$, «antiqui libri ${ }^{341}$, «livres inutiles et anciens $»^{342}$ ou «volumes inutiles $»^{343}$; parfois une furtive indication de la discipline est donnée, comme pour ces livres de droit mentionnés comme «Livres de droit (pluseurs) $»^{344}$ ou comme «Livres de droit $»^{345}$ ou pour ces livres liturgiques à l'usage du diocèse d'Auch, «Libri [...] ad usum ecclesie Auxitanensis» ${ }^{346}$. Et comment deviner quels sont les titres augustiniens dissimulés sous la mention «Augustinus, De variis opusculis» ${ }^{347}$ ?

Certains intitulés sont insuffisants et rendent vaine toute tentative d'identification: dans le cas du liber conciliorum ou consiliorum, emprunté à plusieurs reprises $^{348}$ à la bibliothèque capitulaire et orthographié tantôt «conciliorum » (restitution par Oresme), tantôt «consiliorum» (emprunt et restitution par Pierre de Sihervilla) ${ }^{349}$, il est bien difficile de déterminer ce que recouvre un intitulé à l'orthographe aussi fluctuante: il peut en effet s'agir d'un recueil de décisions conciliaires («liber conciliorum»), ou bien («liber consiliorum») d'un grand nombre de textes ${ }^{350}$. En l'absence du manuscrit conservé, il paraît donc préférable de ne pas trancher et de garder en anonyme cet intitulé. De même, il est impossible

336. Voir, notamment, Saint-Ouen, 24, 27 et 29, Egidius de Campis, ainsi que Ludovicus Blosset, 1489 (art. 26).

337. Rouen, Notre-Dame, chapitre (vente), 1450 (n. st.), 25 février.

338. Ibid.

339. Michael Petit, 1492.

340. Rouen, Notre-Dame, chapitre (vente), 1448, 12 décembre et 1449.

341. Rouen, Notre-Dame, chapitre (vente), 1450, 12 mars.

342. Rouen, Notre-Dame, chapitre (vente), 1459 (n. st.), 19 mars.

343. Rouen, Notre-Dame, chapitre (vente), 1459, 22 août.

344. Guillelmus de Lestrange, 1389 (vente).

345. Rouen, Notre-Dame, chapitre (vente), 1467 (n. st.), 20 février.

346. Rouen, Notre-Dame, chapitre (vente), 1399, 2 novembre et 3 décembre.

347. Petrus Cauchon, 1440 (emprunt).

348. Nicholaus Oresme (restitution) et Petrus de Sihervilla (emprunt), 1370 (n. st.); Egidius de Campis (emprunt), 1400 (n. st.); Egidius de Campis (restitution), puis Guillelmus Gorren (emprunt), 1406.

349. Nicholaus Oresme (restitution), puis Petrus de Sihervilla (emprunt), 1370 (n. st.).

350. L'absence d'incipit et d'explicit pour ce titre interdit tout rapprochement avec les Consilia de Baldi de Ubaldi, identification donnée (LABORDE, 1919, p. 45, n. 5) pour un «Librum consiliorum " emprunté par Egidius de Campis, 1400 (n. st.): il est vrai que la présence de ce texte entre les mains de Nicole Oresme (s'il s'agit bien du même livre emprunté à plusieurs reprises entre 1370 et 1406) aurait constitué une preuve de diffusion extrêmement précoce pour un ouvrage composé à Padoue, sans doute de 1367 à 1379 (DTC, 2, 1937, col. 40). Une vingtaine de possibilités ont été relevées dans Sharpe, 1999, une quinzaine ont été trouvées par In Principio. 
de savoir à qui attribuer les trois volumes de «Postille» ${ }^{351}$, empruntés à Saint-Ouen par Ricardus Piel, en 1372 (?), même si, évidemment le nom de Nicolas de Lyre vient immédiatement à l'esprit ${ }^{352}$. De la même façon, à la cathédrale, le titre «Livre pour prelat appellé Candilecta ${ }^{353}$ évoque la Candela, œuvre théologique de Gerland, mais peut-on qualifier cette œuvre de «Livre pour prelat» ${ }^{354}$ ? Quant aux « 3 volumes de théologie successive vocitata Penthateucon» ${ }^{355}$, il est difficile d'après le seul titre de savoir si ce volume relève, comme indiqué, de la théologie ou de l'exégèse biblique. Le seul intitulé, «De ecclesiastica potestate » ${ }^{356}$, lui, ouvre trop de possibilités ${ }^{357}$ pour que l'on s'arrête à une seule.

Les incertitudes ne sont pas toujours levées lorsque l'on dispose du nom de l'auteur, notamment quand le nom de l'auteur n'est accompagné d'aucun titre. Ainsi, à Saint-Ouen, il paraît impossible de déterminer quel est le texte de Cassien emprunté en 1372 (?) par l'archevêque Philippe d'Alençon et simplement intitulé «Cassianus» ${ }^{358}$. Même la précision de l'incipit «veteris ac Novi Testamenti» ne suffit pas à lever les interrogations: d'après In principio et les éditions de Cassien ${ }^{359}$, en effet, aucune des deux œuvres principales de cet auteur, ses Collationes (CPL, $\mathrm{n}^{\circ}{ }^{512}$ ) et son De institutis coenobiorum $\left(C P L, \mathrm{n}^{\circ} 513\right)$, ne commence par cet incipit. Il ne paraît donc pas possible de trancher en faveur de l'une ou l'autre de ces deux œuvres ${ }^{360}$. De même, le nom, déjà déformé, $d^{\prime}$ "Ogusse ${ }^{361}$ ne permet pas de savoir si l'on a affaire aux Derivationes ou à la Lectura super Decretum d'Hugutio Pisanus. Dans les mentions relatives à la bibliothèque capitulaire, on est confronté au même type d'incertitudes: le seul nom de Sedulius ${ }^{362}$ est ambigu, puisqu'il pourrait s'agir de l'auteur polygraphe carolingien, Sedulius Scottus, ou du poète tardoantique, même si l'importante diffusion du Carmen paschale de ce dernier dans

351. St-Ouen, 33-35, Ricardus Piel.

352. Mais il n'est pas le seul auteur auquel ce terme ait été associé, comme une rapide recherche dans SHARPE, 1999 permet de s'en convaincre.

353. Guillelmus de Lestrange (vente), puis abbé de Valmont (achat), 1389.

354. On notera toutefois la présence d'un article: "Gerlandus» dans le catalogue du trésor et de la bibliothèque dressé après 1183 (Rouen, Bibl. mun., ms 1193 [Y 44] fol. 53).

355. Emprunt de Ludovicus d'Harcourt, 1459.

356. Emprunt de Nicolas Dubois (de Bosco), 1456 (n. st.).

357. Plusieurs auteurs peuvent en effet revendiquer ce titre: Alexander de Santo Elpidio, Jean Gerson, Augustin d'Ancône. En l'absence de tout autre élément (incipit...), il paraît difficile de trancher, même si on peut imaginer que le traité de Gerson pourrait avoir connu une diffusion en France plus immédiate que les deux autres auteurs.

358. St-Ouen, 41, Philippus d'Alençon.

359. CSEL, 13 et 17.

360. Geneviève Nortier, dans la table des auteurs et œuvres dressée à la fin de son travail (NorTIER, 1966, p. 217), paraît assimiler cette entrée au De institutis monachorum, mais sans s'en expliquer. Le témoin subsistant de Cassien provenant de Saint-Ouen (Rouen, Bibl. mun., ms 508 [A 324]) est, lui, un exemplaire du XII ${ }^{e}$ siècle des Collationes, qui par ailleurs ne porte pas de marque de provenance de l'abbaye bénédictine antérieure aux ex-libris des XVII ${ }^{\mathrm{e}}$ et XVIII ${ }^{\mathrm{e}}$ siècles (fol. $2 \mathrm{v}$ ); le dernier feuillet, le fol. 243 est déchiré dans sa longueur, de sorte qu'il n'en reste plus qu'une moitié; et Geneviève Nortier, d'ailleurs, identifie ce manuscrit à l'exemplaire de ce texte provenant de Saint-Évroult.

361. Saint-Ouen, 44, prior conventus.

362. Guillelmus Roussel, 1470 (n. st.), 9 avril. 
les bibliothèques médiévales ${ }^{363}$ incite à pencher en faveur de ce poème biblique désigné par le seul nom de son auteur. L'intitulé «livre de Voragine» donné à propos de la vente des livres de Johannes Le Sesne ${ }^{364}$, s'il désigne bien un ouvrage de Jacques de Voragine, peut s'appliquer à sa Légende dorée, un des grands succès du Moyen Âge, ou à ses Sermons. Même l'association d'un nom d'auteur et d'un titre n'est pas toujours suffisante pour lever les ambiguïtés: comment savoir à quel auteur attribuer les «sermones fratris Guillelmi» restitués à la bibliothèque capitulaire par Hugo Lenvoisie ${ }^{365}$ ou les «Sermones de Tournyaco»" de Lugduno»" ${ }^{367}$ ou encore la "Somme ${ }^{368}$ de Raymond $»^{369}$ ? Quant aux tables de la Cité de Dieu successivement empruntées par Guillelmus Roussel ${ }^{370}$ et par Robertus du Quesnay ${ }^{371}$, il est difficile d'en déterminer le ou les auteurs ${ }^{372}$, particulièrement à partir d'un titre qui semble laisser penser qu'Augustin est l'auteur de la table ${ }^{373}$.

La présence d'incipit ${ }^{374}$ ne permet pas non plus d'identifier, à elle seule, certaines œuvres, comme le montrent, pour la bibliothèque capitulaire, le cas de ce «liber qui incipit "Prefacio. Virorum..." " ${ }^{375}$ restitué avec d'autres par les exécuteurs testamentaires d'Hugo Lenvoisie ${ }^{376}$ ou celui de ce «liber incipiens in secundo folio "Ego N. Dei pacientia [?]; huius..." "377, et finiens in penultimo "Anno Domini CCC $^{0}$ nonagesimo quarto die XXII ${ }^{d a}$ mensis Januarii" ${ }^{378}$. À l'inverse, sans

363. Comme en témoignent SHARPE, 1999 et, pour les témoins subsistants, SPRINGER, 1995, notamment p. 5-6; je remercie Anne-Marie Turcan de sa suggestion qui me paraît effectivement la plus vraisemblable.

364. Johannes Le Sesne (vente), 1474-1475.

365. Restitution par Hugo Lenvoisie, 1414.

366. Des Sermons sont en effet dus à Guibertus et à Stephanus de Tournai.

367. Cette mention d'origine évoque immédiatement Guillelmus Peraldus, auteur de Sermons et souvent qualifié de «Lugdunensis» (STEGMüLLER, 1947, 2: Index auctorum, p. 828); le même adjectif pourrait renvoyer toutefois à d'autres auteurs, tels Florus, auteur d'Homiliae, Eucherius, auteur d'Homiliae ad monachos, très diffusées, ou Agobardus, auteur d'un Sermo ad plebem de fidei veritate. Or, d'après SHARPE, 1999, les œuvres d'Agobard et d'Eucher et les Homiliae de Florus semblent assez rares; il est donc probable que l'on se trouve en présence des Sermons de Guillaume Peyraut.

368. Cet intitulé évoque Raymundus de Pennaforte, auteur de plusieurs sommes (Summa de confessione, Summa matrimonii, Summa de penitentia), dont la plus répandue est la Summa de casibus, mais ce seul argument de la diffusion nous paraît trop faible, en l'absence d'autres éléments, pour nous arrêter à cette identification.

369. Johannes Le Sesne (vente), 1474-1475.

370. Emprunt par Guillelmus Roussel, 1470 (n. st.), 9 avril.

371. Emprunt, puis restitution par Robertus du Quesnay, 1471 (n. st.), 14 mars, puis 19 décembre.

372. On pense bien sûr à la table de Nicolaus Trivet et Thomas Waleys, mais on ne peut écarter celle due à Robert Kilwardby.

373. "tabula beati Augustini in libro de Civitate Dei» (Guillelmus Roussel, 1470 [n. st.], 9 avril) et "tabula beati Augustini de Civitate Dei» (Robertus du Quesnay, 1471 [n. st.]).

374. Cette pratique assez fréquente chez les notaires chargés de la rédaction des décisions capitulaires sera sans doute fort utile quand on entreprendra de rapprocher ces mentions d'ouvrages d'exemplaires subsistants.

375. On peut voir dans cette formulation (comme le suggère Anne-Marie Turcan) le premier mot de la Préface à un ouvrage, mais le seul mot de "virorum» renvoie, d'après In Principio, à un nombre trop grand d'hypothèses (près de 15) pour que l'on s'arrête à une seule.

376. Restitution par Hugo Lenvoisie, 1414.

377. Cet incipit évoque le début d'un formulaire.

378. Emprunt par Johannes Quatreul, 1466. 
incipit, comment déterminer si les Lettres échangées entre Jérôme, d'une part, et Damase et Augustin, d'autre part ${ }^{379}$, sont authentiques ${ }^{380}$ ou pseudépigraphes ${ }^{381}$ ?

D'autres titres restent obstinément obscurs et résistent à toute tentative d'identification, telle ce De Evangeliis et differentia restitué à la bibliothèque capitulaire $^{382}$ ou ces Epistole Ezechielis ad Samuelem ${ }^{383}$. À Saint-Ouen, le De regulis fidei emprunté en 1372 (?) ${ }^{384}$ par Gilles Deschamps demeure non identifié.

Il faut donc se garder de prendre l'analyse qui va suivre comme une vue d'ensemble de collections dont la composition nous échappe largement. Il s'agit simplement de relever, à partir des mentions de circulation ${ }^{385}$, les titres ${ }^{386}$ qui se trouvaient à un moment donné à Saint-Ouen ou à la bibliothèque capitulaire, comme dans d'autres collections liées aux archevêques de Rouen.

\section{Le droit}

Les titres prêtés ou circulant relèvent en très grande partie du droit, et particulièrement du droit canon, ce qui n'a rien d'étonnant dans un milieu canonial et séculier. Tous les livres du Corpus juris canonici font l'objet d'emprunts, à la seule exception des Extravagantes. Parmi le Corpus juris civilis, c'est le Digestum vetus et le Code qui circulent le moins (un seul emprunt chacun à la bibliothèque capitulaire), quand les Authentica, le Volumen et les Feuda n'apparaissent dans aucun des documents examinés.

Les emprunts à Saint-Ouen font ainsi apparaître, pour le droit canon, plusieurs exemplaires du Décret ${ }^{387}$, aucun recueil de Décrétales, un Sexte ${ }^{388}$, ainsi qu'un Sexte assorti de l'Apparatus dû à Johannes Monachus ${ }^{389}$ et associé à la Novella in Decretales Gregorii $I X^{390}$ du canoniste Jean André ${ }^{391}$, et, enfin des Clémentines ${ }^{392}$. À défaut de Décrétales, on trouvait aussi à emprunter

379. Egidius de Campis (restitution), puis Guillelmus Gorren (emprunt), 1413.

380. $B H M, 1 \mathrm{~A}, 1969, \mathrm{n}^{\circ} 15-16,18 \mathrm{~A}-21,35-36$ pour les lettres adressées à et par Damase, $B H M, 1 \mathrm{~A}$, $1969, \mathrm{n}^{\circ} 56,67,101-105,110,112,115-116,131-132,134,141-142$ pour la correspondance échangée avec Augustin.

381. $B H M, 3 \mathrm{~A}, 1970, \mathrm{n}^{\circ} 312,343-347,354-355,363,373$ pour les lettres adressées à et par Damase, $B H M$, $3 \mathrm{~A}, 1970, \mathrm{n}^{\circ} 352$ pour la lettre adressée à Augustin.

382. Restitution par Hugo Lenvoisie, 1414.

383. Johannes Le Sesne (vente), 1474-1475.

384. Saint-Ouen, 27, Egidius de Campis.

385. Les documents pris en compte dans cette enquête sont énumérés en annexe (annexe 1); rappelons que certains ont été édités et d'autres, non.

386. Du moins pour ceux pour lesquels on a réussi à avancer une identification ou du moins à émettre une hypothèse suffisamment plausible. L'annexe 2 présente une table des auteurs et des œuvres qui comporte encore beaucoup d'incertitudes.

387. Saint-Ouen, 2, Ricardus de Barbero; 16, Ludovicus Clerici; 22, Radulphus Boutin; 30, Egidius de Campis.

388. Saint-Ouen, 18, Philippus Jacob et 18bis, Simo de Bosco.

389. SCHULTE, 1956, 2, \$ 49, p. 192.

390. Ibid., $\$ 54$, p. 219-221.

391. Saint-Ouen, 19, Philippus Jacob.

392. Saint-Ouen, 1, Johannes de Foris (ou Dehors). 
à la bibliothèque de Saint-Ouen la Summa copiosa ou Summa super titulis Decretalium d'Henricus de Segusia, ainsi que la Lectura in quinque libros Decretalium $^{393}$ de ce même auteur ${ }^{394}$, ainsi que l'Apparatus in quinque libros

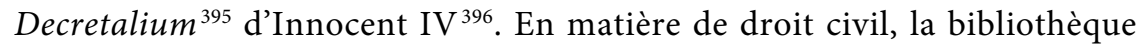
de Saint-Ouen offrait au prêt le Digeste neuve ${ }^{397}$, un ou plusieurs volumes d'Institutes ${ }^{398}$, ainsi qu'une Summa d'Azon ${ }^{399}$. À ces ouvrages juridiques, il faut joindre une encyclopédie de la pratique judiciaire, le Speculum judiciale ${ }^{400}$ de Guillaume Durand ${ }^{401}$ et une Lectura super leges ${ }^{402}$.

Parmi les ouvrages empruntés par Johannes de Foris à Philippe d'Alençon, on ne peut que regretter que l'auteur de lectures sur plusieurs textes du droit civil $^{403}$, un certain $\mathrm{G}$ de Tyonvilla ${ }^{404}$, n'ait pu être identifié. Il est clair toutefois que ce personnage emprunta dans la bibliothèque de l'archevêque les Quaestiones ${ }^{405}$ d'Oldradus de Ponte ${ }^{406}$. Quant aux livres acquis en 1489 par Johannes Masselin à la vente des biens de Ludovicus Blosset, un seul relève du droit, celui commençant par les Casus breves, seu Notabilia Decretalium ${ }^{407}$.

C'est à la bibliothèque capitulaire que l'offre en livres de droit est la plus importante. On peut penser qu'il y avait abondance de textes de droit canon, car ce sont les volumes que l'on trouve le plus souvent mentionnés dans les emprunts et ventes de livres: le Décret ${ }^{408}$, les Décrétales seules ${ }^{409}$, ou associées au Sexte ${ }^{410}$ ou aux Constitutions ${ }^{411}$, le Sexte, assorti d'un triple Apparat ${ }^{412}$ ou glosé ${ }^{413}$, ou associé aux Clémentines ${ }^{414}$, les Clémentines ${ }^{415}$. Parmi les canonistes, les Distinctiones in

393. SChulte, 1956, 2, \$31.

394. Saint-Ouen, respectivement 52 et 55, Philippus Jacob.

395. SChulte, 1956, 2, \$23, p. 92-93.

396. Saint-Ouen, 53, Philippus Jacob.

397. Saint-Ouen, 3, Ricardus de Barbero et 57, Simo de Bosco.

398. Saint-Ouen, 5, Ricardus de Barbero; 20, Radulphus Boutin; 56, Simo de Bosco.

399. Saint-Ouen, 15, Guillelmus de Bellomonte.

400. SChulte, 1956, 2, p. 148-152.

401. Saint-Ouen, 54, Philippus Jacob.

402. Saint-Ouen, 4, Ricardus de Barbero.

403. Philippus d'Alençon, 1367; Pommerol, Monfrin, 2001, 368. 2 B, 118-124, p. 388.

404. Faudrait-il lire «Thiouville ou Tyouville»; voir n. 153.

405. SCHulte, 1956, 2, \$56, p. 232-233.

406. Philippus d'Alençon, 1367; Pommerol, Monfrin, 2001, 368. 2 B, 8o, p. 386-387.

407. Ludovicus Blosset (vente), 1489, art. 26.

408. Rouen, Notre-Dame, chapitre (vente), 1452, 10 mai, achat par Johannes Fabri; 1468, achat par Johannes de Atrio (de Laitre); Rouen, Notre-Dame, fabrique (vente), 1467, 15 septembre, achat par un personnage non identifié.

409. Rouen, Notre-Dame, fabrique (vente), 1467,15 septembre, achat par Thomas Legrant; Rouen, Notre-Dame, chapitre (vente), 1468, achat par Johannes de Atrio (de Laitre).

410. Rouen, Notre-Dame, chapitre (estimation), 1370.

411. Rouen, Notre-Dame, fabrique (vente), $\mathbf{1 4 6 7}, 15$ septembre, achat par Thomas Legrant?

412. Restitution par Nicholaus Oresme, puis emprunt par Petrus Roger de Beaufort, 1370 (n. st.).

413. Rouen, Notre-Dame, chapitre (vente), 1452, 10 mai, achat par Laurentius Surreau.

414. Restitution par Thomas Legrand (ou Magni), puis emprunt par Dionisius Villani (ou Le Villain), 1395.

415. Rouen, Notre-Dame, chapitre (vente), 1468, achat par Guillelmus Auber. 
libros $V$ Decretalium d'Henri Bohic ${ }^{416}$ sont parmi les œuvres qui apparaissent le plus fréquemment ${ }^{417}$, notamment dans les ventes; on relève également, sous le titre «Martinian» une Margarita Decreti ou Summa martiniana ${ }^{418}$ de Martinus Oppaviensis (ou de Troppau) ${ }^{419}$.

Les mentions de textes en circulation révèlent aussi pour la bibliothèque capitulaire un fonds de droit civil assez conséquent: Digeste vieux ${ }^{420}$, Inforciat ${ }^{421}$, Digeste neuf ${ }^{422}$, Code $^{423}$, Institutes $^{424}$.

\section{La liturgie}

La liturgie représente le deuxième secteur parmi les livres en circulation à Rouen à la fin du XIV e siècle et au XV $\mathrm{XV}^{\mathrm{e}}$; encore faut-il prendre garde que les nombreux prêts consentis par le chapitre aux paroisses et chapelles en dépendant n'ont pas été pris en compte dans ce dénombrement, ce qui, à coup sûr, aurait accentué encore le poids de ce type de livres.

Un seul livre liturgique de Saint-Ouen fait l'objet d'un prêt: il s'agit d'un Psautier prêté à Gilles Deschamps ${ }^{425}$.

Si l'archevêque Philippe d'Alençon prête un petit missel à l'usage de Rouen à un certain «dominus Stephanus " ${ }^{426}$, il reçoit trois livres liturgiques en paiement d'une somme que lui devait le chapitre ${ }^{427}$; il s'agit d'un liber pro baptismo et sepultura, d'un missel, et, sans doute, d'un pontifical, qualifié de "pulcer liber episcopalis»; on peut sans risque supposer que les deux autres livres étaient aussi de «beaux livres» liturgiques.

Les livres liturgiques constituent la quasi-totalité de la vente des livres de l'archevêque Guillelmus de Lestrange ${ }^{428}$ : on y relève en effet deux bréviaires à l'usage de Rome, un portatif et l'autre de grand format, ainsi qu'un diurnal toujours à l'usage de Rome ${ }^{429}$, deux missels à l'usage de Rome, quatre "parties » de pontifical et un pontifical à l'usage de Paris, ainsi qu'un ordinaire.

416. SCHUlte, 1956, 2, \$68, p. 266-270.

417. Rouen, Notre-Dame, chapitre (échange), 1460; Rouen, Notre-Dame, chapitre (vente), 1466 ; Rouen, Notre-Dame, chapitre (vente), 1468, achat par Laurentius Surreau.

418. Schulte, 1956, 2, $\mathrm{n}^{\circ} 23$, p. 137-138.

419. Emprunt par Hugo Lenvoisie, 1389.

420. Rouen, Notre-Dame, fabrique (vente), $\mathbf{1 4 6 7}, 15$ septembre, achat par Guillelmus Gallandi.

421. Rouen, Notre-Dame, fabrique (vente), $\mathbf{1 4 6 7}, 15$ septembre, achat? par Thomas Legrant.

422. Rouen, Notre-Dame, fabrique (vente), 1467,15 septembre, achat par Pierre Courel; Rouen, Notre-Dame, chapitre (vente), 1468, achat par Guillelmus Auber.

423. Rouen, Notre-Dame, fabrique (vente), 1467,15 septembre, achat? par Thomas Legrand.

424. Rouen, Notre-Dame, fabrique (vente), 1467, 15 septembre, achats par Guillelmus Gallandi et par Jacquet Duval.

425. Saint-Ouen, 29, Egidius de Campis.

426. Philippus d'Alençon, 1367, art. 35 .

427. Philippus d'Alençon, 1362 (n. st.).

428. Guillelmus de Lestrange (vente), 1389.

429. Qualifié de «journal». 
Outre les volumes envoyés aux différentes paroisses et chapelles dépendant du chapitre ${ }^{430}$, le chapitre de la cathédrale confie également des volumes liturgiques à des chanoines. Pour les livres de la messe on relève ainsi deux emprunts de graduels ${ }^{431}$ et l'abandon en paiement d'un livre de chant («liber cantus»), partie d'hiver ${ }^{432}$. Parmi les livres qui relèvent de la célébration de l'office (canonial à priori), on trouve un livre de chant, un antiphonaire noté, décrit comme complet, reçu en paiement par le chapitre ${ }^{433}$. Les emprunts les plus nombreux concernent les bréviaires ${ }^{434}$, mais on note également le prêt d'un pontifical ${ }^{435}$. On notera qu'aucun missel de la bibliothèque capitulaire n'apparaît dans les prêts ou les ventes décidés par le chapitre.

\section{Bible et exégèse}

Sans surprise également, les emprunts et mentions d'aliénations révèlent un fort contingent de bibles et de commentaires exégétiques. À Saint-Ouen, en effet, on relève cinq emprunts du texte de la Bible ${ }^{436}$. Les commentaires exégétiques ne sont pas absents du fonds bénédictin: trois volumes de postilles demeurées anonymes ${ }^{437}$, les Enarrationes in libros Regum ${ }^{438}$ d'Angelome de Luxeuil $^{439}$, une Expositio in Canticum canticorum ${ }^{440}$ de Grégoire le Grand ${ }^{441}$, les Sermones in Cantica canticorum de Bernard de Clairvaux ${ }^{442}$, une Lectura super Matthaeum ${ }^{443}$ de Thomas d'Aquin ${ }^{444}$.

Les emprunts et mentions d'aliénation concernant la bibliothèque capitulaire font également apparaître d'assez nombreuses bibles: certaines sont

430. On se contentera de rappeler les prêts (les seuls pris en compte dans cette étude) de missels aux paroisses de Magnavilla (Manneville)-la-Goupil (1391), d'Anfreville / Amfreville-les-Champs (1396) et de Sassetot-le-Malgardé, sans doute (1409), de psautiers à Magnavilla (Manneville)la-Goupil (1372) et Saint-Ouen de Prend-en-Bourse ou Prenembourse (1393), de graduels à Magnavilla (Manneville)-la-Goupil (1372) et à la Maîtrise de la cathédrale (1399), de deux livres liturgiques («tempora») couvrant toute l'année liturgique à Magnavilla (Manneville)-la-Goupil (1372), d'un bréviaire à Sassetot (1409) et, enfin, d'un antiphonaire joint à un psautier et d'un Office de saint Louis à la Maîtrise de la cathédrale (1399).

431. Emprunt, puis restitution de Pasquerius de Vaux, 1444, puis 1445; de Thomas Durand, 1375, puis $\mathbf{1 3 7 9 .}$

432. Paiement à Johannes des Essars / Essarts, 1456.

433. Paiement par Guillelmus de Estoutevilla, 1422 (n. st.).

434. Prêts à un abbé d'un couvent de Caen non identifiés, 1379; à Johannes Gilles (ou Egidius), 1379; restitution par Henricus Gorren, 1438 (n. st.); emprunt, puis restitution par Petrus de Laigny, 1439, puis 1442; emprunt par Michael Petit, 1494 (n. st.).

435. Emprunt, puis restitution par Martinus Pinard, 1443 (n. st.), 21 février, puis 3 avril.

436. Saint-Ouen, 8, Egidius Abbatis; Saint-Ouen, 21, Radulphus Boutin; Saint-Ouen, 38, Johannes d'Angerant; Saint-Ouen, 42, prior conventus; Saint-Ouen, 45, prior de Condeto.

437. Saint-Ouen, 33-35, Ricardus Piel.

438. Jullien, Perelman, 1994, notice Ang. 5.

439. Saint-Ouen, 32, Ricardus Piel.

440. CPL, 1709; STEgmüLleR, 1947, 2, n 2639; en l'absence du codex, il est difficile de savoir s'il s'agit du commentaire de Grégoire ou de celui de Robert de Tombelaine.

441. Saint-Ouen, 24, Egidius de Campis.

442. Saint-Ouen, 46, manquant.

443. Torrell, 1993, p. 495.

444. Saint-Ouen, 25, Egidius de Campis. 
empruntées $^{445}$, dont une "porcio evangeliorum ", assez énigmatique ${ }^{446}$, d'autres (sans doute en raison du grand nombre d'exemplaires détenus par la bibliothèque) sont vendues ${ }^{447}$. La bibliothèque capitulaire offrait aussi à ses lecteurs des instruments d'étude de la bible, tels le commentaire ${ }^{448}$ d'Hervé du Bourgdieu sur Isaïe ${ }^{449}$, celui d'un certain docteur Lucien ${ }^{450}$ sur les évangiles ${ }^{451}$, un volume de concordance des évangiles attribué à Jérôme ${ }^{452}$, ainsi que «unum esquatuor» ${ }^{453}$ qu'il faut sans doute comprendre comme "unum ex quattuor», c'est-à-dire comme une concordance des évangiles ${ }^{454}$. Il n'est pas non plus impossible que la bibliothèque capitulaire ait été en mesure de prêter ${ }^{455}$ le Carmen paschale de Sedulius, s'il s'agit bien de cette œuvre désignée par son seul nom d'auteur (voir supra). On se souviendra par ailleurs (voir supra) que, en $1466^{456}$, le chapitre, se préoccupant de l'absence des Postilles de Nicolas de Lyre, résolut de combler cette lacune en vendant un Henri Bohic en deux tomes.

\section{La patristique}

Les mentions de textes prêtés ou aliénés permettent également d'identifier quelques volumes de patristique présents à Saint-Ouen en cette fin du XIV e siècle. Parmi les emprunts à la bibliothèque bénédictine, on relève en effet les Enarrationes in

445. Emprunts ou restitutions de Nicholaus Oresme et de Petrus de Sihervilla, 1370 (n. st.), à nouveau de Petrus de Sihervilla, 1371, puis 1382, avec Guillelmus Carrel, de Ricardus Piel, 1372 et de Guillelmus Gorren, 1416.

446. Restitution de Nicholaus Oresme, 1370 (n. st.).

447. Ventes organisées par le chapitre (Rouen, Notre-Dame, chapitre, 1448, 14 juin et 1452 [n. st.], 13 mars; 1452, achat par Johannes Fabri; Rouen, Notre-Dame, chapitre, Johannes Gauffridus (achat), 1452, 21 avril, puis 26 avril); voir plus haut, passim.

448. Laissé en gage, puis légué au chapitre par Guillelmus Roussel, 1470 (n. st.), 9 avril.

449. STEgmülleR, $3, \mathrm{n}^{\circ} 3260$.

450. Auteur assez mystérieux. L'identification à Lucianus Cestrensis monachus (fl. 1200, ca) cité par SHARPE, 1997, p. 368, paraît peu vraisemblable, cet auteur semblant avoir eu une production assez locale (De laude Cestriae). Aucun auteur de ce nom ne semble avoir écrit sur les évangiles (d'après StegmüLleR, 1947). En revanche, si l'on se penche sur les catalogues d'incunables (et je remercie François Dolbeau pour son heureuse suggestion), on trouve bien, dans une édition de 1496, un "Lodovicus Lucianus artium medicinae doctor", mais qui ne semble pas le bon personnage, puisqu'auteur d'un Prognosticon (HaIN, 1948, II, 1, nº 10277, p. 291). En revanche, un commentateur de Thomas d'Aquin, Marcus Antonius Luciano (O. P.) pourrait bien être l'auteur recherché; il est en effet mentionné comme commentateur/éditeur de l'In Evangelium beati Johannis Evangeliste aurea Expositio de Thomas d'Aquin dans des éditions de Venise, 1508 (Van Praet, 1822, 1, $\mathrm{n}^{\circ}$ 59, p. 57) et Paris, 1520 (Renouard, II, 1520, $\mathrm{n}^{\circ} 2485$ ); en ce cas il aurait circulé en manuscrit avant même l'édition de 1508. Je ne l'ai toutefois pas trouvé dans QuÉTIF, ECHARD, 1961, 1, ce qui pourrait inciter à une certaine prudence.

451. Emprunt, puis restitution de Guillelmus Roussel, 1470 (n. st.), 14 mars, puis 1470, 10 août.

452. Emprunt de Ricardus Piel, 1372.

453. Emprunt de Ricardus Piel, 1372.

454. Identification due à Anne-Marie Turcan; sans autre précision, il est difficile de déterminer de quelle concordance il s'agit: les incipit et explicit repères, en effet, sont trop brefs et trop peu significatifs pour être de quelque utilité.

455. Emprunt de Guillelmus Roussel, 1470 (n. st.), 9 avril.

456. Rouen, Notre-Dame, chapitre (vente), 1466. 
Psalmos $^{457}$ et sans doute les Confessiones ${ }^{458}$ d'Augustin $^{459}$, de même que le texte à identifier ${ }^{460}$ de Jean Cassien mentionné ci-dessus ${ }^{461}$, un texte de Grégoire le Grand, un commentaire d'Origène ${ }^{462}$ sur l'Épître aux Romains ${ }^{463}$ et un recueil ${ }^{464}$ de Sentences des Pères.

Les mentions de livres circulant dans l'entourage des chanoines et des archevêques montrent la présence dans la bibliothèque capitulaire de la Cité de Dieu $^{465}$ d'Augustin, sans doute en plusieurs exemplaires ${ }^{466}$, de Tables ${ }^{467}$ sur ce même livre ${ }^{468}$, des lettres authentiques ou apocryphes échangées entre Augustin, Jérôme et le pape Damase ${ }^{469}$. Quant à l'Exposition sur les Lettres pauliniennes mentionnée ${ }^{470}$ à plusieurs reprises ${ }^{471}$, il est difficile de déterminer, d'après le seul titre, s'il s'agit réellement du commentaire augustinien ou si cet intitulé se réfère à celui de Bède ou à celui de Florus. Plus rare, en revanche, est l'ouvrage de controverse, l'Adversus hereses ${ }^{472}$, d'Irénée ${ }^{473}$ de Lyon ${ }^{474}$. Enfin on relève la

457. $C P L, \mathrm{n}^{\circ} 283$.

458. Sous l'intitulé «De confessionibus»; CPL, $\mathrm{n}^{\circ} 251$.

459. Respectivement Saint-Ouen, 17, Petrus de Sihervilla et 36, Ricardus Piel.

460. CPL, $\mathrm{n}^{\circ} 512$ ou 513.

461. Saint-Ouen, 41, Philippus d'Alençon.

462. $C P G, 1,1983, \mathrm{n}^{\circ} 1457,1$.

463. Saint-Ouen, 7, Egidius Abbatis.

464. Saint-Ouen, 29, Egidius de Campis.

465. $C P L, \mathrm{n}^{\circ} 313$.

466. Emprunt en 1372, puis, en 1382, restitution de Petrus de Sihervilla et emprunt de Egidius de Campis; emprunt de Ricardus Piel, 1372; restitution d'un emprunt de Hugo Lenvoisie, 1414; emprunt et restitution de Laurentius Surreau, 1447 (n. st.); emprunt, puis restitution de Guillelmus Roussel, 1470 (n. st.), 14 mars, puis 1470, 10 août.

467. En l'absence du manuscrit ou d'un incipit, il paraît difficile de déterminer s'il s'agit de la table due à Nicolaus Trevet et Thomas Waleys ou celle de Robert Kilwarby ou encore d'une autre.

468. Emprunt de Guillelmus Roussel, 1470 (n. st.), 9 avril.

469. Restitution par Petrus de Sihervilla et emprunt d'Egidius de Campis, 1382.

470. $C P L, \mathrm{n}^{\circ} 280$ ?

471. Restitution par Egidius de Campis et emprunt par Guillelmus Gorren, 1413; restitution des emprunts de Guillelmus Gorren, 1416; Guillelmus de Deserto, 1466 (n. st.), 14 février.

472. $C P G, 1,1983, \mathrm{n}^{\circ} 1306$; je remercie mon collègue, Philippe Bobichon, de m'avoir indiqué cette piste. Le titre «contra omnes hereses» est un intitulé de cet ouvrage de controverses parfaitement attesté dans les bibliothèques médiévales (SHARPE, 1999, p. 460): voir notamment, à Christ Church de Canterbury, le Catalogue du prieur Eastry, art. 181 et à Londres, l'inventaire anonyme, Anonymous Reginensis, art. 12. Par ailleurs, l'incipit du $2^{\mathrm{e}}$ feuillet, «accipiens a nobis» (et non "a vobis», donné par LABORDE, 1919, n. 2, p. 62) coïncide parfaitement avec un membre de phrase situé à la fin de la préface au 1. I, de l'Adversus haereses ("quasi semen et initia accipiens a nobis», éd. dans Sources Chrétiennes, 264, p. 26), ce qui accrédite la lecture de LABORDE, 1919, et invalide celle de Beaurepaire («accipiens annos»); de même, l'explicit repère «et in omnibus his» relevé sur le dernier feuillet, peut-être rapproché de la conclusion du livre 5, «Et in omnibus his et per omnia idem Deus Pater ostenditur...» (36, 3, éd. dans Sources Chrétiennes, 153, p. 464). Il reste cependant peu de témoins de cette œuvre.

473. La lecture de ce mot diffère d'un auteur à l'autre: «Hyreneus» pour LABORDE, 1919, «Lyrenensis» pour B. de Beaurepaire; comme il a été dit plus haut, la lecture correcte est celle de Laborde, qui a en outre le mérite de confirmer l'identification de ce titre au traité d'Irénée de Lyon.

474. Emprunt, puis restitution par Nicholaus Couppequesne, 1430, 4 août, puis 7 novembre. 
présence des Mysticorum expositiones sacramentorum seu Quaestiones in Vetus Testamentum ${ }^{475}$ d'Isidore de Séville ${ }^{476}$.

Et si les livres donnés en gage par Beaubec ${ }^{477}$ restèrent au chapitre, c'est le secteur de la patristique qui en fut certainement le plus renforcé, avec l'entrée des Homélies de Jean Chrysostome sur Matthieu ${ }^{478}$, du Commentaire de Jérôme sur Ezéchiel ${ }^{479}$, des Retractationes d'Augustin ${ }^{480}$, du De tabernaculo de Bède le Vénérable ${ }^{481}$, des Homeliae XL in Evangelia du pape Grégoire ${ }^{482}$ et de l'Exameron d'Ambroise ${ }^{483}$, mais ces entrées sont loin d'être assurées; quoi qu'il en soit elles nous donnent un tout petit aperçu de certains des textes d'une abbaye cistercienne dont la bibliothèque est bien mal connue ${ }^{484}$.

\section{La théologie}

Quelques grands noms de la théologie médiévale figurent parmi les livres qui circulent à Rouen à la fin du XIV et au XV $\mathrm{XV}^{\mathrm{e}}$ siècles. La bibliothèque de Saint-Ouen possède les Sentences de Pierre Lombard ${ }^{485}$, bien sûr, mais aussi les commentateurs de ce texte: Bonaventure ${ }^{486}$, Gilles de Rome ${ }^{487}$, Guillaume d'Auxerre ${ }^{488}$; on relève aussi dans la bibliothèque bénédictine la Summa Contra Gentiles $^{489}$ et le Scriptum super libros Sententiarum de Thomas d'Aquin ${ }^{490}$, ainsi que des Quaestiones ${ }^{491}$ et un De regulis fidei ${ }^{492}$ (art. 27), titres tous deux demeurés non identifiés. Autre titre tout à fait remarquable, les Météores d'Aristote ${ }^{493}$, de surcroît en français et dont l'absence est constatée.

475. CPL, $\mathrm{n}^{\circ} 1195$; l'incipit du second feuillet «-remus cuiusque» (et non "-temus cuiusque», lu par LABORDE, 1919, n. 2, p. 62) correspond en effet au début du commentaire sur la Genèse «...in quo subsistentes requiesceremus, cuiusque vivificaremur statu...", 1. 89-9o de l'édition Gorman, 2009, p. 4 ; en revanche l'explicit repère, relevé sur l'avant-dernier feuillet, "sensit odorem tuum ", n'a pas été identifié dans la fin de ce commentaire ( $P L, 83$, col. 287-424).

476. Emprunt de Nicholaus Caval, 1430.

477. Mise en gage par Beaubec, 1486.

478. $C P G, 2,1974, \mathrm{n}^{\circ} 4424 \mathrm{a}$.

479. $C P L, \mathrm{n}^{\circ} 587 ; B H M, 2,1959, \mathrm{n}^{\circ} 213$.

480. $C P L, \mathrm{n}^{\circ} 250$.

481. $C P L, \mathrm{n}^{\circ} 1345$.

482. $C P L, \mathrm{n}^{\circ} 1711$.

483. $C P L, \mathrm{n}^{\circ} 123$.

484. BONDÉELLE, 1991, p. 16-17.

485. Saint-Ouen, 6, Egidius Abbatis.

486. Stegmüller, 1947, 1, $\mathrm{n}^{\circ}$ 111; Saint-Ouen, 11 et 13, Egidius Abbatis.

487. Ibid., $\mathrm{n}^{\circ} 43$; Saint-Ouen, 26, Egidius de Campis.

488. Ibid., $\mathrm{n}^{\circ}$ 281; Saint-Ouen, 9, Egidius Abbatis.

489. Je tiens à remercier pour son aide Fabio Gibiino, qui a attiré mon attention sur la réunion en un seul titre de deux ouvrages distincts, et qui a identifié le premier de ces intitulés à la Summa Contra Gentiles.

490. Saint-Ouen, 10, Egidius Abbatis.

491. Saint-Ouen, 23, Guillelmus Trubet.

492. Saint-Ouen, 27, Egidius de Campis.

493. Saint-Ouen, 50, manquant. 
Les emprunts et aliénations de livres révèlent la présence dans la bibliothèque capitulaire de Rouen de Lettres attribuées (à tort ou à raison) ${ }^{494}$ à l'archevêque de Rouen Hugues de Reading ${ }^{495}$, du De claustro animae ${ }^{496}$ et sans doute ${ }^{497}$ $\mathrm{du}$ De avibus ${ }^{498}$, œuvres allégoriques d'Hugues de Fouilloy, ainsi que, peutêtre ${ }^{499}$, du De medicina animae de ce même auteur, beaucoup plus rare ${ }^{500}$, $\mathrm{du}$ Communiloquium siue Summa collationum ad omne genus hominum ${ }^{501} \mathrm{de}$ Thomas Waleys ${ }^{502}$ qui apparaît sous le titre "Valense» ou "Galense » ${ }^{503}$; le De regimine principum de Gilles de Rome, lui, ne resta qu'un temps dans la bibliothèque capitulaire ${ }^{504}$. Parmi les manuels disponibles, on relève aussi le Catholicon de Jean Balbi de Gênes ${ }^{505}$.

Plus rare, le De animalibus d'Albert le Grand figure parmi les livres prêtés à Philippe d'Alençon ${ }^{506}$; la Summa in foro penitentiali de Berenger Fredol ${ }^{507}$ figure, elle, parmi les prêts consentis ${ }^{508}$ par le prélat.

494. Vraisemblablement l'archevêque de Rouen (1130-1164) Hugues de Reading (connu également sous les noms d'Hugues de Boves ou d'Amiens; voir DHGE, 25, 1995, col. 285). Hugues est auteur de plusieurs lettres adressées à divers personnages comme son cousin Mathieu d'Albano, l'abbé de Saint-Martin des Champs, le légat Albéric, Gravion d'Angers ou encore Arnoul de Lisieux, sans même parler de plusieurs souverains [Louis VII, notamment] et pontifes [Innocent II, Eugène III]; voir $P L, 192,1131-1300$, passim : en l'absence d'autre précision, il est donc impossible d'identifier plus précisément ces Lettres.

495. Emprunt sans doute de Ricardus Piel, 1372 : les Lettres y sont attribuées à un Hugo; restitution de l'emprunt d'Hugo Lenvoisie, 1414.

496. Emprunt de Petrus de Sihervilla, 1389.

497. Donné comme anonyme, il s'agit certainement de l'ouvrage d'Hugues de Fouilloy.

498. Emprunt de Johannes Quatreul, 1475; l'entrée de ce titre dans la bibliothèque capitulaire n'est toutefois pas certaine, puisqu'il s'agissait d'un volume laissé en gage par les religieux de Beaubec.

499. Si cet ouvrage, laissé en gage en 1486 par la communauté cistercienne de Beaubec, resta dans la bibliothèque capitulaire; dans la liste des livres de Beaubec (mise en gage par Beaubec, 1486), ce titre se présente en anonyme.

500. Une seule occurrence est mentionnée, sous le nom de Hugues de Saint-Victor, dans SHARPE, 1999 : voir l'article 244, 34 du Catalogus de libris autenticis et apocrifis compilé par Henry de Kirkestede (CBMLC, 11, 2004, p. 246).

501. GlORIEUX, 1933, 2, n ${ }^{\circ} 322$.

502. Emprunt de Johannes Masselin, 1480 [n. st.].

503. Ainsi que l'avait identifié LABORDE, 1919, n. 2, p. 45-46; on trouve en effet cette œuvre sous le titre de «summa Valensis de regimine uite humane», dans le Registrum de la bibliothèque des frères de l'abbaye de Sion, daté de $c a .1500-c a .1524$ (document SS1): art. 496; ce titre est repris par l'édition de Venise 1496 «Summa Ioannis Valensis de regimine vite humane seu Margarita doctorum» (CBMLC, 9, 2001, p. 146).

504. Don de Guillelmus de Deserto, sans doute restitué aux exécuteurs testamentaires du duc de Bedford, 1466 (n. st.), 14 février, puis 1470.

505. Restitutions des emprunts de Hugo Lenvoisie, 1414 et de Guillelmus Gorren, 1416; dans les deux cas l'ouvrage est présenté en anonyme.

506. Emprunt de Philippus d'Alençon, 1367.

507. Sous le titre «Summa Biterrensis seu Berengarii» (prêt par Philippus d'Alençon, 1367); Bérenger Fredol était précisément évêque de Béziers; on relève d'ailleurs le titre «Summa Berengarii» dans l'inventaire du monastère anglais prémontré de Tichfield, dressé le 29 septembre 1400, art. $74 \mathrm{C}$ (CBMLC, 3, 1992, p. 203); en revanche, le titre «Summa biterrensis» semble plus rare dans les inventaires de bibliothèques et mérite d'être relevé.

508. À Johannes de Foris. 


\section{La pastorale}

À Saint-Ouen, sont signalés les Sermons ${ }^{509}$ de Jean Halgrin d'Abbeville ${ }^{510}$ et des Sermones nobilissimi ${ }^{\text {511 }}$, demeurés anonymes.

La pastorale est également représentée dans la bibliothèque capitulaire par des recueils de Sermons: l'un ${ }^{512}$ est attribué à un certain Guillaume ${ }^{513}$, l'autre ${ }^{514}$ sans doute à Guillaume Peyraut ${ }^{515}$, un troisième ${ }^{516}$ est de Jacques de Voragine ${ }^{517}$, d'autres ${ }^{518}$ sont dus à l'évêque parisien Maurice de Sully ${ }^{519}$, à Nicolas de Aquaevilla (Hacqueville) ${ }^{520}$, peut-être à Guy d'Évreux ${ }^{521}$; un dernier recueil ${ }^{522}$ est d'un auteur dit «de Tournyaco ${ }^{523}$. S'ils restèrent acquis à la bibliothèque capitulaire, les livres laissés en gage par les religieux de Beaubec ${ }^{524}$ pourraient avoir apporté aux chanoines un exemplaire des Sermons de Pierre Chrysologue.

\section{Règles et ouvrages d'édification}

Deux règles seulement figurent parmi les livres en circulation et toutes deux appartiennent au fonds de Saint-Ouen: une Règle de saint Benoît, seule ${ }^{525}$ et qualifiée de «closata» ${ }^{526}$, et associée au Psautier et à des Sentences des Pères ${ }^{527}$.

509. Il est impossible de déterminer à quelle collection de sermons il est fait ici référence (SCHNEYER, 3, 1971, p. 510-566).

510. Peut-être Saint-Ouen, 12, Egidius Abbatis: le titre y est présenté comme une «Somma»; SaintOuen, 32, Ricardus Piel.

511. Saint-Ouen, 14, Egidius Abbatis.

512. Restitution des emprunts de Hugo Lenvoisie, 1414.

513. Il s'agit peut-être des Sermons du dominicain Guillaume Peyraut, auteur de deux séries de sermons, l'une sur les épîtres et évangiles de l'année, l'autre sur les fêtes des saints (SCHNEYER, 2, 1970, p. 533-576); plusieurs auteurs du nom de Guillaume ont effectivement écrit des sermons, mais ceux de Guillaume Peyraut qui ont connu une large diffusion, sont attestés dans cette bibliothèque (voir, infra, l'emprunt de Guillaume du Désert).

514. Emprunt de Guillaume du Désert, 1466, 13 novembre.

515. Qualifié de "Guillelmus Lugdunensis»; il s'agit très vraisemblablement de Guillaume Peyraut, auteur, comme déjà dit, de deux séries de sermons, l'une sur les épîtres et évangiles de l'année, l'autre sur les fêtes des saints (SCHNEYER, 2, 1970, p. 533-576).

516. Emprunt de Johannes Gouel, 1471.

517. Il est impossible d'être plus précis sur la collection de Sermons que recouvre cet intitulé trop vague (SCHNEYER, 3, 1971, p. 221-273).

518. Restitution de l'emprunt de Johannes de Pontissera, 1381.

519. SCHNEYer, 4, 1972, p. 170-178.

520. Échange de Guillelmus, abbé de Beaubec, 1470.

521. Intitulés "Sermones Guidonis», ce qui ne permet pas de déterminer de quelle collection il est question (SCHNEYeR, 3, 1971, p. 319-365); vente des biens de Johannes Le Sesne, 1474-1475.

522. Mentionné lui aussi dans la vente des biens de Johannes Le Sesne, 1474-1475.

523. On a vu qu'on ne pouvait déterminer s'il s'agissait de Guibert ou d'Étienne (voir supra); voir SCHNEYER, 3, 1971, p. 283-318 (Guibertus) ou SCHNEYER, 5, 1973, p. 509-513 (Stephanus).

524. Mise en gage par Beaubec, 1486.

525. Saint-Ouen, 43, prior conventus.

526. C'est-à-dire, selon l'interprétation d'Anne-Marie Turcan, sans doute glosée.

527. Saint-Ouen, 29, Egidius de Campis. 
Parmi les ouvrages à visée d'édification, on relève un Liber scintillarum ${ }^{528} \mathrm{de}$ Défensor de Ligugé ${ }^{529}$ et, sans doute l'Architrenius ${ }^{530}$ de Jean de Hanville ${ }^{531}$; ce secteur de la bibliothèque paraissait recherché puisque, parmi les ouvrages constatés comme manquants, l'on note deux volumes en relevant: un Speculum monachorum ${ }^{532}$ d'Arnulfus de Boeriis ou de l'abbé du Mont-Cassin Bernardus Ayglier ${ }^{533}$, et le De miseria humanae conditionis ${ }^{534} \mathrm{~d}^{\prime}$ Innocent III $^{535}$.

Au nombre des ouvrages circulant autour de la cathédrale, on note ${ }^{536}$ une Règle dite des "Hermites Gruel ${ }^{537}$ et un liber de viciis et virtutibus ${ }^{538}$.

\section{L'histoire et l'hagiographie}

Les livres d'histoire en circulation sont peu nombreux: la Rerum romanarum historia ${ }^{539} \mathrm{~d}$ 'Anneus Lucius Florus que prête Saint-Ouen à Nicole Oresme ${ }^{540}$ est sans doute le seul exemplaire de ce texte à circuler en Normandie ${ }^{541}$; il serait plus téméraire de risquer une identification pour le volume de Chroniques dont l'absence est constatée ${ }^{542}$.

C'est aussi à la bibliothèque bénédictine que se trouve le seul titre d'hagiographie repéré parmi les livres en circulation à Rouen : il se pourrait ${ }^{543}$ qu'il s'agisse

528. Sous le titre «Ysidorus de virtutibus»; d'après In principio, cet intitulé n'est partagé que par deux témoins tous deux conservés à Bamberg (Staatsbibliothek, Patr. 102, fol. 1 et Patr. 134, fol. 1); d'après l'incipit de ces deux manuscrits, cet intitulé qui n'a aucun écho dans l'œuvre connue d'Isidore de Séville, désignerait plutôt le recueil de citations de l'Écriture Sainte et des Pères sur des sujets de morale, composé par un moine de Saint-Martin de Ligugé et connu comme le Liber scintillarum de Defensor de Ligugé; or l'auteur le plus cité dans ce recueil, est de loin Isidore, ce qui pourrait expliquer ce libellé inhabituel.

529. Saint-Ouen, 28, Egidius de Campis.

530. Identification proposée pour l'intitulé «Liber architroum».

531. Saint-Ouen, 31, Egidius de Campis.

532. Présenté en anonyme dans le document, mais associé aux Sermons de Bernard de Clairvaux sur le Cantique des cantiques; comme dans l'exemplaire signalé parmi les livres du prieur Simon Bozoun de Norwich (liste B 58, art. 16; voir CBMLC, 4, 1996, p. 302), il est impossible de déterminer d'après le seul titre s'il s'agit de l'œuvre du cistercien Arnulfus de Boeriis ou de celle de l'abbé du Mont-Cassin, Bernardus Ayglier, raison pour laquelle le titre a été laissé en anonyme.

533. Saint-Ouen, 46, manquant.

534. Intitulé «Tractatus Innocentii pro parte de miseria hominis».

535. Saint-Ouen, 47, manquant.

536. Vente des biens de Guillelmus de Lestrange, 1389.

537. Ce titre n'a été relevé que d'après l'édition Lestrange, 1888, sans être vérifié sur l'original.

538. Johannes Le Sesne (vente de ses biens), 1474-1475.

539. Sur l'identification probable de ce texte, fondée sur l'intitulé donné dans le catalogue mauriste de dom Bellaise, voir Peyrafort-Huin, sous presse, n. 53.

540. Saint-Ouen, 39, Nicholaus Oresme.

541. Son retour à Saint-Ouen est attesté par le fait qu'il y fut décrit au XVII ${ }^{e}$ siècle par dom Bellaise (Peyrafort-Huin, sous presse).

542. Saint-Ouen, 48, manquant.

543. Mais, sans certitude, comme indiqué plus haut. 
de la Légende dorée ${ }^{544}$ de Jacques de Voragine ${ }^{545}$ et on peut se demander si c'est le même volume dont l'absence fut constatée sans doute après cet emprunt ${ }^{546}$.

Les emprunts à la bibliothèque capitulaire révèlent la présence probable d'un ouvrage assez peu représenté dans les bibliothèques médiévales ${ }^{547}$, même s'il en subsiste encore aujourd'hui environ 25 témoins: l'intitulé Epistola quam auctor libri diligit pourrait en fait être une corruption du titre ${ }^{548}$ de la lettre dédicatoire au cardinal Guillaume Peyre de Godin ${ }^{549}$ placée par l'auteur Tholomaeus de Fiadonis Lucanus en tête de son Historia ecclesiastica nova ${ }^{550}$. L'emprunt du De bello judaico du Ps.-Hegesippe ${ }^{551}$ est assez tardif; quant au volume de Chroniques prêté ${ }^{52}$, il est bien difficile de savoir de quel ouvrage il s'agit, de même que dans le cas du même titre vendu parmi les biens de l'archevêque Guillaume de Lestrange ${ }^{553}$.

L'absence, parmi ces mentions, de livres d'histoire qui se trouvaient dans un grand nombre d'établissements religieux (on pense à l'Historia ecclesiastica d'Eusèbe-Jérôme, à l'Historia scholastica de Pierre Comestor, au Speculum historiale de Vincent de Beauvais), sans compter, peut-être celle des histoires de la Normandie, démontre, s'il en était besoin, que l'on ne peut faire fond de ces seules mentions pour reconstituer ces deux bibliothèques.

\section{Les sciences}

Les rares mentions de livres relevant des sciences concernent toutes la bibliothèque capitulaire; on découvre ainsi un livre de médecine associé à un herbier («et sunt ibidem plures herbe figurate») ${ }^{554}$. Parmi les livres peut-être entrés à la bibliothèque capitulaire à la suite de leur mise en gage par la communauté de Beaubec ${ }^{555}$, figurait apparemment un bestiaire («liber de bestiis figurarum») ${ }^{556}$.

544. D’après l'intitulé, «Legenda sanctorum quasi Legenda aurea».

545. Saint-Ouen, 40, Johannes Bosquet.

546. Saint-Ouen, 49, manquant; l'intitulé des deux volumes est en effet identique.

547. Aucune occurrence relevée dans SHARPE, 1999.

548. «Epistola, quam auctor libri dirigit domino Guillelmo de Baiona tituli sancte Cecilie prebytero cardinali», Tholomeus von LuCCA, 2009; identification suggérée, sans doute à juste titre, par Anne-Marie Turcan.

549. Promu le 23 décembre 1312 cardinal du titre de Sainte-Cécile, ce prélat fut transféré le 12 septembre 1317 au titre épiscopal de Sainte-Sabine, ce qui permet ainsi de dater la lettre dédicatoire de Ptolémée de Lucques.

550. Restitution des emprunts de Hugo Lenvoisie, 1414

551. Emprunts de Ludovicus d'Harcourt, 1479 (n. st.) et de Guillelmus Le Brument, 1488 (n. st.), 3 mars, puis restitution, juin.

552. Emprunt de Johannes Bureau, 1451 (n. st.).

553. Vente des biens de Guillelmus de Lestrange, 1389.

554. Emprunt d'Henricus de Fiscano, 1399, puis restitution par lui et emprunt par Nicholaus Le Couete, 1401.

555. Mise en gage par Beaubec, 1486.

556. Cet exemplaire semble avoir échappé à Muratova, 1999. 


\section{Ouvrages pratiques}

La bibliothèque capitulaire offrait aussi la ressource d'instruments de travail, tel ce dictionnaire, qualifié de "unum notabilem librum nominatum Dicionarium in tribus voluminibus $»^{57}$ ou tel cet ouvrage qui parait être un formulaire et qui semblait daté du 22 janvier $1395^{558}$, d'après une description assez obscure ${ }^{559}$. Quant au Papias mentionné parmi les livres laissés en gage par les religieux de Beaubec ${ }^{560}$ et peut-être acquis ainsi par la bibliothèque capitulaire, on peut supposer qu'il s'agissait de l'Elementarium doctrinae rudimentum du grammairien italien, particulièrement diffusé $e^{51}$.

\section{Les classiques}

Les classiques ne sont pas absents de ces échanges: Saint-Ouen peut prêter le De officiis de Cicéron ${ }^{562}$.

Parmi les livres circulant autour de la bibliothèque capitulaire, on relève un De senectute de Cicéron ${ }^{563}$, un Commentaire de Virgile, peut-être celui dû à Maurus Servius Honoratus ${ }^{564}$, et surtout les Naturae historiarum libri de

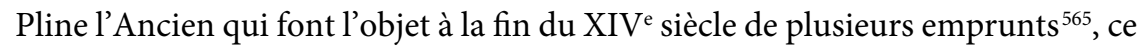
succès étant peut-être dû au caractère encyclopédique de l'ouvrage.

Et vers la fin du XV siècle apparaît à la bibliothèque capitulaire un des premiers signes tangibles de la Renaissance humaniste, avec l'emprunt ${ }^{566}$ d'une $^{\prime}$ ouvre de Boccace identifiée, sans certitude aucune, au De claris mulieribus ${ }^{567}$.

Les mentions de circulation des textes à Rouen à la fin du XIV et au XV ${ }^{e}$ siècle révèlent bien sûr la présence majoritaire de textes de droit canon et civil ainsi que d'ouvrages d'exégèse biblique et de livres liturgiques; peut-être plus

557. Paiement par Zano de Castiglione, 1431.

558. Une recherche menée dans les tomes français du Catalogue des manuscrits datés-F n'a pas permis de retrouver cet exemplaire.

559. «... quemdam librum incipientem in secundo folio "Ego N. Dei pacientia ([?] ; on attendrait plutôt "Dei gratia", voire "Dei providentia": s'agit-il d'une erreur du rédacteur?) huius...", et finientem in penultimo "Anno Domini CCC $^{o}$ nonagesimo quarto (?) die XXII ${ }^{\text {da }}$ mensis Januarii" "; il s'agit sans doute d'un formulaire: voir RockINGER, 1863, p. 297.

560. Mise en gage par Beaubec, 1486.

561. Voir Sharpe, 1999.

562. Saint-Ouen, 30, Egidius de Campis.

563. Vente des biens de Johannes Le Sesne, 1474-1475.

564. Son In tria Virgilii Opera Expositio; c'est du moins ce que suggère, sans doute à juste titre, ERNOUF, 1878, art. 18.

565. Restitution par Nicholaus Oresme, 1370 (n. st.); emprunt et restitution par Petrus de Sihervilla, 1370 (n. st.), puis 1370, 3 juin; second emprunt par Petrus de Sihervilla, 1372; restitution par Petrus de Sihervilla et emprunt par Egidius de Campis, 1382.

566. Emprunt de Petrus Escoulant, 1480.

567. Le titre mentionné, «librum intitulatum De mulieribus illustribus» évoque immédiatement le De claris mulieribus de Boccace. On peut se demander s'il n'y aurait pas eu confusion de ce titre avec le De casibus virorum illustrium de Boccace qu'il laissa à la bibliothèque capitulaire. 
étonnante est la faible part de l'histoire et de l'hagiographie dans ces échanges. Quelques textes sont assez remarquables par leur rareté ou leur nouveauté: on pense à l'Anneus Julius Florus, à l'Aristote de Saint-Ouen, ou au Boccace de la bibliothèque capitulaire; ces textes donnent l'impression de bibliothèques vivantes, qui, du moins pour la bibliothèque capitulaire, la seule que l'on puisse suivre sur plusieurs décennies, évoluent avec le temps. En revanche, la prédominance absolue du latin (à la seule exception des Météores d'Aristote, seul texte relevé en français) montre que l'élan donné par Charles V n'a eu aucune suite dans des institutions qui, ayant accueilli Nicole Oresme (le chapitre) ou ayant contribué à son travail (Saint-Ouen), auraient pu être sensibles au courant de traductions lancé dans les sphères de pouvoir avec lesquelles les membres de ces institutions n'ont jamais cessé de garder des liens. Il est vrai que ces bibliothèques sont celles d'ecclésiastiques, traditionnellement peu ouvertes aux ouvrages en vernaculaire.

\section{La terminologie: quelques remarques}

Il vaut enfin la peine de s'arrêter un instant sur la terminologie utilisée pour le prêt. Il n'est pas question de faire ici une étude lexicographique qui dépasserait nos compétences et les quelques exemples réunis sont loin d'être exhaustifs ${ }^{568}$, tant la matière disponible à Rouen révèle de richesse. Tout au plus peut-on esquisser quelques remarques sur le vocabulaire utilisé pour le prêt.

Le terme qui revient sans conteste le plus souvent et, sur toute la période, est le verbe "accommodare», souvent employé au participe passé comme adjectif («de libro accommodato») ${ }^{569}$. Le terme "accommodare» signifie en effet prêter un objet, puis prêter de l'argent, enfin mettre quelqu'un à la disposition de quelqu'un d'autre ${ }^{570}$. On sait aussi que «accommodare» et surtout le substantif français qui en est dérivé "accommodation " peuvent être employés aux XVII ${ }^{e}$ et XVIII ${ }^{e}$ siècles avec le sens de "rétablir une chose qui est en désordre " ${ }^{571}$. Mais à Rouen, aux XIV et $\mathrm{XV}^{\mathrm{e}}$ siècles, ce terme appartient bien au vocabulaire du prêt ${ }^{572}$.

568. Pour ne pas alourdir un article déjà touffu, nous avons choisi de ne pas donner toutes les références dans lesquelles on relève les différents termes retenus.

569. Sous ses diverses formes, on trouve le verbe dans nombre de notices d'emprunt ou de restitution que l'on pourra consulter dans LABORDE, 1919, passim, VAGENHEIM, 2011, p. 14 et plusieurs transcr. IRHT, MPH; dans l'emprunt de Johannes Quatreul, 1475, on trouve le substantif, «accommodatio». Dans la notice de Guillelmus Roussel, 1470 (n. st.), 14 mars, le terme «accommodare» a été cancellé et remplacé par «accordare».

570. Niermeyer, 1984, p. 11; Dictionary, 1975, p. 15.

571. La Curne de Sainte-Palaye, 1, 1875, p. 42; sur l'emploi de ce verbe dans ce sens à Saint-Allyre au milieu du XVII ${ }^{\mathrm{e}}$ siècle, voir Peyrafort-Huin, 2009, p. 95.

572. Cette acception rejoint celle relevée à Fribourg en Brisgau en 1419 par PowITz, 1996, notamment p. 294 ("acomodare nec concedere» au sens de aushändigen, c'est-à-dire de remettre quelque chose à quelqu'un); je remercie Anne-Marie Turcan-Verkerk de m'avoir signalé cette référence. 
Un autre verbe de la même famille, «commodare» se trouve au moins une fois comme verbe ${ }^{573}$ et est ailleurs employé comme participe substantivé (voir sous «concedere»); parmi les sens de ce verbe, on relève celui de prêter des objets gratuitement pour un usage temporaire ${ }^{574}$, mais aussi celui de «rendre service» que l'on retrouve dans l'expression «ad commodum capituli ecclesie " ${ }^{575}$, que l'on pourrait traduire par «au profit, au service du chapitre», «à l'usage du chapitre». Une autre expression est construite à partir du verbe «accomodare»; il s'agit de "tradidisse [...] in accomodato seu precario tradere $»^{576}$.

Le verbe «concedere», d'un usage moins fréquent ${ }^{577}$, semble employé avec un sens proche de celui d' "accommodare», c'est-à-dire avec le sens d' "accorder", sous-entendu «en prêt». Toutefois, dans le cas du livre donné à Johannes des Essarts en paiement d'écrits « extraordinaires» effectués par le notaire ${ }^{578}$, le verbe «concedere» garde bien le sens de "concéder». Ce même verbe est également associé au terme "precarium», dans les expressions «concedere et tradere precario (?) $»^{579}$, «In precarium seu commodatum concedere ${ }^{580}$ ou «In precario dare et concedere» ${ }^{581}$. Ce terme signifie une donation, une concession à titre précaire ${ }^{582}$, c'est-à-dire, en droit, au sens étymologique du precarium romain, que l'accord est résiliable à la première demande du propriétaire. C'est sans doute le sens des formules par lesquelles les emprunteurs s'engagent à restituer les emprunts «ad voluntatem dominorum» ou «ad beneplacitum dominorum»" À deux reprises ${ }^{584}$, le terme "precario» est associé au verbe "habere» et dans deux autres $\operatorname{cas}^{585}$ au verbe «tradere», sous la forme d'un participe passé employé comme adjectif ( in precario tradito» et "traditus in precario»).

Dans l'un de ces deux derniers cas ${ }^{586}$, le verbe «tradere» est aussi employé sans autre précision, mais dans le sens de «traditus in precario». De fait, on trouve assez fréquemment ce verbe sans autre précision, avec le sens probable de "prêter? confier? ${ }^{587}$, mais on ne peut exclure que s'y ajoute la nuance d'«apporter» puisque dans la plupart des cas relevés, il s'agit de prêts destinés

573. Emprunt de Petrus Escoulant, 1480.

574. NiermeYer, 1984, p. 218; Dictionary, 1981, p. 396.

575. Rouen, Notre-Dame, chapitre (vente), 1450, 12 mars.

576. Ludovicus d'Harcourt, 1479 (n. st.).

577. Je n'en ai relevé que trois occurrences: emprunts de Petrus de Sihervilla, 1372; Ricardus Piel, 1372 ; Radulphus Roussel, 1443.

578. Paiement à Johannes des Essars / Essarts, 1456.

579. Emprunt, puis restitution par Martinus Pinard, 1443 (n. st.).

580. Emprunt par Johannes Quatreul, 1475.

581. Emprunt par Petrus Escoulant, 1480.

582. BLAISE, 1975, p. 729.

583. Voir supra, n. 149 et 151.

584. Emprunts de Guillelmus de Deserto, 1466, 13 novembre; de Johannes Gouel, 1471.

585. Emprunt de Guillelmus de Deserto, 1466, 13 novembre; Laurentius Surreau («traditus in precario»), 1447 (n. st.).

586. Emprunt de Laurentius Surreau, 1447 (n. st.).

587. Prêts à Magnavilla (Manneville)-la-Goupil, 1372; à Caen, abbé et couvent (non identifiés), 1379; à Johannes Gilles (ou Egidius), 1379; à Saint-Ouen de Prenembourse, 1393; à Anfrevilla, 1396; à la Maîtrise des enfants de chœur de Notre-Dame de Rouen, 1399. 
à être apportés à l'extérieur, soit à des paroisses, soit à des individus, plus ou moins éloignés du chapitre. Dans une formule, ce verbe est précisé par «in commendam ${ }^{588}$ et dans un cas ${ }^{589}$, on relève l'emploi du verbe "tradere» avec un pronom réfléchi. Toutefois, dans un cas au moins ${ }^{590}$, le verbe «tradere» garde son sens plein de "apporter»: il s'agit en effet de "tradere in capitulo", c'est-à-dire d'apporter au chapitre des livres légués et dans un autre cas, ce verbe associé à «in custodia ${ }^{591}$ semble insister sur la garde, la surveillance que devra exercer l'emprunteur.

Un autre groupe d'expressions dérive du verbe «mutuare» qui signifie de façon courante emprunter de l'argent ou autre chose, de même que la forme passive «mutuari»; on trouve ainsi un «De libro mutuato " 592 et, même un «De libro mututo $(s i c) »^{593}$. Mais il prend aussi le sens de prêter, comme dans «domini [...] mutuaverunt magistro Dionisio Villani ${ }^{594}$ ou dans «De libro ... mutuando» $\$$. Le plus souvent la formule comprend le substantif «mutuum» et un verbe: «In mutuo recepere " ${ }^{596}$, «Mutuo dare et concedere ${ }^{597}$ ou «mutuo... dari (?)» ${ }^{598}$, "Concedere et tradere in mutuo ${ }^{599}$, «mutuo tradere ${ }^{600}$ ou «mutuo tradi»" ${ }^{601}$, ou encore «Mutuo habere» ${ }^{602}$. Parfois aussi le substantif est employé seul, comme on l'a vu supra, dans «causa mutui»" ${ }^{603}$ ou dans «De mutuo libri»" ${ }^{604}$ ou encore dans «in formam mutui» ${ }^{605}$.

Sans surprise, le terme usuel en matière de gage est "pignus», comme on le voit dans "attulit in capitulo librum [...] in pignus» ${ }^{606}$; parfois, la déclinaison n'est pas tout à fait respectée, comme dans «dedit ipse Quatreul in pignis...» ${ }^{607}$ ou dans "datus in pignis " ${ }^{608}$; on relève aussi un adjectif bâti, de façon un peu hardie, à partir du substantif, comme dans «de libris impignotis pro religiosis

588. Emprunt de Hugo Lenvoisie, 1389.

589. «quem sibi tradidit ma. Johannes de Pontissera" (restitution de l'emprunt de Johannes de Pontissera, 1381).

590. Don / legs de Guillelmus de Deserto, 1466 (n. st.), 14 février.

591. Emprunt par Petrus de Laigny, 1439.

592. Emprunt par Michael Petit, 1494 (n. st.).

593. Gage donné par Johannes Gouel, 1471.

594. Restitution par Thomas Legrand/Magni, puis emprunt par Dionisius Villani, 1395.

595. Emprunt par Guillelmus Le Brument, 1488 (n. st.), 3 mars.

596. Restitution par Nicholaus Oresme, 1370 (n. st.).

597. Emprunt par Guillelmus Le Brument, 1488 (n. st.), 3 mars.

598. Restitution par Egidius de Campis, 1413.

599. Emprunt par Egidius de Campis, 1400 (n. st.).

600. Emprunt par Petrus de Sihervilla, 1371; restitution par Egidius de Campis, 1413.

601. Emprunt par Michael Petit, 1492.

602. Restitution par Egidius de Campis, 1406; restitution des emprunts de Guillelmus Gorren, 1416.

603. Prêt à Magnavilla (Manneville)-la-Goupil, 1372.

604. Emprunt par Michael Petit, 1492.

605. Emprunt par Michael Petit, 1494 (n. st.).

606. Emprunt par Guillelmus Roussel, 1470 (n. st.), 9 avril; on relève une formule voisine ( in pignore [...] tradidit in capitulo unum aliud librum») dans l'emprunt de Nicholaus Dubois (de Bosco), 1456 (n. st.).

607. Emprunt par Johannes Quatreul, 1475.

608. Restitution par Guillelmus Roussel, 1470, 10 août. 
de Bello Becco» ${ }^{609}$; le plus souvent le substantif «pignus» est associé au verbe «dare» comme dans «dando pignus» ${ }^{610}$ ou encore "Copia inventarii librorum datorum in pignus... $»^{611}$ ou encore dans «qui dedit in pignus librum dictum Glosam ordinariam... $»^{612}$.

À côté de ce terme consacré, on trouve au moins un exemple d'une expression sans doute plus rare, «dare in securitate» qui est équivalente de «dare in pignus», au moins dans un cas: «et in securitate dedit unum alium librum... » ${ }^{613}$. Il ne faudrait toutefois pas en déduire que l'expression «in securitate» est univoque, car on la trouve également employée dans un sens, plus classique sans doute, de "en sécurité», comme dans «de ponendo in libraria huius ecclesie in securitate duo volumina ${ }^{614}$.

Quant à la restitution des livres, sans surprise, le terme employé est le verbe «restituere» ${ }^{615}$, ainsi que le substantif dérivé «restitutio ${ }^{616}$. Deux fois au moins le verbe «restituere» est doublé par un autre verbe: dans un cas, «tradere» ${ }^{617}$, dans l'autre, «reddere ${ }^{618}$. Dans un cas au moins, on trouve l'expression «ipsos libros reapportare in capitulo ${ }^{619}$.

Ce trop bref relevé des termes utilisés dans les documents pour désigner les opérations de prêt et de restitution des volumes est loin d'être exhaustif. Le corpus est cependant déjà important, tant par le nombre de documents que par l'arc chronologique ainsi embrassé. On n'a cependant pas le sentiment de pouvoir discerner une évolution chronologique des termes utilisés pendant la période envisagée; il est plus vraisemblable que chaque notaire (les rédacteurs des registres capitulaires) avait sa propre terminologie, mais sans doute faudrait-il une étude plus spécifique pour acquérir quelque certitude. Un point intéressant nous paraît être que si l'on peut dégager quelques termes qui semblent revenir fréquemment, il faut aussi se garder de tout esprit systématique, car ainsi que nous l'avons déjà remarqué et comme le soulignait déjà Clark (voir supra), les termes sont rarement univoques et demandent toujours à être compris en lien avec le contexte.

609. Emprunt par Johannes Quatreul, 1475.

610. Emprunt par Guillelmus Roussel, 1470 (n. st.), 14 mars.

611. Mise en gage par Beaubec, 1486.

612. Emprunt par Robertus du Quesnay, 1471 (n. st.).

613. Emprunt par Johannes Gouel, 1471.

614. Dépôt par le Mont-St-Michel, 1465.

615. Restitution par Nicholaus Oresme, 1370 (n. st.); restitution par Thomas Durand, 1379; emprunt par Hugo Lenvoisie, 1389; restitution par Petrus de Laigny, 1442; restitution par Martinus Pinard, 1443 (n. st.) ; restitution par Guillelmus Roussel, 1470, 10 août; restitution par Robertus du Quesnay, 1471, 19 décembre; emprunt par Petrus Escoulant, 1480; il ne s'agit là que de quelques exemples pris dans une liste trop longue pour être donnée intégralement.

616. Restitution par Petrus de Laigny, 1442; restitution par Martinus Pinard, 1443 (n. st.), 3 avril; restitution par Guillelmus Roussel, 1470, 10 août, 14 mars; emprunt par Guillelmus Le Brument, 1488 (n. st.); emprunt par Michael Petit, 1494 (n. st.).

617. "tradidit et restituit in capitulo» (Thomas Durand, 1379); «fuit restitutum in capitulo et traditum " (restitution à la chapelle Sainte-Agathe de la cathédrale, 1396).

618. « reddere capitulo huius ecclesie vel librum predictum restituere» emprunt par un abbé et couvent non identifiés de Caen, 1379.

619. Prêt à Magnavilla (Manneville)-la-Goupil, 1372. 
Au terme de cette enquête, il apparaît clairement qu'il y a bien un mouvement de circulation des textes et des livres à Rouen à la fin du XIV et durant le $\mathrm{XV}^{e}$ siècles. Les échanges sont nombreux et s'étendent à une grande partie de la Normandie; outre les paroisses liées au chapitre, on voit en effet des prêts ou des échanges toucher diverses villes de la province: les sièges épiscopaux, tels Lisieux, Bayeux, Avranches, des villes comme Caen, des monastères, telle l'abbaye cistercienne de Beaubec, mais aussi des abbayes et prieurés bénédictins normands dont les membres bénéficient de prêts ou de ventes (on pense à Valmont, à Beaulieu). En outre la carrière des emprunteurs, mieux connue grâce aux travaux de Vincent Tabbagh, montre une grande mobilité du monde ecclésiastique et, notamment, canonial, mobilité qui évidemment a dû favoriser la circulation des textes et des livres. En ce qui concerne les influences qui ont pu s'exercer sur la métropole normande, on peut s'interroger sur le rôle joué par Paris: on a vu que la proximité des deux cités avait facilité l'implantation comme doyen du chapitre de Nicole Oresme au moment où il mettait en œuvre le grand programme de traductions voulu par le roi Charles $\mathrm{V}$ et où, du fait de l'absence de l'archevêque, il devenait un représentant quasi officiel du roi dans l'église de Rouen. Mais on peut donner d'autres exemples de cette proximité: un grand nombre des chanoines de Rouen ont fait leurs études à Paris, certains y ont encore des prébendes et l'on a de préférence recours à eux quand il s'agit d'acheter ou de vendre des livres; on pense à un Ricardus Perchart, chargé de vendre un exemplaire du commentaire sur les Décrétales d'Henri Bohic, peut-être précisément parce qu'il était curé de Saint-Gervais à Paris ${ }^{620}$, ou à la vente de la bibliothèque de l'archevêque Guillaume de Lestrange qui s'effectua à Paris.

Par ailleurs, il ressort des documents examinés que si les mentions de prêts et de circulation sont relativement nombreuses, elles paraissent surtout concerner des personnages d'une certaine importance. Certes, plusieurs emprunteurs, à Saint-Ouen comme à la bibliothèque capitulaire, ne sont pas identifiés et d'autres semblent tout à fait ordinaires, tel ce moine de Beaulieu, Guillelmus Trubet, ou tels des chanoines sans caractéristique particulière, comme un Petrus Escoulant ou un Robertus du Quesnay qui semblent avoir simplement mené une existence banale de chanoines. Encore faut-il être bien conscient de la limite de nos connaissances, notamment en ce qui concerne les origines et la carrière des religieux, sur lesquels on ne dispose pas toujours d'une étude solide ${ }^{621}$. Mais l'impression qui se dégage de cette étude est que les personnages qui apparaissent dans ces mentions de circulation de livres sont des personnages d'un certain rang, liés soit aux sphères du pouvoir politique (on pense, bien sûr, à un Nicole Oresme, à un Philippe d'Alençon, à un Jean Bureau) ou ecclésiastique

620. Sur la forte présence normande à Paris, on renverra à Gousset, 1999.

621. Même pour Saint-Ouen, et malgré le témoignage de Pommeraye, 1662, il n'a pas été possible d'identifier le prieur en fonction en 1372. 
(nombre des emprunteurs ayant recours à la bibliothèque capitulaire sont des dignitaires du chapitre, quand ils ne sont pas des familiers de l'archevêque). On a d'ailleurs souligné que la carrière et les déplacements de certains de ces emprunteurs expliquaient la difficulté pour le chapitre de récupérer ses ouvrages prêtés. Et l'on peut remarquer que, sauf peut-être à Saint-Ouen, les emprunts sont rarement massifs, cinq à six volumes au plus, comme si les emprunteurs disposaient d'une bibliothèque en propre (on a vu que c'est le cas, évidemment, de Philippe d'Alençon, mais aussi de certains chanoines de la cathédrale qui ont par ailleurs disposé de leurs livres par testament). On peut alors se poser la question de l'image que nous donnent les sources de ces échanges. Les documents nous présentent-ils la réalité des échanges de livres, particulièrement en ce qui touche aux emprunts à la bibliothèque capitulaire? On peut remarquer en effet que certains chanoines, connus pour avoir eu des bibliothèques qu'ils ont, pour autant que l'on puisse le savoir ${ }^{622}$, divisées entre divers héritiers, n'apparaissent pas dans les documents attestant de ces échanges de livres: on peut se borner à ne citer que quelques cas, tels un Philippe de La Rose qui en 1470 répartissait entre divers légataires une dizaine d'ouvrages dont un Pétrarque ${ }^{623}$, un Andreas Marguerie qui en 1433 déposa à la bibliothèque capitulaire 12 livres en 17 volumes qu'il entendait léguer au chapitre ${ }^{624}$, un Johannes Jouglet qui en 1488 disposa de 13 livres, dont des livres en français et plusieurs volumes d'Ovide ${ }^{625}$, ou un Petrus Leschamps, alias d'Esneval qui, en 1484 léguait plus de dix livres, tous imprimés ${ }^{626}$. On peut donc légitimement se demander s'il n'y aurait pas là un effet de trompe-l'œil et si les documents étudiés ne nous présenteraient pas qu'une partie seulement de la réalité. Dans le cas de Saint-Ouen, le document subsistant est bien trop partiel et l'histoire de l'abbaye trop mal connue pour que l'on puisse se prononcer. Dans le cas de la bibliothèque capitulaire et, notamment, des emprunts, il est vrai que l'extraordinaire attention portée par le chapitre à maints détails de la vie de la bibliothèque pourrait laisser penser que ces documents nous livrent, du moins pour les années où ils sont conservés, une vision quasi exhaustive du fonctionnement de la bibliothèque. Toutefois, on peut éventuellement se demander si le fait qu'aucun emprunt ne soit noté pour certains chanoines susceptibles d'utiliser la bibliothèque capitulaire n'est pas significatif: ne pourrait-on penser que seuls ont été mis par écrit les emprunts dont la restitution pouvait poser problème, soit du fait du rang de l'emprunteur auquel il était difficile d'adresser une réclamation, soit du fait de l'éloignement ou du caractère particulièrement gyrovague de certains chanoines partagés

622. On remarquera en effet que les testaments sont loin eux aussi de refléter la situation réelle des bibliothèques de chanoines: à plusieurs reprises les livres à partager entre les différents légataires ne sont pas mentionnés dans le testament mais dans des documents adjacents, susceptibles donc d'être plus aisément égarés.

623. Rouen, Arch. dép. Seine-Maritime, G 3433 (testament).

624. Rouen, Arch. dép. Seine-Maritime, G 2127, fol. 226v-227 (don) et G 3437 (testament); TABbaGH, 2008, p. 40, n. 75 et n. 77 , p. 41 et n. 87.

625. Rouen, Arch. dép. Seine-Maritime, G 3432 (testament).

626. Rouen, Arch. dép. Seine-Maritime, G 3436 (testament). 
entre plusieurs prébendes ou appelés ailleurs (à Paris, en Avignon ou ailleurs) pour le conseil du roi, du pape ou du régent anglais? On peut aussi imaginer que l'opposition souvent très vive entre l'archevêque et son chapitre a pu jeter la suspicion sur la plupart des familiers et officiers de l'archevêque que l'on retrouve en nombre parmi les emprunteurs notés dans les registres capitulaires (que l'on songe au nombre de décisions capitulaires concernant le prêt des clefs de la bibliothèque au pénitencier de l'archevêque, Johannes Fabri). On a parfois l'impression que tout se passe comme si le chapitre prêtait les livres bon gré, mal gré et s'empressait de mettre par écrit des prêts qu'il ne pouvait pas refuser, mais qu'il assortissait de conditions de plus en plus contraignantes. Il y aurait sûrement à prolonger la recherche pour vérifier, si faire se peut, ce qui n'est qu'une hypothèse fondée sur une impression.

Par ailleurs, si la circulation des livres à Rouen est bien réelle, elle ne s'effectue qu'à l'intérieur d'un cercle relativement fermé; certes, encore une fois, nombre de personnages cités dans les documents n'ont pu être identifiés, notamment parmi les acheteurs aux différentes ventes. Mais, pour ceux qui ont été identifiés (le plus grand nombre), ces ventes mettent précisément en lumière que ces échanges tournent dans l'ensemble en circuit fermé: le chapitre met en vente des ouvrages qui sont principalement (mais pas exclusivement) achetés par des chanoines, qui en légueront une partie (ou d'autres items) à la bibliothèque capitulaire. Là encore, il faudrait davantage approfondir la recherche pour mesurer si ces différents legs permettent ou non de renouveler la bibliothèque.

$\mathrm{Au}$-delà de leurs lacunes et des interrogations qu'ils suscitent, ces différents documents attestent la richesse des deux bibliothèques prises en compte. La personnalité de certains emprunteurs, leurs liens avec les milieux de pouvoir et de savoir montrent que les deux bibliothèques de Rouen constituaient un recours possible pour des personnages non dépourvus par ailleurs de possibilités. Et de fait, même s'il n'est guère possible d'identifier tous les textes cités et même si ces textes ne représentent qu'une infime partie des fonds conservés tant à Saint-Ouen qu'à Notre-Dame de Rouen, on retire l'impression d'une bibliothèque solide à Saint-Ouen et vivante à la cathédrale, où l'on peut mieux percevoir une ouverture aux nouveaux courants intellectuels (l'humanisme, notamment), comme aux nouveautés technologiques (l'imprimerie). Bien sûr, il s'agit d'une vue très partielle qui demande à être complétée.

Cette étude montre à l'évidence l'extraordinaire richesse des sources sur les bibliothèques de Rouen, sources dont le moindre mérite n'est pas de donner de précieuses informations sur des bibliothèques dont on ne connaissait quasiment rien (on pense en particulier à la bibliothèque cistercienne de Beaubec). Ces sources, pour peu qu'on en scrute tous les aspects ${ }^{627}$, constituent un apport

627. Cette enquête pourrait être prolongée dans diverses directions, par exemple, en analysant les informations que nous donnent les registres capitulaires sur la gestion des manuscrits de la bibliothèque capitulaire: ainsi on peut se demander si l'étiquette mentionnée sur les plats du livre prêté à Pierre Cauchon est une pratique généralisée à l'ensemble des volumes (Petrus Cauchon [emprunt par l'intermédiaire de Nicholaus Caval], puis [restitution], 1440, puis 1442). 
précieux à l'étude de la vie intellectuelle, non seulement de Rouen et de la Normandie, mais aussi d'un grand nombre d'acteurs de la vie politique et religieuse de la fin du XIV et du XV ${ }^{e}$ siècles.

Ces résultats, si partiels soient-ils, mettent en lumière l'intérêt d'exploiter plus systématiquement encore ce remarquable gisement de sources que représentent les registres de la bibliothèque capitulaire de Rouen.

\section{Bibliographie}

ANSTRuther, Roberto (éd.), Epistola Herberti de Losinga, primi episcopi Norwicensis, Osberti de Clara et Elmeri prioris Cantuariensis, nunc primum è codicibus mss. editæ à Roberto Anstruther, Bruxellis, A. Vandale (Scriptores monastici), 1846.

BEAUREPAIRE, Charles de, Inventaire sommaire des Archives départementales antérieures à 1790, Seine-Maritime (ex-Inférieure), Archives ecclésiastiques, sér. G, 2, Paris, P. Dupont, 1874 .

BeCKer, Gustav, Catalogi bibliothecarum antiqui, Bonn, M. Cohen, 1885.

Beltran, Evencio, "Continuité de l'humanisme français au $\mathrm{XV}^{e}$ siècle: l'exemple de Pierre de La Hazardière», in L'Aube de la Renaissance: études réunies par D. Cecchetti, L. Sozzi, L. Terreaux, Genève, Slatkine (Bibliothèque Franco Simone, 18), 1991, p. 123-136.

BeRNIER, Adhelm (éd. et trad.), Jehan Masselin, Journal des États généraux de France tenus à Tours en 1484, sous le règne de Charles VIII [...], publ. et trad. pour la première fois sur les mss inédits de la Bibliothèque du roi, Paris, Impr. royale, 1835.

BLAISE, Albert, Dictionnaire latin-français des auteurs du Moyen Âge = Lexicon latinitatis Medii Aevi, Turnhout, Brepols, 1975.

BondÉELle-Souchier, Anne, Bibliothèques cisterciennes dans la France médiévale: répertoire des abbayes d'hommes, Paris, Éd. du CNRS (Documents, Études et Répertoires, publiés par l'IRHT, 41; Histoire des bibliothèques médiévales, 6), 1991.

BoüARD, Michel de, «Le rôle de Simon du Bosc dans la politique française pendant le Grand Schisme d'Occident», in Jumièges, Congrès scientifique du XIII centenaire (Rouen, 10-12 juin 1954), I, Rouen, Lecerf, 1955, p. 85-88.

Boudet, Marcel, «Le prieuré de Beaulieu près Rouen », Revue des Sociétés savantes de Haute-Normandie, 34, 2, 1964, p. 7-25.

Bouveret (Bénédictins du), Colophons de manuscrits occidentaux des origines au XVI siècle, 5, Colophons signés P-Z (14889-18951), Fribourg (CH), Éd. universitaires (Spicilegii Friburgensis subsidia, 6), 1979.

Bozzolo, Carla et Ornato, Ezio, Pour une histoire du livre manuscrit au Moyen Âge. Trois essais de codicologie quantitative, Paris, Éd. du CNRS (Centre régional de publication de Paris), 1983.

BRÉQUIGNY, Louis Georges Oudard Feudrix de, Ordonnances des rois de France de la troisième race recueillies par ordre chronologique, 14, les Ordonnances depuis la vingt-cinquième année du règne de Charles VII, jusqu'à sa mort en 1461, Paris, Imprimerie royale, 1790. 
Catalogue des manuscrits en écriture latine portant des indications de date, de lieu ou de copiste publié sous la direction de C. Samaran et R. MARICHaL, Paris, Éditions du CNRS, 1-7, 1959-1984.

Cazelles, Raymond, Société politique, noblesse et couronne sous Jean le Bon et Charles $V$, Genève, Paris, Droz (Mémoires et documents publiés par la Société de l'École des chartes, 28), 1982.

Chéruel, Adolphe, Histoire de Rouen pendant l'époque communale: 1150-1382, suivie de pièces justificatives, publiées pour la première fois d'après les archives départementales et municipales de cette ville, 1-2, Rouen, N. Périaux, 1843-1844.

Clark, John Willis, The care of books: an essay on the development of Libraries and their fittings, from the earliest times to the end of the eighteenth century, $2^{\text {nd }} \mathrm{ed}$., Cambridge, Cambridge University Press, 1902; réimpr. London, Variorum Reprints, 1975; en ligne: http://www.gutenberg.org/files/26378/26378-h/26378-h. htm.

Costé, Alain, «L'œuvre scientifique de Nicole Oresme», Bulletin de la Société historique de Lisieux, fasc. 37, janvier 1997; en ligne: http://www.math.unicaen.fr/lmno/ Oresme/Oresme.html.

CBMLC $=$ Corpus of British Medieval Library Catalogues, t. 1-14, Richard SHARPE et alii (éd.), London, The British library in association with the British Academy, 1990- en cours de publication.

CBMLC, 3, $1992=$ The libraries of the Cistercians, Gilbertines and Premonstratensians, ed. by D. N. Bell, Londres, British library, in assoc. with the British Academy (Corpus of British Medieval Libraries Catalogues, 3), 1992.

CBMLC, 4, 1996 = English Benedictine libraries. The shorter catalogues, R. SHARPE, J. P. Carley, R. M. Thompson, A. G. Watson (éd.), Londres, British library, in assoc. with the British Academy (Corpus of British Medieval Libraries Catalogues, 4), 1996.

CBMLC, 9, 2001 = Syon abbey, Vincent GILLESPIE (éd.), with the libraries of the Carthusians, A. I. Doyle (éd.), Londres, British library, in assoc. with the British Academy (Corpus of British medieval library catalogues, 9), 2001.

CBMLC, 11, 2004 = Henry of Kirkestede, Catalogus de libris autenticis et apocrifis, Richard H. and Mary A. Rouse (éd.), Londres, British library, in assoc. with the British Academy (Corpus of British medieval library catalogues, 11), 2004.

CGM in- $8^{\circ}, 1,1886=$ Catalogue général des manuscrits des bibliothèques publiques de France, sér. in-8 ${ }^{\circ}$, t. 1, par Henri OMONT, Paris, Plon, 1886.

DBF, 17,1989 = Dictionnaire de biographie française, Michel Prevost, Jean-Charles Roman D’Amat, Henri Tribout de Morembert (dir.), 17, Guérout-LapalièreHumann, Paris, Letouzey et Ané, 1989, col. 631, $\mathrm{n}^{\circ} 33$.

DHGE, 23, 1990 = Dictionnaire d'histoire et de géographie ecclésiastiques, Roger AuBERT (dir.), 23, Haegy-Herlemundus, Paris, Letouzey et Ané, 1990, col. 332, $\mathrm{n}^{\circ} 5$.

DHGE, 25, 1995 = Dictionnaire d'histoire et de géographie ecclésiastiques, Roger AuBERT (dir.), 25, Hubert-Iriarte Estañán, Paris, Letouzey et Ané, 1995.

DTC, 2, 1937 = Dictionnaire de droit canonique, 2: Baccalauréat-cathedraticum, Raoul Naz (dir.), Paris, Letouzey et Ané, 1937. 
DAIREAux, Christiane, «Les divers périls auxquels ont échappé, au cours des siècles, les archives du chapitre de la cathédrale de Coutances", in Chapitres et cathédrales de Normandie, Sylvette Lemagnen et Philippe Manneville (dir.), Actes du $31^{\mathrm{e}}$ congrès (Bayeux, 16-20 octobre 1996), Caen, Musée de Normandie (Annales de Normandie - Série des Congrès des société historiques et archéologiques de Normandie, 2), 1997, p. 91-96.

Delalain, Paul, Étude sur le libraire parisien du XIII a au XV siècle, d'après les documents publiés dans le cartulaire de l'Université de Paris, Paris, Typographie de Delalain fr., 1891.

Deliste, Léopold, «Documents sur les livres et les bibliothèques au Moyen Âge», Bibliothèque de l'École des chartes, sér. 3, 1, 1849, p. 216-231, en particulier «IV. Du prêt des livres dans l'abbaye de Saint-Ouen, sous Charles V» (édition p. 227-230 et analyse).

Delisle, Léopold (éd.), Mandements et actes divers de Charles V, 1364-138o, recueillis dans les collections de la Bibliothèque nationale, Paris, Imprimerie nationale, 1874.

Denifle, Henri, Chatelain, Émile, Chartularium Universitatis Parisiensis, t. II, ab anno 1286 usque ad annum 1350, Paris, fr. Delalain, 1891, réimpr. Bruxelles, Culture et civilisation, 1964.

Denifle, Henri, Chatelain, Émile, Chartularium Universitatis Parisiensis, t. III, ab anno 1350 usque ad annum 1394, Paris, fr. Delalain, 1894, réimpr. Bruxelles, Culture et civilisation, 1964.

Dictionnaire topographique du Département de Seine-Maritime [...] élaboré [...] par Charles de Beaurepaire [...] revu, complété, entièrement refondu et publié par dom Jean Laporte et al., 1, $A$ à G, 2, $H$ à $Z$, Paris, Bibliothèque nationale, 1982, Paris, CTHS, 1984.

Dictionary of medieval Latin from British sources, Londres, Oxford, University Press for the British Academy, fasc. 1, A-B, 1975; fasc. 2, C, 1981.

DolbeAu, François, «Quelques aspects des relations entre bibliothèques d'établissements religieux (XII ${ }^{\mathrm{e}}-\mathrm{XV}^{\mathrm{e}}$ siècles)», in Naissance et fonctionnement des réseaux monastiques et canoniaux, Actes du premier colloque international du CERCOR (Saint-Étienne, 16-18 septembre 1985), Nicole Bouter (dir.), Saint-Étienne, Publications de l'Université de Saint-Étienne (CERCOR, Travaux et recherches, 1), 1991, p. 495-509.

Dubois, Henri (dir.), Un censier normand du XIII siècle: le Livre des Jurés de l'abbaye Saint-Ouen de Rouen, Paris, CNRS Éditions (Documents, Études et Répertoires, publiés par l'IRHT, 62), 2001.

Ernouf, Alfred-Auguste, baron, «Catalogue de vente d'une bibliothèque du XV ${ }^{e}$ siècle», Bulletin du bibliophile, 1878, p. 75-82; transcr. en ligne dans le billet de blog de J.-L. Deuffic (3 janvier 2012), «Plus que toutes» : sur quelques manuscrits de Jean Blosset, grand sénéchal de Normandie ( 4 mai 1531).

Fasti ecclesiae gallicanae. Répertoire prosopographique des évêques, dignitaires et chanoines de France de 1200 à 150o, 2, Diocèse de Rouen, Vincent TabBaGH (dir.), Turnhout, Brepols, 1998.

Fasti ecclesiae gallicanae. Répertoire prosopographique des évêques, dignitaires et chanoines de France de 1200 à 1500, 9, Diocèse de Sées, par Pierre Desportes, Jean-Pascal Foucher, † Françoise Loddé, Laurent Vallière, Turnhout, Brepols, 2005. 
FÉLIX, Julien, Inventaire de Pierre Surreau, receveur général de Normandie, suivi du testament de Laurens Surreau et de l'inventaire de Denise de Foville, Rouen, Paris (Société de l'histoire de Normandie. Documents $d u X V^{e}$ siècle), 1892; en ligne: http://archive.org/stream/inventairedepieoosurrgoog\#page/n7/mode/2up.

Formeville, Henri, Notice historique sur l'ancien évêché-comté de Lisieux (1 $1^{\text {re }}$ partie), Caen, Typographie F. Le Blanc-Hardel, 1871, 38 p. (Extrait des Mémoires de la Société des Antiquaires de Normandie, $3^{e}$ série, $t$. XXVIII.); en ligne: http://www. bmlisieux.com/normandie/evecheo1.htm.

Fouré, André, abbé, «Jehan Masselin, doyen du chapitre de Rouen, 1433-1500 », Revue des sociétés savantes de Haute-Normandie, 66, 2, 1972, p. 15-29.

FourNier, Gilbert, «Listes, énumérations, inventaires. Les sources médiévales et modernes de la Bibliothèque du Collège de Sorbonne (première partie: Les sources médiévales)», Scriptorium, 64, 2011, 1, p. 158-215.

Gallia Christiana, in provincias ecclesiasticas distributa [...] operâ \& studio monachorum Congregationis S. Mauri ordinis S. Benedicti, tomus undecimus: de provincia Rotomagensi [...], Parisiis, 11, Ex typographia regia, 1759.

Gaussin, Pierre-Roger, «Les conseillers de Charles VII (1418-1461). Essai de politologie historique», Francia, 10, 1982, p. 67-130.

Gazeau, Véronique, Normannia monastica, 2. Prosopographie des abbés bénédictins ( $X^{e}$-XII ${ }^{e}$ siècles), Caen, Publications du CRAHM, 2007.

Gibson, Margaret, Lanfranc of Bec, Oxford, Clarendon Press, 1978.

Glorieux, Palémon, Répertoire des maîtres en théologie de Paris au XIII siècle, 1-2, Paris, J. Vrin (Études de philosophie médiévale, 17), 1933.

Glorieux, Palémon, Aux origines de la Sorbonne, I, Robert de Sorbonne. L'homme, le collège, les documents, Paris, J. Vrin (Études de philosophie médiévale, 53), 1966.

Gorochov, Nathalie, Le collège de Navarre, de sa fondation (1305) au début du XVI siècle (1418), Paris, H. Champion (Études d'histoire médiévale, 1), 1997.

Gousset, Marie-Thérèse, «Libraires d'origine normande à Paris au XIVe siècle», in Manuscrits et enluminures dans le monde normand ( $X^{e}-X V^{e}$ siècles), Actes du colloque de Cerisy-la-Salle, 1995, Pierre Bouet et Monique Dosdat (dir.), Caen, Presses universitaires de Caen, 1999, $2^{\mathrm{e}}$ éd., Caen, Office universitaire d'études normandes, Université de Caen, Presses universitaires de Caen, 2005, p. 169-18o.

LABorde, Léon de, «Étude sur la bibliothèque de la cathédrale de Rouen, le Portail des Libraires, les commencements de l'imprimerie à Rouen», textes et notes revus par le chanoine Porrée et l'abbé F. Blanquart, Bulletin du Bibliophile, 1919, (TAP, p. 5-83).

La Curne de Sainte-Palaye, Jean-Baptiste, Dictionnaire historique de l'ancien langage françois, t. I, $A-A o$, Paris, Niort, Favre, 1875.

LAffitte, Marie-Pierre, «La librairie de Georges d'Amboise à Gaillon», in Léonard de Vinci entre France et Italie, "miroir profond et sombre», Actes du colloque international de l'Université de Caen (3-4 octobre 1996), Silvia Fabrizio-Costa et Jean-Pierre Le Goff (dir.), Caen, Presses universitaires de Caen, 1999, p. 261-273.

Laffitte, Marie-Pierre, "La librairie de Monseigneur": contenu et aménagements de la bibliothèque de Gaillon", in Au seuil de la Renaissance. Le cardinal Georges d'Amboise (1460-1510), Actes du colloque Georges d'Amboise, l'homme et son œuvre (Rouen, 8 au 9 octobre 2010), Jean-Pierre Chaline (dir.), Rouen, Société d'histoire de Normandie, 2012, p. 139-158. 
Laffitte, Marie-Pierre, "Georges d'Amboise et les livres», in Georges I ${ }^{\text {er }}$ d'Amboise (1460-1510), une figure plurielle de la Renaissance, Colloque international (2-3 décembre 2010), Rennes, Presses universitaires de Rennes, 2013, p. 189-198.

LANGlois, Pierre, Recherches sur les bibliothèques des archevêques et du chapitre de Rouen, Rouen, Fleury, Lebrument, 1853 (tiré-à-part extrait du Précis de l'Académie des Sciences Belle-Lettres et Arts de Rouen, 1851-1852).

Lechat, Jean-Baptiste, abbé, «Répertoire des archives de l'évêché de Coutances», in Actes $d u$ 81 ${ }^{e}$ Congrès national des Sociétés savantes, Rouen-Caen, 1956, Paris, Impr. Jemmapes, 1956, p. 19-48.

Lestrange, Henry, comte de, Inventaire et vente des biens meubles de Guillaume de Lestrange, archevêque de Rouen... mort en 1389, Paris, A. Picard, 1888.

Masson, André, «Le mobilier et la décoration de la bibliothèque de Cîteaux», Bulletin monumental, 122, 1964, p. 59-68.

Menut, Albert Douglas (éd.), Nicole Oresme, Le Livre de Yconomique d'Aristote: critical edition of the French text from the Avranches manuscript with the original Latin version, éd. Philadelphia, American Philosophical Society (Transactions of the American philosophical society, N.S., vol. 47, part 5), 1957.

Menut, Albert Douglas (éd.), Nicole Oresme, Le Livre de Politiques d'Aristote: published from the text of the Avranches manuscript 223, ed. Philadelphie, American Philosophical Society (Transactions of the American philosophical society, N.S., vol. 6o, part 6), 1970.

Michel, Francisque, Chronique des abbés de Saint-Ouen, publiée pour la première fois [...], Rouen, É. Frère, 1840 ; en ligne: http://www.archive.org/stream/ chroniquedesabboomichgoog\#page/n4o/mode/1up.

Millet, Hélène, Les chanoines du chapitre cathédral de Laon, 1272-1412, Rome, École française de Rome, [Paris, diffusion de Boccard] (Collection de l'École française de Rome, 56), 1982.

Millet, Hélène, «Le cardinal Gilles des Champs (ca. 1350-1414)», in Les prélats, l'Église et la société: $X I^{e}-X V^{e}$ siècles: hommage à Bernard Guillemain, Françoise BériacLainé et Anne-Marie Dom (dir.), Bordeaux, Université Michel de Montaigne, CROCEMC, 1994, p. 231-241.

Millet, Hélène, «Comment mettre fin au Grand Schisme d'Occident? L'opinion des évêques et des chapitres de Normandie en 1398 ", in Chapitres et cathédrales de Normandie, Sylvette Lemagnen et Philippe Manneville (dir.), actes du $31^{\mathrm{e}}$ congrès (Bayeux 16-20 octobre 1996), Caen, Musée de Normandie (Annales de Normandie - Série des Congrès des sociétés historiques et archéologiques de Normandie, 2), 1997, p. 231-240.

Poulle, Emmanuel et Millet, Hélène (éd.), Le vote de la soustraction d'obédience en 1398. Tome I, Introduction, édition et fac-similés des bulletins du vote, Paris, CNRS Éd. (Documents, Études et Répertoires, publiés par l'IRHT, 36), 1988.

Mouradian, Georges, Roquelet, Alain, Répertoire numérique des Archives départementales antérieures à 179o, Seine-Maritime, Archives ecclésiastiques, série $H$, t. IV (fasc. 2), Abbaye de Saint-Ouen de Rouen (14 H 927 à 14 H 1534), par Georges Mouradian; introduction et index général, par Alain Roquelet, Rouen, Imprimerie administrative, 1980 . 
Monstier, Arthur du, Neustria pia seu de omnibus et singulis abbatiis et prioratibus totius Normaniae, Rothomagi, J. Berthelin, 1663; en ligne: http://gallica.bnf.fr/ ark:/12148/bpt6k114546q.

Muratova, Xenia, "Le bestiaire médiéval et la culture normande», in Manuscrits et enluminures dans le monde normand ( $X^{e}-X V^{e}$ siècles), Actes du colloque de Cerisyla-Salle, 1995, Pierre Bouet et Monique Dosdat (dir.), Caen, Presses universitaires de Caen, 1999, $2^{\mathrm{e}}$ éd., Caen, Office universitaire d'études normandes, Université de Caen, Presses universitaires de Caen, 2005, p. 151-166.

Neveux, François, «Nicole Oresme et le clergé normand au XIV siècle», in Autour de Nicole Oresme, Actes du Colloque Oresme organisé à l'Université de Paris XII; Jeannine Quillet (éd.), Paris, Vrin (Bibliothèque d'histoire de la philosophie), 199o, p. 9-36; partiellement en ligne: www.vrin.fr/html/main.htm?action=loadbook\& isbn=2711610179.

Neveux, François, Bayeux et Lisieux, villes épiscopales de Normandie à la fin $d u$ Moyen Âge, Caen, Édition du Lys, 1996.

Niermeyer, Jan Frederick, Mediae latinitatis Lexicon minus, Leiden, E. J. Brill, 1976, réimpr. 1984.

Nortier, Geneviève, Les bibliothèques médiévales des abbayes bénédictines de Normandie: Fécamp, le Bec, le Mont Saint-Michel, Saint-Évroult, Lyre, Jumièges, Saint-Wandrille, Saint-Ouen, Caen, Impr. Caron, 1966.

Ornato, Ezio, La face cachée du livre médiéval. L'histoire du livre vue par Ezio Ornato, ses amis et ses collègues, Rome, Viella (I libri di Viella, 10), 1997.

Pecia, Blog consacré au manuscrit médiéval, par Jean-Luc Deuffic; en ligne: http:// blog.pecia.fr/.

Peyrafort-Huin, Monique, «Un puzzle multiséculaire: jalons pour reconstituer la bibliothèque clermontoise de Saint-Allyre (premier volet)», in Parva pro magnis munera. Études de littérature tardo-antique et médiévale offertes à François Dolbeau par ses élèves, Monique Goullet (dir.), Turnhout, Brepols, 2009 (Instrumenta patristica et mediaevalia, 51), p. 75-118.

Peyrafort-Huin, Monique, «Les inventaires de bibliothèques normandes: un dossier de sources à reprendre», in L'Historiographie médiévale normande et ses sources antiques, Actes du colloque de Cerisy, 2009, Marie-Agnès Lucas-Avenel, Pierre BAuduin (éd.), Caen, Presses universitaires de Caen, sous presse.

Pommeraye, François, Histoire de l'abbaye royale de S. Ouen de Rouen, divisée en 5 livres [...] le tout recueilly [...] par un religieux bénédictin de la Congrégation de Saint Maur [François Pommeraye], Rouen, R. Lallemant, 1662; en ligne: http://books. google.fr/books?id=gBIXC $3 \mathrm{hZ}_{3} \mathrm{MgC} \&$ printsec $=$ frontcover $\# \mathrm{v}=$ onepage $\& \mathrm{q} \& \mathrm{f}=$ false .

Pommerol, Marie-Henriette Jullien (de), «Le prêt des livres à la fin du Moyen Âge (XIII ${ }^{\mathrm{e}}-\mathrm{XV}^{\mathrm{e}}$ siècles) », in Du copiste au collectionneur. Mélanges d'histoire des textes en l'honneur d'André Vernet, Donatella Nebbiai-Dalla Guarda et Jean-François Genest, Turnhout, Brepols (Bibliologia, 18), 1998, p. 339-374.

Pommerol, Marie-Henriette Jullien (de) et Monfrin, Jacques (éd.), Bibliothèques ecclésiastiques au temps de la Papauté d'Avignon. II. Inventaires de prélats et de clercs français, Paris, CNRS Éditions (Documents, études et répertoires publiés par l'Institut de recherche et d'histoire des textes, 61; Histoire des bibliothèques médiévales, 12), 2001. 
Powitz, Gerhardt, «Libri inutiles in mittelalterlichen Bibliotheken: Bemerkungen über Alienatio, Palimpsestierung und Makulierung», in La conservation des manuscrits et des archives au Moyen Âge, XI ${ }^{\mathrm{e}}$ colloque du CIPL, Bruxelles, 1995; actes éd. par P. Bourgain et A. Derolez (= Scriptorium, 50, 2, 1996), p. 288-304.

QUÉTIF, Jacques, EchARD, Jacques, Scriptores ordinis Praedicatorum recensiti, notisque historicis et criticis illustrati, Tomus primus: Notitia ordinis qualis fuit ab initio ad an. MD, Fac-simile, Torino, Bottega d'Erasmo, 1961.

Rouse, Richard H. et Rouse, Mary A., "La bibliothèque du collège de Sorbonne », in Histoire des bibliothèques médiévales, 1 , Les bibliothèques médiévales du VIe siècle à 1530, André VERNET (dir.), Paris, 1989, p. 113-123.

Schмiтt, Franciscus Salesius, S. Anselmi Cantuariensis archiepiscopi Opera omnia, III, [...] Franciscus Salesius Schmitt, Edinburgi, apud T. Nelson et filios, 1946.

Taвbagh, Vincent, Le clergé séculier du diocèse de Rouen à la fin du Moyen Âge (13591493), thèse pour le doctorat d'État, dir. J. Heers, Université de Paris IV, 1988.

TAввAGH, Vincent, «Survivre par l'écrit chez les ecclésiastiques rouennais du XV $\mathrm{XV}^{\mathrm{e}}$ siècle», Tabularia «Études», 8, 2008, p. 25-44.

Toscano, Gennaro, «La librairie du château de Gaillon: les manuscrits enluminés d'origine italienne acquis par le cardinal Georges d'Ambroise », in Léonard de Vinci entre France et Italie, "miroir profond et sombre ", Actes du colloque international de l'Université de Caen (3-4 octobre 1996), Silvia FABrizio-Costa et Jean-Pierre Le Goff (dir.), Caen, Presses universitaires de Caen, 1999, p. 275-290.

Toscano, Gennaro, «Le cardinal Georges d'Amboise (1460-1510) collectionneur et bibliophile", in Les cardinaux de la Renaissance et la modernité artistique, Frédérique Lemerle, Yves Paunels et Gennaro Toscano (dir.), Villeneuve d'Ascq, IRHiS-Institut de Recherches Historiques du Septentrion (Histoire et littérature de l'Europe du Nord-Ouest), 2009, p. 51-88.

VAGENHEIM, Ginette, «Sources pour l'histoire de la libraria ecclesiae rothomagensis: l'inventaire des livres de Robert de Croismare, archevêque de Rouen (1482-1493) dans les registres capitulaires de la cathédrale», La Bibliofilía, 113, 1, 2011, p. 7-21.

Valois, Noël, La France et le Grand Schisme d'Occident, 2-3, Paris, A. Picard, 1896-1901.

VAn MoÉ, Émile, «Les Éthiques, Politiques et Économiques d'Aristote, traduits par Nicole Oresme, manuscrit de la Bibliothèque de la ville de Rouen », Les Trésors des bibliothèques de France, fasc. IX, 1929, p. 3-15.

VENARD, Marc, «Les livres chez les chanoines de Rouen (1500-1650)", Revue d'histoire de l'Église de France, 83, $\mathrm{n}^{\circ}$ 210, 1997, p. 133-143 (= Livres et culture du clergé à l'époque moderne, colloque de Marseille, 1995).

Vielliard, Jeanne, avec la collab. de Pommerol, Marie-Henriette Jullien de (éd.), Le registre de prêt de la bibliothèque du collège de Sorbonne [1402-1536]. Diarium Bibliothecae Sorbonae. Paris, Mazarine, ms 3323, Paris, CNRS Éditions (Documents, études et répertoires publiés par l'Institut de recherche et d'histoire des textes, 57; Histoire des bibliothèques médiévales, 8), 2000.

WALLER, Katharine, «Rochester cathedral library. An English book collection based on Norman models», in Les Mutations socio-culturelles au tournant des XI ${ }^{e}$-XII ${ }^{e}$ siècles, études anselmiennes (IV ession), colloque [...] (Le Bec Hellouin, 1982), Paris, Éditions du CNRS (Colloques internationaux du CNRS), 1984, p. 237-250. 


\section{Et pour les textes:}

BHM, $1 \mathrm{~A}, 2,3 \mathrm{~A}=$ Lambert, Bernard, Bibliotheca hieronymiana manuscripta: la tradition manuscrite des cuvres de saint Jérôme, 1 A-4 B. Steenbrugis, in abbatia Sancti Petri, Hagae Comitis, Martinus Nijhoff (Instrumenta patristica, IV), 1969-1972.

CPG, 1-2 (1983-1974) = Clavis Patrum Graecorum, 1, Patres antenicaeni, 2, Ab Athanasio ad Chrysostomum, cura et studio Mauritii Geerard, Turnhout, Brepols, 1983, 1974.

$C P L=$ Clavis Patrum Latinorum, éd. $3^{\text {a }}$ aucta et emendata, Steenbrugge, in abbatia Sancti Petri, Turnhout, Brepols (Corpus Christianorum. Series latina), 1995.

CSEL, 13 = Cassiani opera : Collationes XXIII, ed. Michael Petschenig; ed. altera supplementis aucta, cur. Gottfried Kreuz, Wien, Verlag der Österreichischen Akademie der Wissenschaften (Corpus scriptorum ecclesiasticorum latinorum, 13), 2004

CSEL, 17 = Cassiani opera $:$ De institutis coenobiorum, De incarnatione contra Nestorium, ed. Michael Petschenig; ed. altera supplementis aucta, cur. Gottfried Kreuz, Wien, Verlag der Österreichischen Akademie der Wissenschaften (Corpus scriptorum ecclesiasticorum latinorum, 17), 2004.

Gorman, Michael M. (éd.), Isidorus episcopus Hispalensis, Expositio in Vetus Testamentum, Genesis: textum ad fidem codicum antiquiorum restituit M. Gorman; fontes... detexerunt M. Dulaey et Michael M. Gorman, Freiburg im Breisgau, Herder (Vetus latina... Aus der Geschichte der Lateinischen Bibel, 38) 2009.

HaIn, Ludovicus, Repertorium bibliographicum, in quo libri omnes ab arte typographica inventa usque ad annum MD typis expressi..., II, 1, Milano, Görlich, 1948.

In Principio Online - 11 (2013), Turnhout, Brepols, 2013; en ligne: http://www.brepolis. net/BRP_Info_En.html?show=info.

Jullien, Marie-Hélène et Perelman, Françoise (éd.), Clavis des auteurs latins $d u$ Moyen Âge, territoire français, 735-987, t. I, Abbon de Saint-Germain - Ermold le Noir, Turnhout, Brepols (Corpus christianorum. Continutio Mediaevalis), 1994.

$P L, 83=$ Patrologiae cursus completus [...] accurante J.-P. Migne, t. 83, Petit-Montrouge, J.-P. Migne, 1862.

PL, 192 = Patrologiae cursus completus [...] accurante J.-P. Migne, t. 192, Parisiis, Garnier fr. et J.-P. Migne, 1880 .

Renouard, Philippe, Inventaire chronologique des éditions parisiennes du XVI siècle, II, 1511-1520, Paris, Imprimerie municipale (Histoire générale de Paris), 1977.

Reynolds, Leighton D. (éd.), Texts and transmission: a survey of the Latin classics, Oxford, Clarendon Press, 1982.

Rockinger, Ludwig (ed.), Briefsteller und Formelbücher des eilften bis vierzehnten Jahrhunderts, München 1863, réimpr. New York, B. Franklin (Burt Franklin research \& Source work series, 10), 1961.

SCHNEYER, Johannes Baptist, Repertorium der Lateinischen Sermones des Mittelalters, für die Zeit von 1150-1350, Münster Westfalen, Aschendorffsche Verlagsbuchhandlung (Beiträge zur Geschichte der Philosophie und Theologie des Mittelalters, Bd. 43, Heft 1-5): Autoren E-H, 1970; Autoren I-J, 1971; Autoren L-P, 1972; Autoren R-Schluss [W], 1973. 
Schulte, Johann Friedrich von, Die Geschichte der Quellen und Literatur des canonischen Rechts, II, Von Papst Gregor IX. bis zum Concil von Trient, Stuttgart, F. Enke, 1877, réimpr. Graz, Akademische Druck-u. Verlagsanstalt, 1956.

SHARPE, Richard, A handlist of the Latin writers of Great Britain and Ireland, before 1540, Tunhout, Brepols (Publications of the Journal of medieval latin, 1), 1997.

ShARPE, Richard, Corpus of British medieval Library catalogues, List of identifications, 3rd ed., London, British Medieval Library Catalogues Committee, 1999; mise à jour, 2013; publication électronique : http://www.history.ox.ac.uk/faculty/staff/ profile/sharpe/research.html.

Sources Chrétiennes, 264 = Irénée de Lyon, Contre les hérésies, livre I: éd. critique par Adelin Rousseau et Louis Doutreleau, t. II: texte et traduction, Paris, Éditions du Cerf (Sources chrétiennes, 264), 1979.

Sources Chrétiennes, 153 = Irénée de Lyon, Contre les hérésies, livre V: éd. critique par Adelin Rousseau, Louis Doutreleau et Charles Mercier, $t$. II: texte et traduction, Paris, Éditions du Cerf (Sources chrétiennes, 153), 1969.

SPRINGer, Carl P. E.,The manuscripts of Sedulius : a provisional handlist, Philadelphia, American Philosophical Society (Transactions of the American Philosophical Society, 85, 5), 1995.

Stegmüller, Fridericus (éd.), Repertorium biblicum Medii Aevi, Matriti, Consejo Superior de Investigaciones Científicas, Instituto Francisco Suárez, t. 2-5, Auctores, $A-Z, 1950-1955$.

STEgmülleR, Fridericus, Repertorium commentariorum in Sententias Petri Lombardi, 1, Textus, 2, Indices, Herbipoli (Würzburg), F. Schoningh, 1947.

Tholomeus von Lucca, Historia ecclesiastica nova, nebst Fortsetzungen bis 1329, hrsg. von Ottavio Clavuot, nach Vorarbeiten von Ludwig Schmugge, Hannover, Hahnsche Buchhandlung, 2009 (MGH, Scriptores, 39).

Torrell, Jean-Pierre, Initiation à saint Thomas d'Aquin. Sa personne et son cuvre, Fribourg (CH), Éditions universitaires, Paris, Éditions du Cerf (Vestigia, 13), 1993.

Van Praet, Joseph, Catalogue des livres imprimés sur vélin de la Bibliothèque du Roi, 1-5, Paris, de Bure fr., 1822-1828. 


\section{Annexe 1}

Table des documents pris en compte dans l'étude

Dans cette première table, sont indiqués:

- le nom de la personne morale ou physique,

- le type d'acte mentionné (vente, achat, emprunt, prêt, restitution...),

- la date, réduite au millésime, sauf en cas d'ambiguïé,

- la cote du document (dans la quasi totalité des cas, il s'agit d'un document conservé aux Archives départementales de la Seine-Maritime; seuls ont donc été indiqués les autres dépôts),

- les références à l'édition utilisée ou la mention de la transcription ; «transcr. IRHT, MPH» fait référence à des transcriptions effectuées pour l'IRHT par l'auteur de cet article.

La «clef» des documents, utilisée en particulier dans les notes en bas de page, est constituée par le nom des personnes associé à la date (ces éléments sont indiqués en caractères gras).

Dans le cas de certaines ventes, le nom des acheteurs (et, parfois même, celui de la personne qui s'est portée acquéreur, sans succès) a également été indiqué.

Les références sont classées par ordre alphabétique des noms de personnes, c'est-à-dire de «clefs».

Amfreville/Anfreville ${ }^{628}$ (prêt à), 1396: G 2119, fol. 67v; éd. LABORDE, 1919, n. $2, \$ 2$, p. 47 .

Beaubec, Saint-Laurent et Notre-Dame, O. Cist. (mise en gage), 1486: G 2143, f. $145-145 \mathrm{~V}$; transcr. IRHT, MPH.

Caen, abbé et couvent (non identifiés) (emprunt), 1379: G 2118, f. 68v; transcr. IRHT, MPH.

Egidius de Campis

- (emprunt), 1400 (n. st.) : G 2119, fol. 122v; éd. part. LABORDE, 1919, n. 5, p. 45.

- (restitution), puis Guillelmus Gorren (emprunt), 1406: G 2120, fol. 78 ; transcr. IRHT, MPH.

- (restitution), puis Guillelmus Gorren (emprunt), 1413: G 2121, fol. 115v; transcr. IRHT, MPH.

Guillelmus, abbé de Beaubec (échange), 1470: Troyes, MAT, ms 1549, fol. 113; éd. Bouveret, 1979, $\mathrm{n}^{\circ}$ 15585; Dolbeau, 1991, n. 43, p. 502.

628. Sans doute Saint-Pierre d'Amfreville-les-Champs (plutôt que Amfreville-la-Mi-Voie?); dép. Seine-Maritime, cant. Doudeville. 


\section{Guillelmus de Deserto}

- (don/legs), 1466 (n. st.), 14 février: G 2137, fol. 21v; transcr. IRHT, $\mathrm{MPH}$.

- (emprunt), 1466, 13 novembre: G 2137, fol. 72; transcr. IRHT, MPH.

- (restitution aux exécuteurs testamentaires du duc de Bedford), 1470: G 2138, fol. 156; transcr. IRHT, MPH.

Guillelmus de Estoutevilla, miles (paiement), 1422 (n. st.): G 2123, fol. XXVI (25); éd. LABORDE, 1919, n. 1, \$2, p. 61.

Guillelmus Gorren (restitution), 1416: G 2122, fol. 14v-15; éd. LABORDE, 1919, n. 4, p. $60-61$.

Guillelmus Le Brument (emprunt par l'intermédiaire de Ludovicus de Groussy, puis restitution), 1488 (n. st.), 3 mars, puis juin: G 2143 fol. 290, puis G 2144 fol. 17; éd. et ind. Vagenheim, 2011, p. 14 (avec la date de 1487 en ancien style).

\section{Guillelmus de Lestrange}

- (vente), 1389: G 9, fol. 11a; éd. Lestrange, 1888, p. 60.

- (vente), abbé de Valmont (achat), 1389: G 9, fol. 5a; éd. Lestrange, 1888, p. 26.

- (vente), Elias de Lestrange (achat), 1389: G 9, fol. 5a; éd. Lestrange, 1888, p. 27; G 9, fol. 11a; éd. Lestrange, 1888, p. 60-61 et p. 61.

- (vente), Guido Rabaschier (achat), 1389: G 9, fol. 5a; éd. Lestrange, 1888 , p. 26.

- (vente), Guido Rabaschier (acquéreur) et Huguelin de Morant (achat), 1389: G 9, fol. 5a; éd. Lestrange, 1888, p. 26-27.

- (vente), Johannes Ysebarre (achat), 1389: G 9, fol. 5a; éd. Lestrange, 1888 , p. 26.

- (vente), Johannes Ysebarre (acquéreur) et Elias de Lestrange (achat), 1389: G 9, fol. 5a; éd. Lestrange, 1888, p. 26.

- (vente), neveux (achat), 1389: G 9, fol. 11a; éd. Lestrange, 1888, p. 61.

Guillelmus Roussel

- (emprunt et restitution), 1470 (n. st.), 14 mars, puis 1470, 10 août: G 2138, fol. 111; transcr. IRHT, MPH.

- (emprunt et mise en gage, puis legs), 1470 (n. st.), 9 avril: G 2138, fol. 114v; transcr. IRHT, MPH.

\section{Henricus de Fiscano}

- (emprunt), 1399: G 2119, fol. 118v; éd. Laborde, 1919, n. 1, § 4, p. 44-45; éd. Vagenheim, 2011, p. 9.

- (restitution), puis Nicholaus Le Couete/Couette (emprunt), 1401: G 2119, fol. 156v; éd. Laborde, 1919, n. 1, p. 45.

Henricus Gorren (restitution), 1438 (n. st.): G 2128, fol. 106v; éd. LAbORDE, 1919 , n. 4, p. 62-63. 


\section{Hugo Lenvoisie}

- (emprunt), 1389: G 2117, fol. 78v; éd. Laborde, 1919, n. 1, \$ 2, p. 44.

- (restitution), 1414: G 2121, fol. 124V; éd. LANGLois, 1853, p. 17 (éd. des seuls titres); éd. Laborde, 1919, n. 3, p. 60.

Johannes Bureau, 1451 (n. st.): G 2134, fol. 42v; ind. Beaurepaire, 2, 1874, p. 227.

Johannes Deudemare, 1447 (n. st.) : G 2131, fol. 89; éd. LABOrde, 1919, n. 3, $\S 1-2$, p. 64-65.

Johannes des Essars / Essarts (paiement à), 1456 : G 2135, fol. 106 ; transcr. IRHT, $\mathrm{MPH}$.

Johannes Gilles (ou Egidius) (emprunt), 1379: G 2118, f. 77v; éd. LABORDE, 1919, n. $1, \$ 2$, p. 58 .

Johannes Gouel (emprunt et mise en gage), 1471: G 2138, fol. 230v; transcr. IRHT, MPH.

Johannes Le Sesne (vente de ses biens), 1474-1475: G 70, fol. 17; transcr. IRHT, $\mathrm{MPH}$.

Johannes Masselin (emprunt), 1480 (n. st.): G 2141, fol. 8; éd. LABORDE, 1919, n. 2 , p. $45-46$.

Johannes de Pontissera (restitution après sa mort), 1381: G 2118, fol. 103v; éd. LABORDE, 1919, n. $1, \S 3$, p. 58.

\section{Johannes Quatreul}

- (emprunt), 1466: G 2137, fol. 27v; transcr. IRHT, MPH.

- (emprunt), 1475: G 2139, fol. 205; transcr. IRHT, MPH.

Laurencius Surreau (emprunt et restitution), 1447 (n. st.) : G 2131, fol. 94v; éd. LABORDE, 1919, n. 3, \$3, p. 65.

Ludovicus Blosset (vente), Johannes Masselin (achat), 1489: G 3669; éd. Ernouf, 1878, p. 75-82 (avec des commentaires et quelques identifications).

\section{Ludovicus d'Harcourt}

- (emprunt), 1459: G 2135, fol. 226v; ind. BeAurepaire, 2, 1874, p. 231-233.

- (emprunt par l'intermédiaire de Robertus du Quesnay), 1479 (n. st.) : G 2140, fol. 172v; éd. VAGenheim, 2011, p. 14 (avec la date de 1478 en ancien style).

Magnavilla (Manneville)-la-Goupil ${ }^{629}$

- (prêt à), 1372: G 2115, f. 91; transcr. IRHT, MPH.

- (prêt à), 1391: G 2117, fol. 112; éd. LabORDE, 1919, n. 2, \$1, p. 46-47.

629. Saint-Jean Baptiste, puis la Sainte-Vierge de Magnavilla (Manneville)-la-Goupil; dép. SeineMaritime, cant. de Goderville. 
Martinus Pinard (emprunt, puis restitution par l'intermédiaire de Guillelmus de Liveto), 1443 (n. st.): G 2130, fol. 130v; transcr. IRHT, MPH.

\section{Michael Petit}

- (emprunt), 1492: G 2144, fol. 274; éd. Langlois, 1853, n. 3, p. 23 (sans indication de cote).

- (emprunt), 1494 (n. st.): G 2144, fol. 366v; transcr. IRHT, MPH.

Mont-Saint-Michel (dépôt), 1465: G 2137, f. 19v; éd. FéLIX, 1892: p. 214, nº IV.

Nicholaus Caval (emprunt), 1430: G 2126, fol. 35v; éd. LABORDE, 1919, n. 3, p. 62.

Nicholaus Couppequesne (emprunt, puis restitution), 1430, 4 août, puis 7 novembre: G 2126, fol. 35v; éd. LABORDE, 1919, n. 2, p. 62.

Nicholaus Dubois (de Bosco) (emprunt), 1456 (n. st.): G 2135, fol. 91v; transcr. IRHT, MPH.

\section{Nicholaus Oresme}

- (restitution), Petrus de Sihervilla (emprunt, puis restitution), 1370 (n. st.), puis 1370, 3 juin: G 2115, fol. 48 ; transcr. IRHT, MPH; ind. et éd. Beaurepaire, 2, 1874, p. 206-207 (éd. incomplète des seuls titres de livres).

- (restitution), Petrus Roger de Beaufort (emprunt), 1370 (n. st.) : G 2115, fol. 48 ; transcr. IRHT, MPH; ind. et éd. BEAUREPAire, 2, 1874, p. 206207 (éd. incomplète des seuls titres de livres).

Pasquerius de Vaux (emprunt par l'intermédiaire de Robertus Suttor et Petrus de Laigny, puis restitution), 1444, puis 1445: G 2130, fol. 188v et fol. 220v; éd. LABORDE, 1919, n. 1, $\$ 1$, p. 46.

Petrus Cauchon (emprunt par l'intermédiaire de Nicholaus Caval, puis restitution), 1440, puis 1442: G 2129, fol. 111; éd. LABORDE, 1919, n. 2, $\$ 2$ 2, p. 63.

Petrus Escoulant (ou Escoullant) (emprunt), 1480: G 2141, fol. 93; transcr. IRHT, MPH.

Petrus de Laigny (emprunt, puis restitution), 1439, puis 1442: G 2129, fol. 68v; transcr. IRHT, MPH.

Petrus de Sihervilla

- (emprunt), 1371: G 2115, fol. 76; transcr. IRHT, MPH.

- (emprunt), 1372: G 2115, fol. 88; transcr. IRHT, MPH.

- (restitution), Egidius de Campis (emprunt), 1382: G 2118, fol. 108v; ind. et éd. des seuls titres Beaurepaire, 2, 1874, p. 213.

- (restitution), Guillelmus Carrel (emprunt), 1382: G 2118, fol. 108v; ind. et éd. des seuls titres Beaurepaire, 2, 1874, p. 213.

- (emprunt), 1389: G 2117, fol. 66v; éd. LABORDE, 1919, n. 1, § 1, p. 44.

\section{Philippus d'Alençon}

- (paiement à), 1362 (n. st.): G 4422; transcr. IRHT, MPH. 
- (emprunt ou prêt), 1367: Vaticano (Città del), Archivio Segreto Vaticano, Registra Avenionensia, 161, fol. 310-314; éd. Pommerol, MONFrin, 2001, 368.2 B, p. 384-388.

Radulphus Roussel (emprunt), 1443: G 2130, fol. 163; éd. LABORDE, 1919, n. 1, p. 64.

Ricardus Piel (emprunt), 1372: G 2115, fol. 88; transcr. IRHT, MPH.

Robertus du Quesnay (emprunt et mise en gage, puis restitution), 1471 (n. st.), 14 mars, puis 19 décembre: G 2138, fol. 137; transcr. IRHT, MPH.

Rouen, Notre-Dame, cathédrale, Maîtrise des enfants de chœur (prêt à), 1399: G 2119, fol. 112; transcr. IRHT, MPH.

\section{Rouen, Notre-Dame, chapitre}

- (estimation), 1370: G 2115, fol. 61; transcr. IRHT, MPH.

- (vente), 1399, 2 novembre: G 2119, fol. 120 ; éd. LABORDE, 1919, p. 35 , n. $2, \S 1$.

- (vente), Nicholaus Le Couete / Couette (achat), 1399, 3 décembre: G 2119, fol. 121v; éd. LABORDE, 1919, p. 35, n. 2, \$ 2.

- (vente), 1448, 14 juin: G 2131, fol. 265 ; éd. LAborde, 1919, n. 2, \$ 3, p. 35.

- (vente), 1448, 12 décembre: G 2131, fol. 229v; éd. LabORDE, 1919, p. 35 , n. $1, \S 1$.

- (vente), 1449: G 2134, fol. 2; éd. Laborde, 1919, p. 35, n. 1, \$2.

- (vente), 1450 (n. st.), 25 février: G 2134, fol. 38 ; éd. LABORDE, 1919, n. 2 , $\$ 4$, p. 36.

- (vente), 1450, 12 mars: G 2134, fol. 98v; éd. Laborde, 1919, p. 35-36, n. $1, \S 5$.

- (vente), 1451 (n. st.): G 2134, fol. 90 (et non fol. 9ov, comme indiqué par Laborde); LABORDE, 1919, éd. n. 2, \$10, p. 29-30 (délibération du 16 janvier 1451 [n. st.]).

- (vente), 1452 (n. st.), 19 février: G 2134, fol. 157v (et non fol. 151v, comme indiqué par Laborde); LABORDE, 1919, éd. n. 2, \$11, p. 29-30 (délibération du 19 février 1452 [n. st.]).

- (vente), 1452 (n. st.), 13 mars: G 2134, fol. 161v (et non 154v, comme indiqué par Laborde); éd. LABORDE, 1919, n. 2, \$ 7, p. 35-36.

- (vente), Johannes Gauffridus (achat), 1452, 21 avril, puis 26 avril: G 2134, fol. 168-169 (et non fol. 161-162, comme indiqué par Laborde); éd. LABORDE, 1919, n. 2, § 8-9, p. 36.

- (vente), Johannes Fabri (achat), 1452, 10 mai: G 2134, fol. 172 (et non 165, comme indiqué par Laborde); éd. LABORDE, 1919, n. 2, \$10, p. 35-36.

- (vente), Laurentius Surreau (achat), 1452, 10 mai: G 2134, fol. 172 (et non 165, comme indiqué par Laborde); éd. Laborde, 1919, n. 2, \$12, p. 36-37.

- (vente), 1459 (n. st.), 19 mars: G 2135, fol. 191v; ind. Beaurepaire, 2, 1874, p. 231-233. 
- (vente), 1459, 22 août: G 2135, fol. 220; ind. Beaurepaire, 2, 1874, p. 231-233.

- (échange confié à Guillelmus Roussel), 1460: G 2136, fol. 15V; transcr. IRHT, MPH.

- (vente), 1466: G 2137, fol. 85v; éd. Félix, 1892, p. 214, $n^{\circ} \mathrm{V}, \mathrm{n} .2$ et p. 215, VI.

- (vente), 1467 (n. st.), 20 février: G 2137, fol. 103; éd. Laborde, 1919, n. 3, $\$ 15$, p. 41.

- (vente), Guillelmus Auber (achat), 1468: G 2138, fol. 14v; éd. Félix, 1892 : éd. partielle avec id. des titres p. 215-216, $\mathrm{n}^{\circ}$ VII.

- (vente), Johannes de Atrio / de Laitre (achat), 1468: G 2138, fol. 14v; éd. Félix, 1892: éd. partielle avec id. des titres p. 215-216, $n^{\circ}$ VII.

- (vente), Laurentius Surreau (achat), 1468: G 2138, fol. 14V; éd. Félix, 1892 : éd. partielle avec id. des titres p. 215-216, $\mathrm{n}^{\circ}$ VII.

\section{Rouen, Notre-Dame, Fabrique}

- (vente), 1467, 15 septembre: G 2503, fol. 3-4; transcr. IRHT, MPH.

- (vente), Guillelmus Gallandi (achat), 1467, 15 septembre: G 2503, fol. 3-4; transcr. IRHT, MPH.

- (vente), Jacquet Duval (achat), 1467, 15 septembre: G 2503, fol. 3-4; transcr. IRHT, MPH.

- (vente), Petrus Courel (achat), 1467, 15 septembre: G 2503, fol. 3-4; transcr. IRHT, MPH.

- (vente), Thomas Legrant (achat?), 1467, 15 septembre: G 2503, fol. 3-4; transcr. IRHT, MPH.

\section{Rouen, Saint-Ouen,}

- 1, J[ohannes] de Foris / Dehors, 1372 (?) : 14 H 17, fol. 7v; éd. Dubois, 2001, p. 12.

- 2-5, Ricardus de Barbero, 1372: $14 \mathrm{H} \mathrm{17}$, fol. 7v; éd. Dubois, 2001, p. 12.

- 6-14, Egidius Abbatis, 1372 (?) : $14 \mathrm{H} \mathrm{17}$, fol. 7v; éd. Dubois, 2001, p. 12-13.

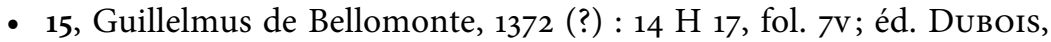
2001, p. 13.

- 16, Ludovicus Clerici, 1372 (?): $14 \mathrm{H}$ 17, fol. 7v; éd. Dubois, 2001, p. 13.

- 17, Petrus de Sihervilla, 1372 (?) : $14 \mathrm{H}$ 17, fol. 7v; éd. Dubois, 2001, p. 13.

- 18-19, Philippus Jacob, 1372 (?) : $14 \mathrm{H}$ 17, fol. 7v; éd. Dubois, 2001, p. 13.

- 18bis, Simo de Bosco, 1379 (n. st.), 25 janvier : 14 H 17, fol. $7 \mathrm{v}$; éd. Dubors, 2001, p. 13.

- 20-22, Radulphus Boutin, 1372 (?) : $14 \mathrm{H} \mathrm{17}$, fol. 7v; éd. Dubois, 2001, p. 13.

- 23, Guillelmus Trubet, monachus de Bello Loco, 1372 (?) : 14 H 17, fol. 7v; éd. Dubois, 2001, p. 13.

- 24-31, Egidius de Campis, 1372 (?): 14 H 17, fol. 7v; éd. Dubois, 2001, p. 13.

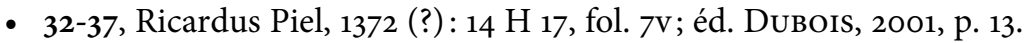

- 38, Johannes d'Angerant, évêque de Beauvais, 1372 (?) : $14 \mathrm{H} \mathrm{17}$, fol. 7v; éd. Dubois, 2001, p. 13. 
- 39, Nicholaus Oresme, 1372 (?): $14 \mathrm{H}$ 17, fol. 7v; éd. Dubois, 2001, p. 13.

- 40, Johannes Bosquet, 1372 (?): $14 \mathrm{H} \mathrm{17}$, fol. 7v; éd. Dubois, 2001, p. 13.

- 41, Philippus d'Alençon, 1372 (?): $14 \mathrm{H} \mathrm{17}$, fol. 7v; éd. Dubois, 2001, p. 13.

- 42-44, prior conventus, 1372 (?): $14 \mathrm{H} \mathrm{17}$, fol. 7v; éd. Dubois, 2001, p. 13.

- 45, prior de Condeto, 1372 (?) : $14 \mathrm{H} \mathrm{17,} \mathrm{fol.} \mathrm{7v;} \mathrm{éd.} \mathrm{Dubois,} \mathrm{2001,} \mathrm{p.} 13$.

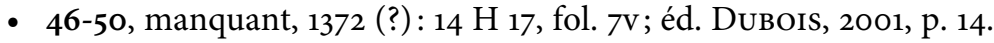

- 51-55, Philippus Jacob, 1374 (n. st.) : 14 H 17, fol. 8 ; éd. Dubois, 2001, p. 14.

- 56, Simo de Bosco, 1379 (n. st.), 5 février: 14 H 17, fol. 8 ; éd. Dubois, 2001, p. 14.

Rouen, Notre-Dame, Sainte-Agathe ${ }^{630}$, chapelle (restitution à), 1396: G 2119, fol. $67 \mathrm{v}$; éd. LABORDE, 1919, n. $2, \S 3$, p. 47.

Saint-Ouen de Prend-en-Bourse / Prenembourse ${ }^{631}$ (prêt à), 1393: G 2119, f. 15V; éd. LABORDE, 1919, n. 2, $\$ 4$, p. 47-48.

Sassetot $^{632}$ (prêt à), 1409 (n. st.): G 2121, fol. 18v; éd. LABORDE, 1919, n. 2, §5, p. 48.

Thomas Durand (emprunt, puis restitution), 1375, puis 1379: G 2116, fol. 65 et $\mathrm{G} \mathrm{2118,} \mathrm{f.} 75 \mathrm{~V}$; éd. LABORDE, 1919, n. 1, $\S 1$, p. 58 (sans la mention de restitution).

Thomas Legrand/ Magni (restitution), Dionisius Villani (emprunt), 1395 : G 2119, f. 51v; éd. LABORDE, 1919, n. 1, \$3, p. 44.

Zano de Castiglione (paiement par), 1431: G 2127, fol. non repéré; ind. Beaurepaire, 2, 1874, p. 222.

630. Chapelle du bas coté nord de la cathédrale.

631. Saint-Ouen de Prend-en-Bourse/Prenembourse; dép. Seine-Maritime, cant. Longueville, c. Bertreville-Saint-Ouen.

632. Sans doute Saint-Vaast de Sassetot-le-Malgardé (plutôt que Sassetot-le-Mauconduit), dép. SeineMaritime, cant. Bacqueville, c. Bacqueville-en-Caux. 


\section{Annexe 2}

Table des auteurs et des œuvres cités

La table des auteurs et des œuvres est classée par ordre alphabétique d'auteurs ou de titres pour les anonymes.

Les formes des noms et des titres relevés dans les documents sont données entre parenthèses.

Pour désigner le document dans lesquels apparaissent ces auteurs et titres, on a utilisé la "clef» des documents (voir l'annexe $\mathrm{n}^{\circ}{ }^{1}$ ), indiquée en gras.

Les noms et les titres restitués avec un bon degré de certitude sont suivis par un ${ }^{*} »$; s'il s'agit d'une hypothèse, ils sont suivis de «*?».

Albertus Magnus, De animalibus: Philippus d'Alençon, 1367.

Ambrosius Mediolanensis, Exameron (Exameron, id est opus sex dierum): Beaubec, 1486.

Angelomus Luxoviensis*, Enarrationes in libros Regum (liber qui dicitur Angelinus Super Regum): Saint-Ouen, 32, Ricardus Piel.

Anneus Lucius Florus*, Rerum romanarum historia? (liber qui dicitur Julius Folius): Saint-Ouen, 39, Nicholaus Oresme.

Aristoteles ${ }^{*}$, Meteorologica (Metheores translatees en franchois): Saint-Ouen, 50, manquant.

Augustinus Hipponensis,

- Confessiones? (De confessionibus): Saint-Ouen, 36, Ricardus Piel.

- De civitate Dei: Petrus de Sihervilla, 1372; Petrus de Sihervilla, puis Egidius de Campis, 1382; Hugo Lenvoisie, 1414.

- De variis opusculis: Petrus Cauchon, 1440, puis 1442.

- Enarrationes in Psalmos (Super primam et secondam et terciam partem Psalterii): Saint-Ouen, 17, Petrus de Sihervilla.

- Epistolae (Epistolae ad Jeronimum et è contra): Petrus de Sihervilla, puis Egidius de Campis, 1382.

- Expositio quarumdam propositionum ex Epistola ad Romanos? (Expositiones [...] super expositione Epistolarum s. Pauli ad Romanos, excerpte de diversis tractatibus): Guillelmus de Deserto, 1466 (n. st.), 14 février.

- Retractationes: Beaubec, 1486.

- v. aussi : Hieronymus ou Hieronymus (Ps. $)^{*}$; Tabula beati Augustini de Civitate Dei.

Augustinus Hipponensis*, De civitate Dei: Ricardus Piel, 1372; Laurencius Surreau, 1447 (n. st.); Guillelmus Roussel, 1470 (n. st.), 14 mars, puis 1470, 10 août.

Azo, Summa (Somma Assonis super jus civili): Saint-Ouen, 15, Guillelmus de Bellomonte. 
Beda, De tabernaculo (Expositionem de tabernacolo ac vasis eius et vasis sacerdotum): Beaubec, 1486.

Berengarius [Fredoli ${ }^{*}$ ], Summa in foro penitentiali (Summa Biterrensis seu Berengarii): Philippus d'Alençon, 1367.

Bernardus Clarevallensis, Sermones in Cantica canticorum (tractatus super Cantica canticorum secundum Benardum $[s i c]$ ): Saint-Ouen, 46, manquant. Biblia:

- Biblia: Nicholaus Oresme, puis Petrus de Sihervilla, 1370 (n. st.), puis 1370, 3 juin ; Petrus de Sihervilla, 1371 ; Ricardus Piel, 1372 ; Saint-Ouen, 8, Egidius Abbatis; Saint-Ouen, 21, Radulphus Boutin; Saint-Ouen, 38, Johannes d'Angerant; Saint-Ouen, 42, prior conventus; Saint-Ouen, 45, prior de Condeto; Petrus de Sihervilla, puis Guillelmus Carrel, 1382; Guillelmus Gorren, 1416; Rouen, Notre-Dame, chapitre (vente), 1448, 14 juin; Rouen, Notre-Dame, chapitre (vente), Johannes Fabri (achat), 1452, 10 mai; Rouen, Notre-Dame, chapitre (vente), 1452 (n. st.), 13 mars; Rouen, Notre-Dame, chapitre (vente) Johannes Gauffridus (achat), 1452, 21 avril, puis 26 avril.

- Evangelia (porcio evangeliorum): Nicholaus Oresme, 1370 (n. st.).

- Concordantiae: (parve concordanciae): Philippus d'Alençon (emprunt au Couvent O.F.M. de Rouen), 1367; (De concordia evangelistarum): Ricardus Piel, 1372; (unum esquatuor): Ricardus Piel, 1372.

- Biblica:

- Summa Biblie (Libellus de Summa Biblie): Philippus d'Alençon (emprunt au curé de Sainte-Agathe), 1367.

- In Pentateuchum (Postille super Ponthatotum [sic], Josue et super libros Regum): Saint-Ouen, 33, Ricardus Piel.

- In Josue (Postille super Ponthatotum [sic], Josue et super libros Regum): Saint-Ouen, 33, Ricardus Piel.

- In Reges (Postille super Ponthatotum [sic], Josue et super libros Regum): Saint-Ouen, 33, Ricardus Piel.

- In Prophetas (Glosa ordinaria super parvis Prophetis): Robertus du Quesnay, 1471 (n. st.), 14 mars, puis 19 décembre.

- In evangelia (Postille super quatuor evangelistas): Saint-Ouen, 35, Ricardus Piel.

- In Epistolas Pauli (Postille super Epistolas Pauli et Apocalisim): Saint-Ouen, 34, Ricardus Piel.

- In Apocalisim (Postille super Epistolas Pauli et Apocalisim): SaintOuen, 34, Ricardus Piel.

- v. aussi: Ambrosius Mediolanensis; Angelomus Luxoviensis*; Augustinus Hipponensis; Bernardus Clarevallensis; de Evangeliis et differentia; Epistole Ezechielis ad Samuelem; Gregorius Magnus; Herveus [Burgidolensis ${ }^{\star}$ ]; Hieronymus; Hieronymus (Ps.) $)^{\star}$; Isidorus Hispalensis; Johannes Chrysostomus; Marcus Antonius Luciano*?, ed.; Nicolaus de Lira; Origenes; Thomas de Aquino. 
Biblica* :

- In Penthateucum ${ }^{*}$ ? (3 volumes de théologie successive vocitata Penthateucon): Ludovicus d'Harcourt, 1459.

Bonaventura

- Comment. In libros Sententiarum I et IV (Postille fratris Bone Aventure [sic] super primum et qua[r]tum Sentenciarum): Saint-Ouen, 13, Egidius Abbatis.

- Comment. In libros Sententiarum III et IV (Postille super tercium et qua[r]tum Sentenciarum): Saint-Ouen, 11, Egidius Abbatis.

Candilecta (Livre pour prelat appellé Candilecta): Guillelmus de Lestrange (vente), puis abbé de Valmont (achat), 1389.

Cassianus (Johannes), [Non id.] (Liber qui dicitur Cassianus et se commenche «veteris ac Novi Testamenti»): Saint-Ouen, 41, Philippus d'Alençon.

Casus breves, seu Notabilia Decretalium cum aliis: Ludovicus Blosset (vente), puis Johannes Masselin (achat), 1489.

Cicero $^{*}$, Marcus Tullius (Tulius)

- De officiis: Saint-Ouen, 30, Egidius de Campis.

- De senectute: Johannes Le Sesne, 1474-1475.

Corpus juris canonici:

- Decretum (Decret, Textus Decreti, texte de Decrect): Saint-Ouen, 2, Ricardus de Barbero; Saint-Ouen, 16, Ludovicus Clerici; Saint-Ouen, 22, Radulphus Boutin; Saint-Ouen, 51, Philippus Jacob; Rouen, Notre-Dame, chapitre (vente), Johannes Fabri (achat), 1452, 10 mai; Rouen, Notre-Dame, Fabrique (vente), 1467, 15 septembre; Rouen, Notre-Dame, chapitre (vente), Johannes de Atrio/de Laitre (achat), 1468.

- Decretales (texte de Decretalles): Rouen, Notre-Dame, Fabrique (vente), Thomas Legrant (achat?), 1467, 15 septembre; Rouen, NotreDame, Fabrique (vente), Thomas Legrant (achat?), 1467, 15 septembre; Rouen, Notre-Dame, chapitre (vente), Johannes de Atrio/de Laitre (achat), 1468.

- Decretales, cum apparatu: Rouen, Notre-Dame, chapitre (estimation), 1370.

- Sextus (Sextum Decretalium): Saint-Ouen, 18, Philippus Jacob; SaintOuen, 18bis, Simo de Bosco; Thomas Legrand / Magni (restitution), puis Dionisius Villani (emprunt), 1395.

- Sextus, cum apparatu ( $\mathrm{vI}^{\text {tus }}$ decretalium cum apparatu triplici) : Nicholaus Oresme, puis Petrus Roger de Beaufort, 1370 (n. st.).

- Clementinae (Clementines): Saint-Ouen, 1, Johannes de Foris / Dehors; Thomas Legrand / Magni (restitution), puis Dionisius Villani (emprunt), 1395; Rouen, Notre-Dame, chapitre (vente), Guillelmus Auber (achat), 1468. 
- v. aussi: Casus breves, seu Notabilia Decretalium; Henricus Bohic; Henricus de Segusia; Hugutio Pisanus?; Innocentius IV papa; Johannes Andreae; Johannes Monachus; Martinus Oppaviensis (de Tropau).

Corpus juris civilis

- Digestum vetus (Geste vielle): Rouen, Notre-Dame, Fabrique (vente), Guillelmus Gallandi (achat), 1467, 15 septembre.

- Inforciatum (Inforciat): Rouen, Notre-Dame, Fabrique (vente), Thomas Legrant (achat?), 1467, 15 septembre; Johannes Gouel, 1471.

- Digestum novum (Digeste neuve, Geste nove, Digeste nove): SaintOuen, 3, Ricardus de Barbero; Saint-Ouen, 57, Simo de Bosco; Rouen, Notre-Dame, Fabrique (vente), Petrus Courel (achat), 1467, 15 septembre; Rouen, Notre-Dame, chapitre (vente), Guillelmus Auber (achat), 1468.

- Codex (Code): Rouen, Notre-Dame, Fabrique (vente), Thomas Legrant (achat?), 1467, 15 septembre.

- Instituta (Institut, Institute sans glose, Institute): Saint-Ouen, 5, Ricardus de Barbero; Saint-Ouen, 20, Radulphus Boutin; Saint-Ouen, 56, Simo de Bosco; Rouen, Notre-Dame, Fabrique (vente), Guillelmus Gallandi (achat), 1467, 15 septembre; Rouen, Notre-Dame, Fabrique (vente), Jacquet Duval (achat), 1467, 15 septembre.

- v. aussi : Azo; G. de Tyonvilla.

De bestiis figurarum (liber de bestiis figurarum): Beaubec, 1486 .

De ecclesiastica potestate: Nicholaus Dubois (de Bosco), 1456 (n. st.).

De Evangeliis et differentia: Hugo Lenvoisie, 1414.

De regulis fidei: Saint-Ouen, 27, Egidius de Campis.

Defensor Locogiacensis monachus ${ }^{\star}$ (Ysidorus), Liber scintillarum ${ }^{\star}$ (De virtutibus): Saint-Ouen, 28, Egidius de Campis.

Dictionarium (unum notabilem librum nominatum Dicionarium in tribus voluminibus): Zano de Castiglione (paiement par), 1431.

Egidius de Roma:

- Comment. in Sententias Petri Lombardi (Questionez super primum librum Sentenciarum editus a fratre Egidio de Roma): Saint-Ouen, 26, Egidius de Campis.

- De regimine principum: Guillelmus de Deserto, 1466 (n. st.), 14 février, puis 1470.

- Epistole Ezechielis ad Samuelem: Johannes Le Sesne, 1474-1475.

[Formulaire, un] (quemdam librum incipientem in secundo folio «Ego N. Dei pacientia [?] huius...», et finientem in penultimo "Anno Domini $\mathrm{CCC}^{\circ}$ nonagesimo quarto (?) die XXII ${ }^{\mathrm{da}}$ mensis Januarii») : Johannes Quatreul, 1466. 
G. de Tyonvilla,

- Lecture: Philippus d'Alençon (prêt à J[ohannes] de Foris), 1367.

- Lecture super Digestum vetus: Philippus d'Alençon (prêt à J[ohannes] de Foris), 1367.

- Lecture super Inforciatum: Philippus d'Alençon (prêt à J[ohannes] de Foris), 1367.

Gregorius Magnus,

- Expositio in Canticum canticorum: Saint-Ouen, 24, Egidius de Campis.

- Homeliae XL in Evangelia (Omeliae super evangelia): Beaubec, 1486.

Guido Ebroicensis*? (Sermones Guidonis): Johannes Le Sesne, 1474-1475.

Guillelmus, Sermones (liber qui incipit «Incipiunt sermones fratris Guillelmi»): Hugo Lenvoisie, 1414.

Guillelmus Autissiodorensis, Summa aurea super 4 libros Sententiarum (Somma): Saint-Ouen, 9, Egidius Abbatis.

Guillelmus Durandi*, Speculum judiciale: Saint-Ouen, 54, Philippus Jacob.

Guillelmus Peraldus* (Guillelmus Lugdunensis), Sermones: Guillelmus de Deserto, 1466, 13 novembre.

Hegesippus (Ps.), De bello judaico (Liber historie Egezipi, Liber Egesippi): Ludovicus d'Harcourt, 1479 (n. st.); Guillelmus Le Brument, 1488 (n. st.), 3 mars, puis 1488 , juin.

Henricus Bohic (H. Bouys, H. Bouyc, Henricus Bouic), Distinctiones in libros V Decretalium (libri magistri H. Bouys [pro Bohic], duo volumina H. Bouyc, Henricus Bouic in duobus voluminibus): Rouen, Notre-Dame, chapitre (échange confié à Guillelmus Roussel), 146o; Mont-Saint-Michel, 1465; Rouen, Notre-Dame, chapitre (vente), 1466; Rouen, Notre-Dame, chapitre (vente), Laurentius Surreau (achat), 1468.

Henricus de Segusia (Hostiensis, Ostiensis)

- Lectura in Decretales (Hostiense in lectura en 2 volumes): Saint-Ouen, 55, Philippus Jacob.

- Summa copiosa ou Summa super titulis Decretalium (Somme de Ostiensis aultrement appellé Copieuse): Saint-Ouen, 52, Philippus Jacob.

Herveus [Burgidolensis ${ }^{*}$ ] (magister Herveus), In Isaiam (de exposicione super Ysaiam): Guillelmus Roussel, 1470 (n. st.), 9 avril.

Hieronymus

- In Ezechielem (super Ezechielem): Beaubec, 1486.

Hieronymus ou Hieronymus (Ps.)*

- Concordancie evangeliorum: Guillelmus de Deserto, 1466 (n. st.), 14 février.

- Epistulae ad Augustinum: Egidius de Campis, puis Guillelmus Gorren, 1413; Guillelmus Gorren, 1416. 
- Epistulae ad Damasum papam: Egidius de Campis, puis Guillelmus Gorren, 1413.

Historia

- Chronique(s) (Cronica ab initio mundi, Cronique en papier): SaintOuen, 48, manquant; Guillelmus de Lestrange (vente), puis Elias de Lestrange (achat), 1389; Johannes Bureau, 1451 (n. st.).

- v. aussi: Anneus Lucius Florus ${ }^{*}$; Hegesippus (Ps.); Tholomaeus de Fiadonis Lucanus ${ }^{*}$ ?

Hugo archiepiscopus Rothomagensis, Epistola: Hugo Lenvoisie, 1414.

Hugo [archiepiscopus Rothomagensis*], Epistolae: Ricardus Piel, 1372.

Hugo de Folieto (Fouilloy)*

- De avibus: Johannes Quatreul, 1475.

- De claustro animae: Petrus de Sihervilla, 1389.

Hugo de Folieto*?, De medicina anime: Beaubec, 1486.

Hugutio Pisanus (Ogusse), Derivationes ou Lectura super Decretum?: Saint-

Ouen, 44, prior conventus.

Innocentius III, papa, De miseria humanae conditionis (Tractatus Innocentii pro parte de miseria hominis): Saint-Ouen, 47 , manquant.

Innocentius IV, papa (Ignoscent), Apparatus in quinque libros Decretalium (Lecture de Ignoscent sus les anchiennes decretalles): Saint-Ouen, 53, Philippus Jacob.

Irenaeus Lugdunensis*, Adversus hereses (Hyreneus Lugdunensis contra omnes [aliquas pour Laborde] hereses, cujus secundum folium incipit "accipiens a nobis», ultimum "et in omnibus his»): Nicholaus Couppequesne, 1430, 4 août, puis 7 novembre.

Isidorus Hispalensis, Mysticorum expositiones sacramentorum seu Quaestiones in Vetus Testamentum (super Vetus Testamentum; cujus operis Ysidori secundum folium incipit «-remus cujusquam», et penultimum folium incipit «sensit odorem tuum»): Nicholaus Caval, 1430.

Jacobus* de Voragine (Voragine),

- Sermones: Johannes Gouel, 1471.

- Sermones ou Legenda aurea? (livre de Voragine): Johannes Le Sesne, 1474-1475.

Jacobus de Voragine ${ }^{\star}$, Legenda sanctorum quasi Legenda aurea: Saint-Ouen, 40, Johannes Bosquet; Saint-Ouen, 49, manquant.

Johannes Andreae (Johannes Andrieu),

- Glosa in Sextum (Glosa): Rouen, Notre-Dame, chapitre (vente), Laurentius Surreau (achat), 1452, 10 mai. 
- Novella in Decretales Gregorii IX (Lectura archidiaconi et Johannis Andree super textum Decretalium): Saint-Ouen, 18bis, Simo de Bosco; Saint-Ouen, 19, Philippus Jacob.

Johannes Balbus Januensis ${ }^{\star}$, Catholicon: Hugo Lenvoisie, 1414; Guillelmus Gorren, 1416.

Johannes Boccace*?, De claris mulieribus? (De mulieribus illustribus): Petrus Escoulant (ou Escoullant), 1480.

Johannes Chrysostomus, In Matthaeum homeliae (expositio Chrisostomi super Matheum): Beaubec, 1486.

Johannes Halgrinus de Abbatisvilla (Johannis de Albivilla),

- Sermones (Melie [sic pro: Omelie] Johannis de Abbisvilla): Saint-Ouen, 37, Ricardus Piel.

- Sermones? (Somma): Saint-Ouen, 12, Egidius Abbatis.

Johannes de Hanville*? (Liber architroum), Architrenius: Saint-Ouen, 31, Egidius de Campis.

Johannes Monachus, Apparatus in librum Sextum (textus dicto Sexti Johannis Monachi super eodem Sexto): Saint-Ouen, 19, Philippus Jacob.

Jus $^{\star}$, v. aussi: Guillelmus Durandi ${ }^{\star}$; Lectura super leges; Liber, libri (non identifié), Livres de droit, Libri (nonnulli) juris; Oldradus de Ponte.

Lectura super leges: Saint-Ouen, 4, Ricardus de Barbero.

Liber, libri [non identifié]

- (Antiqui libri): Rouen, Notre-Dame, chapitre (vente), 1450, 12 mars.

- (assertum librum consistentem in libraria): Michael Petit, 1492.

- (liber conciliorum ou consiliorum): Nicholaus Oresme, puis Petrus de Sihervilla, 1370 (n. st.), 4 mars, puis 1370, 3 juin; Egidius de Campis, 1400 (n. st.); Egidius de Campis, puis Guillelmus Gorren, 1406; Guillelmus Gorren, 1416.

- (liber qui incipit «Prefacio. "Virorum..."»): Hugo Lenvoisie, 1414.

- (Libri) : Rouen, Notre-Dame, chapitre (vente), 1450 (n. st.), 25 février; Rouen, Notre-Dame, chapitre (vente), 1451 (n. st.); Rouen, NotreDame, chapitre (vente), 1452 (n. st.), 19 février; Rouen, Notre-Dame, chapitre (vente), 1452 (n. st.), 13 mars.

- (Libri antiqui): Rouen, Notre-Dame, chapitre (vente), 1448, 12 décembre; Rouen, Notre-Dame, chapitre (vente), 1449.

- (Libri (nonnulli) juris): Rouen, Notre-Dame, chapitre (vente), 1467 (n. st.), 20 février.

- (Livres de droit [pluseurs]): Guillelmus de Lestrange (vente), neveux (achat), 1389.

- (livres inutiles et anciens): Rouen, Notre-Dame, chapitre (vente), 1459 (n. st.), 19 mars.

- (volumes inutiles): Rouen, Notre-Dame, chapitre (vente), 1459, 22 août. 
Liturgica,

- Antiphonarium: Thomas Durand (emprunt, puis restitution), 1375, puis 1379; (notatum, completum): Guillelmus de Estoutevilla, 1422 (n. st.).

- Antiphonarium cum Psalterio: Rouen, Notre-Dame, Cathédrale, Maîtrise des enfants de chœur, 1399.

- Breviarium: Caen, abbé et couvent (non identifiés), 1379; Johannes Gilles (ou Egidius), 1379; Sassetot (prêt à), 1409 (n. st.); (notatum) : Petrus de Laigny, 1439, puis 1442; (papireum): Michael Petit, 1494 (n. st.).

- Breviarium ad usum Romae (Breviaire en grant volume à l'usage de Romme): Guillelmus de Lestrange (vente), 1389; (Breviaire portatif à l'usage de Romme): Guillelmus de Lestrange (vente), 1389.

- Breviarium ad usum Rothomagensem (Breviarium notatum ad usum Rothomagensem) : Henricus Gorren, 1438 (n. st.).

- Diurnale ad usum Romae (Journal, à l'usage de Romme): Guillelmus de Lestrange (vente), puis Elias de Lestrange, 1389.

- Graduale (Gradale, Gradalle) : Magnavilla (Manneville)-la-Goupil, 1372; Thomas Durand (emprunt, puis restitution), 1375, puis 1379; Rouen, Notre-Dame, Cathédrale, Maîtrise des enfants de chœur, 1399; Pasquerius de Vaux, 1444, puis 1445.

- Liber cantus, partie d'hiver (liber cantus dictus dimidium tempus incipiens in Adventum): Johannes des Essars / Essarts, 1456.

- liber pro baptismo et sepultura: Philippus d'Alençon, 1362 (n. st.).

- Libri ad usum ecclesie Auxitanensis: Rouen, Notre-Dame, chapitre (vente), 1399, 2 novembre; Rouen, Notre-Dame, chapitre (vente), Nicholaus Le Couete / Couette (achat), 1399, 3 décembre.

- [livres liturgiques couvrant toute l'année] (duo tempora): Magnavilla (Manneville)-la-Goupil, 1372.

- Martyrologium [ad usum Angliae?] (Martilogium [sic], Matrilogium [sic] de Anglia): Guillelmus de Deserto, 1466 (n. st.), 14 février, puis 1470.

- Missale (Missale euvangelistarum et epistolarum): Philippus d'Alençon, 1362 (n. st.) ; Magnavilla (Manneville)-la-Goupil, 1391; Amfreville / Anfreville, 1396; Rouen, Notre-Dame, Sainte-Agathe, chapelle (restitution à), 1396; Sassetot (prêt à), 1409 (n. st.).

- Missale ad usum Romae (Messel à l'usage de Romme, Messel ancien, à l'usage de Romme): Guillelmus de Lestrange (vente), puis Johannes Ysebarre, puis Elias de Lestrange, 1389; Guillelmus de Lestrange (vente), puis Guido Rabaschier, puis Huguelin de Morant (achat), 1389.

- Missale ad usum Rothomagensem (Missale parvum domini ad usum Rothomagensem): Philippus d'Alençon, 1367.

- Officium sancti Ludovici: Rouen, Notre-Dame, Cathédrale, Maîtrise des enfants de chœur, 1399.

- Ordinarium ad usum Rothomagensem (Ordinaire de Rouen): Guillelmus de Lestrange (vente), puis Guido Rabaschier (achat), 1389. 
- Pontificale (pulcer liber episcopalis, Partie de pontifical noster, Partie de pontifical ros, Partie de pontifical plaustre, Partie de pontifical tagii): Philippus d'Alençon, 1362 (n. st.); Guillelmus de Lestrange (vente), Elias de Lestrange (achat), 1389; Martinus Pinard, 1443 (n. st.).

- Pontificale ad usum Parisiensem (Pontifical [...] à l'usage de Paris): Guillelmus de Lestrange (vente), Johannes Ysebarre (achat), 1389.

- Psalterium: Saint-Ouen, 29, Egidius de Campis; Magnavilla (Manneville)-la-Goupil, 1372; (Psalterium, cum kalendario et ymnis, antiphonis, recommendacione et servicio mortuorum): Saint-Ouen de Prend-en-Bourse / Prenembourse, 1393.

- Psalterium ad usum Parisiensem: Guillelmus de Deserto, 1466 (n. st.), 14 février, puis 1470.

- v. aussi: Candilecta.

Marcus Antonius Luciano*?, ed. Thomas de Aquino, In evangelium beati Johannis evangeliste aurea expositio (doctor vocatus Lucianus super evangeliis): Guillelmus Roussel, 1470 (n. st.), 14 mars, puis 1470, 10 août.

Martinus Oppaviensis (de Tropau)*, Margarita Decreti ou Summa martiniana (liber vocatus Martinian): Hugo Lenvoisie, 1389.

Mauritius de Sully (Mauricius episcopus Parisiensis), Sermones ad populum per annum (Sermones): Johannes de Pontissera, 1381.

Maurus Servius Honoratus`?, In tria Virgilii Opera Expositio*? (Virgilius commentatus): Ludovicus Blosset (vente), Johannes Masselin (achat), 1489.

Medicina (tractatus de medicina et funt in eodem plures herbe figurate): Henricus de Fiscano, 1399; Henricus de Fiscano, puis Nicholaus Le Couete/Couette, 1401.

Nicolaus de Aquaevilla (Haqueville, Waterton), Sermones (Summa Nicolay de Aquavilla): Guillelmus, abbé de Beaubec, 1470.

Nicolaus de Lira, Postilla litteralis super totam Bibliam? (Repertorium de Lira, super Bibliam): Ludovicus Blosset (vente), Johannes Masselin (achat), 1489.

Oldradus de Ponte (Oldratus), Quaestiones: Philippus d'Alençon (prêt à J[ohannes] de Foris), 1367.

Origenes (Origines), Comment. in Epistolam ad Romanos, 1. X (Super epistolas Pauli ad Romanos): Saint-Ouen, 7, Egidius Abbatis.

Papias, Elementarium? (Papias): Beaubec, 1486.

Petrus Chrysologus, Ravennatensis archiepiscopus (Petrus Ravanatus episcopus), Sermones: Beaubec, 1486.

Petrus Lombardus*,

- Sentenciae: Saint-Ouen, 6, Egidius Abbatis.

- v. aussi: Bonaventura; Egidius de Roma; Guillelmus Autissiodorensis; Thomas d'Aquin. 
Plinius Secundus, dit Plinius maior

- Naturae historiarum libri (Naturalis hystorie): Nicholaus Oresme, puis Petrus de Sihervilla, 1370 (n. st.), puis 1370, 4 mars, puis 3 juin.

- Naturae historiarum libri* (Plinius Secundus): Petrus de Sihervilla, 1372; Petrus de Sihervilla, puis Egidius de Campis, 1382.

Quaestiones (questionez): Saint-Ouen, 23, Guillelmus Trubet, monachus de Bello Loco.

Raymundus de Pennaforte ${ }^{\star}$ ?, Summa de casibus ${ }^{\star}$ ? (Somme de Raymond): Johannes Le Sesne, 1474-1475.

Règle des Hermites Gruel: Guillelmus de Lestrange (vente), Elias de Lestrange (achat), 1389.

Regula sancti Benedicti: Saint-Ouen, 29, Egidius de Campis.

- Regula sancti Benedicti, glosata (Regula sancti Benedicti closata): SaintOuen, 43, prior conventus.

Sedulius ${ }^{\star}$ ?, Carmen paschale*? (Sedulius): Guillelmus Roussel, 1470 (n. st.), 9 avril.

Sentenciae patrum: Saint-Ouen, 29, Egidius de Campis.

Sermones, Homeliae

- (Liber Omeliarum): Johannes Deudemare, 1447 (n. st.).

- (Sermones de Lugduno) : Ricardus Piel, 1372.

- (Sermones nobilissimi): Saint-Ouen, 14, Egidius Abbatis.

- (Sermones de Tournyaco) : Johannes Le Sesne, 1474-1475.

- v. aussi : Guido Ebroicensis*?; Guillelmus; Guillelmus Peraldus*; Jacobus* de Voragine; Johannes Halgrinus de Abbatisvilla; Mauritius de Sully; Nicolaus de Aquaevilla; Petrus Chrysologus.

Speculum monachorum: Saint-Ouen, 46, manquant.

Tabula beati Augustini de Civitate Dei: Robertus du Quesnay, 1471 (n. st.), 14 mars, puis 19 décembre ; (tabula beati Augustini in libro de Civitate Dei per ordinem alphabeti): Guillelmus Roussel, 1470 (n. st.), 9 avril.

Tholomaeus de Fiadonis Lucanus*?, Historia ecclesiastica nova, Epistula dedicatoria $^{\star}$ ? (Epistola quam auctor libri diligit): Hugo Lenvoisie, 1414.

Thomas de Aquino,

- Lectura super Matthaeum: Saint-Ouen, 25, Egidius de Campis.

- Scriptum super libros Sententiarum (Super librum Sentenciarum): Saint-Ouen, 10, Egidius Abbatis.

- Summa Contra Gentiles (De veritate catholice fidei contra errores infidelium editus a fratre Thoma de Aquino): Saint-Ouen, 10, Egidius Abbatis.

- v. aussi Marcus Antonius Luciano*? 
Thomas Waleys ${ }^{\star}$, Communiloquium siue Summa collationum ad omne genus hominum* (Liber ecclesie dictus "Valence"): Radulphus Roussel, 1443; (Liber seu volumen nuncupatum la "Somme de Galense"): Johannes Masselin, 1480 (n. st.).

Vitae sanctorum, v. Jacobus de Voragine ${ }^{\star}$ ?

Virtutes et vitia:

- Johannes Le Sesne, 1474-1475.

- v. aussi: Defensor Locogiacensis monachus*. 